\title{
ANÁLISE DA SOBREVIDA EM PACIENTES COM LÚPUS ERITEMATOSO SISTÊMICO
}

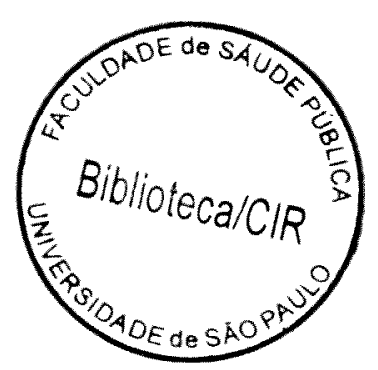

LUIZ CARLOS LATORRE

Tese apresentada à Faculdade de Saúde Pública da Universidade de São Paulo para a obtenção do título de Doutor em Saúde Pública

ORIENTADORA: PROF.ASSOCIADA SABINA LÉA DAVIDSON GOTLIEB

São Paulo - 1997 


\section{À Maria do Rosario}

Por todos esses anos de apoio, dedicação e carinho. Pelo incentivo constante, sem o qual este trabalho não seria realizado. Pela sua alegria de viver e trabalhar. Por tudo.

Aos meus queridos filhos Henrique e Adriana,

Estímulo maior do nosso trabalho, pela constante torcida no sucesso dessa tese. Pela sua futura compreensão das ausências e impaciências durante esses anos. Pela sua amizade e amor.

Aos meus pais e irmãos,

Pelo exemplo de retidão e trabalho. Pela amizade e apoio.

$\mathcal{A}$ todos os pacientes deste trabalfo,

Pela amizade e paciência, apesar de conviverem com enfermidade tão desgastante física e psicologicamente; especialmente àqueles que, mesmo sem saber, contribuíram para algum esclarecimento, possivelmente útil, aos que ainda permanecem lutando. 


\section{AGRADECIMENTOS}

À Professora Sabina Léa Davidson Gotlieb, pela sua orientação precisa e constante durante toda a realização deste trabalho. Por todos os ensinamentos transmitidos, pela delicadeza, carinho e incentivo. Pelas sugestões e correções sempre tão pertinentes e construtivas. Pela amizade e compreensão.

À Professora Maria do Rosario Dias de Oliveira Latorre, pela análise estatística da tese. Por todo amor e carinho com os quais sempre pude contar durante esses anos. Pela idéia do trabalho e incentivo constante durante toda a sua execução.

Ao Professor Cristiano Augusto de Freitas Zerbini, pela amizade, incentivo e ensinamentos, médicos e de vida, que tem me proporcionado durante tantos anos de convívio.

Aos amigos do Hospital Helíopolis, Paulo Roberto S. Romanelli, Maria Guadalupe B. Pippa, Lenise Brandão, Wagner Ikehara e Cleber Resende, pela amizade, sugestões e substituições durante minhas ausências.

Ao Departamento de Epidemiologia da Faculdade de Saúde Pública da USP, na pessoa do Professor José Maria Pacheco de Souza, professores e funcionários, pela acolhida e apoio durante esses anos. 


\section{RESUMO}

Estudos epidemiológicos com análise multivariada de fatores prognósticos em pacientes com lúpus eritematoso sistêmico ainda não foram publicados no Brasil. Assim sendo, o objetivo deste trabalho foi analisar os fatores de risco para a mortalidade, bem como para a perda da função renal, em uma coorte de pacientes com lúpus eritematoso sistêmico (LES).

Uma coorte de 253 pacientes foi acompanhada em um hospital público do Município de São Paulo, por um período de 17 anos (1978-1995), de acordo com protocolo padronizado. Foram realizadas duas análises de sobrevida: a primeira foi a análise até o óbito e, a segunda, a análise da sobrevida até o surgimento da insuficiência renal terminal. As variáveis independentes foram as características demográficas desses pacientes, bem como as alterações clínicas e laboratoriais mais comumente relacionadas ao LES. $O$ teste de associação pelo $\chi^{2}$ foi realizado com o objetivo de avaliar a associação entre as variáveis independentes e o óbito. As curvas de sobrevida foram calculadas utilizando o método de Kaplan-Meier e os fatores de risco foram estimados pelo modelo de riscos proporcionais de Cox.

Os fatores prognósticos para o óbito dos pacientes com LES foram a presença de insuficiência renal terminal (razão de riscos- $H R=2,73$ ), de envolvimento pulmonar isolado $(\mathrm{HR}=2,94)$ ou associado com envolvimento cardíaco $(\mathrm{HR}=3,77)$ e a utilização de imunossupressor $(\mathrm{HR}=0,45)$. Os fatores prognósticos para o óbito dos pacientes com nefrite lúpica foram a presença de insuficiência renal terminal $(\mathrm{HR}=2,75)$ e a utilização de imunossupressor $(\mathrm{HR}=0,24)$.

Os fatores de risco para o desenvolvimento de insuficiência renal terminal dos pacientes com LES foram a idade no início da doença entre 7 e 15 anos $(H R=3,61)$, a presença de hipertensão arterial sistêmica $(H R=5,21)$ e a presença de anemia hemolítica $(H R=9,35)$. O fator de risco para a perda da função renal dos pacientes com nefrite lúpica foi a presença de alteração hematológica do tipo anemia hemolitica $(\mathrm{HR}=3,64)$ ou plaquetopenia $(\mathrm{HR}=6,69)$. 


\begin{abstract}
Epidemiological studies using multivariate analysis of risk factors in patients with systemic lupus erythematosus (SLE) have not yet been published in Brazil.

The objective of this study was to analyse the risk factors of mortality and of end stage renal disease (ESRD) in patients with systemic lupus erythematosus (SLE) according to demographic, clinical, and laboratory variables.

A cohort of 253 patients was followed over a 17-year period (from 1978 to 1995) according to a standard protocol in a single center. Two survival analyses were performed. The first analysis consisted of the survival time from the date of diagnosis of SLE to the last contact or death. The second analysis consisted of the survival time from the date of diagnosis of SLE to the occurrence of ESRD. The independent variables were the demographic characteristics, as well as clinical and laboratory information most commonly associated with SLE. The $\chi^{2}$ test was performed in order to evaluate the association between the independent variables and the death or ESRD. The survival curves were calculated using the Kaplan-Meier method. The prognostic factors were estimated by the Cox proportional hazard model.

The risk factors for death in patients with SLE were ESRD, lung involvement alone or associated with cardiac involvement and no use of immunossupressors. The risk factors for death in patients with lupus nephritis were ESRD and no use of immunossupressors.

The risk factors for ESRD in patients with SLE were age at onset of the disease between 7 and 15 years old, high blood pressure and haemolitic anemia. The risk factor for ESRD in patients with lupus nephritis were haemolitic anemia or plaquetopenia.
\end{abstract}




\section{ÍNDICE}

1. Introdução

$\begin{array}{ll}\text { 2. Objetivos } & 14\end{array}$

3. Material e Métodos

$\begin{array}{ll}\text { - Casuística } & 15\end{array}$

- Delineamento 15

- Instrumento de coleta 15

- Variáveis 16

- Análise estatística 17

4. Resultados e Discussão

- Descrição dos pacientes 22

- Análise de sobrevida até o óbito (global) 33

- Análise de sobrevida até a evolução para a insuficiência renal 56 terminal

- Análise de sobrevida até o óbito dos pacientes com nefrite 71 lúpica

- Análise de sobrevida até o desenvolvimento da insuficiência 84 renal terminal dos pacientes com nefrite lúpica

- Análise de sobrevida até o óbito após a insuficiência renal 96 terminal

5. Considerações Finais 99

$\begin{array}{ll}\text { 6. Conclusões } & 102\end{array}$

$\begin{array}{ll}\text { Referências Bibliográficas } & 104\end{array}$

$\begin{array}{ll}\text { Anexos } & 114\end{array}$ 


\section{INTRODUÇÃO}

\subsection{DEFINIÇÃO}

O lúpus eritematoso sistêmico (LES) é uma doença inflamatória crônica, de etiologia desconhecida, que afeta, predominantemente, mulheres jovens. Múltiplos órgãos podem ser acometidos, tais como pele, articulações, sistema hematológico, pulmões, rins, coração e sistema nervoso, em qualquer combinação e nos mais diversos níveis de gravidade. Seu curso é caracterizado por períodos de remissão e de atividade, com intervalos de tempo variados. Pacientes com LES apresentam anormalidades do sistema imunológico, caracteristicamente marcadas pela formação de múltiplos auto-anticorpos dirigidos a antígenos nucleares. Embora, até o momento, não exista cura, o tratamento pode ser eficaz no controle do processo inflamatório, mantendo as condições de vida, e prevenindo as disfunções orgânicas ${ }^{73}$.

\subsection{ETIOLOGIA}

Até o momento, nenhum agente etiológico foi associado ao LES. No entanto, uma série de evidências relacionadas a fatores ambientais e genéticos é bem conhecida, sendo que o peso de cada fator varia de doente para doente. $O$ ponto final comum, nesses pacientes, é sempre a produção excessiva e anormal de anticorpos dirigidos contra proteínas próprias, a maioria delas existentes nos núcleos das células (auto-anticorpos anti-nucleares) ${ }^{81}$.

No que se refere à influência do genótipo, há um aumento na freqüência do LES em parentes de indivíduos doentes ( 5 a 12\%), várias vezes maior do que na população em geral ${ }^{4}$. Do mesmo modo ocorre uma concomitância de 14 a $57 \%$ de presença de LES em gêmeos monozigóticos ${ }^{17}$. Alguns marcadores genéticos, também, têm sido encontrados, mais comumente, nos pacientes com LES do que na população em geral, como, por exemplo, HLA-B8 ${ }^{71}$, HLA-DR3 ${ }^{4}$ e deficiência de complemento ${ }^{72}$.

Com relação à influência dos fatores ambientais, é sabido que algumas drogas podem desencadear uma síndrome semelhante ao lúpus idiopático 
denominada lúpus induzido por drogas, cujo mecanismo etiopatogenético permanece desconhecido. As drogas mais comumente referidas são a hidralazina e a procainamida ${ }^{94}$. Outros fatores ambientais estão implicados no desencadeamento da ativação do lúpus idiopático já instalado, porém, discutemse os seus papéis como iniciadores do processo patológico no indivíduo sadio. Têm-se como exemplos destes fatores a luz ultra-violeta e as infecções, tanto virais como bacterianas ${ }^{94}$.

\subsection{PATOGENIA}

Mesmo não se conhecendo a etiologia, está claro que a lesão tecidual é causada pela deposição de complexos formados por antígenos próprios ligados a auto-anticorpos em nível dos vasos sangüíneos, com conseqüente disfunção dos órgãos nutridos por essa circulação alterada ${ }^{93}$. A presença desses complexos nos vasos e tecidos pode ser evidenciada indiretamente através da detecção de inúmeros auto-anticorpos circulantes, da determinação do consumo de componentes do complemento, bem como da presença dos próprios complexos, muitas vezes detectados na circulação do paciente doente. De modo direto, pode se detectar a presença dos imunecomplexos através da eluição ou, ainda, pela análise dos mesmos no próprio tecido envolvido, especialmente nos rins, através de imunofluorescência ou microscopia eletrônica ${ }^{94}$.

\subsection{QUADRO CLÍNICO}

\subsubsection{Sintomas gerais}

Fadiga ( 80 a $100 \%$ dos pacientes), perda de peso (60\%) e febre (80\%) são os sintomas gerais mais comuns; náusea, vômito, edema, perda de cabelo, cefaléia, insônia e outros sintomas gerais podem ocorrer, porém, menos freqüentemente 59,73 .

\subsubsection{Manifestações músculo-esqueléticas}

Artrite ou artralgia são muito comuns, atingindo cerca de $95 \%$ dos pacientes, habitualmente não causando deformidades. Quando estas ocorrem, 
são facilmente redutiveis devido à pouca erosão e destruição articular ${ }^{3}$. Nódulos sub-cutâneos, necrose asséptica, osteoporose, dor e/ou fraqueza muscular são achados freqüentes e, muitas vezes, podem estar associados à terapêutica crônica com corticosteróides ${ }^{18}$.

\subsubsection{Lesões muco-cutâneas}

As lesões de pele e mucosa ocorrem, sintomaticamente, em mais de $80 \%$ dos pacientes $^{73}$. Cerca de $60 \%$ dos casos apresentam fotossensibilidade, traduzida pela exacerbação da doença na pele frente à exposição solar ${ }^{18}$. A inflamação na pele pode se manifestar de formas variadas, com lesões eritematosas, descamativas, bolhosas, discóides, profundas, sub-agudas e mistas $^{73}$. A queda de cabelos ocorre em, aproximadamente, $75 \%$ dos pacientes com doença ativa e, na maioria das vezes, é reversível com a melhora clínica. $\mathrm{O}$ rash malar, característico da doença, ocorre em, aproximadamente, $50 \%$ dos casos $^{18}$. O envolvimento de membranas mucosas, especialmente oral e nasal, manifesta-se em 27 a $41 \%$ dos doentes, com ulcerações usualmente dolorosas ${ }^{18}$.

\subsubsection{Lesões vasculares}

Essas lesões aparecem em, aproximadamente, $50 \%$ dos pacientes e se manifestam, clinicamente, de formas variadas: eritema peri-ungueal, livedo reticular, telangiectasias, fenômeno de Raynaud e vasculites variadas (púrpuras, urticárias, necrose de pele e extremidades $)^{79}$.

\subsubsection{Manifestações pulmonares}

Os pulmões podem ser afetados em sua circulação, na pleura, diafragma ou em seu parênquima. Dor toráxica, tosse ou dispnéia são os achados iniciais desse tipo de envolvimento. A dor do tipo pleural ocorre em, aproximadamente, $45 \%$ dos pacientes, sendo que metade dos casos é acompanhada de derrame ${ }^{66}$. A pneumonite lúpica aguda é menos comum (5 a 12\%) e está associada a um maior risco de mortalidade precoce na evolução do quadro ${ }^{45}$.

\subsubsection{Manifestações cárdio-vasculares}

O coração pode estar envolvido em todas as suas camadas: pericárdio ( 8 a $48 \%$ dos casos), miocárdio ( 8 a $78 \%$ ) e endocárdio (16 a 44\%). Os casos 
definidos somente por meio de sintomas e sinais clínicos contribuem para as freqüências mais baixas; já naqueles onde se utiliza a propedêutica armada (radiologia, eletro e ecocardiograma) as freqüências desses acometimentos são, evidentemente, maiores ${ }^{39,73}$. Tromboflebites, trombose venosa profunda $\mathrm{e}$ trombo-embolia pulmonar podem ocorrer, estando ou não associadas à presença de anticorpos anti-fosfolípides ${ }^{73}$.

\subsubsection{Alterações hematológicas}

A anemia se desenvolve em, aproximadamente, $50 \%$ dos pacientes e pode ser, mais comumente, devido à maturação ineficiente pela inflamação crônica ou uremia. Menos freqüentemente, pode ser decorrente de hemólise pela formação de anticorpos contra as hemácias, especialmente nos seus determinantes Rh (10 a $40 \%$ dos casos $)^{44,76}$. A leucopenia, abaixo de 4000 células $/ \mathrm{mm}^{3}$, ocorre em 15 a $20 \%$ dos pacientes. Caracteristicamente, na doença ativa, desenvolve-se linfopenia (abaixo de 1500 células $/ \mathrm{mm}^{3}$ ) face à formação de anticorpos contra linfócitos, principalmente da linhagem $\mathrm{T}$ supressora ${ }^{44}$. A trombocitopenia aparece em 25 a $50 \%$ dos casos, sendo que as formas mais intensas (menos de 50000 células $/ \mathrm{mm}^{3}$ ) são notadas em cerca de $10 \%$ dos pacientes ${ }^{76}$. Do mesmo modo, os mecanismos são imunológicos com a formação de anticorpos antiplaquetas e sequestro pelo sistema retículo-endotelial, especialmente o baço ${ }^{73}$. A linfadenopatia ocorre em, aproximadamente, $50 \%$ dos pacientes e a esplenomegalia em 10 a $20 \%{ }^{73}$. Anticorpos contra fatores da coagulação (VIII, IX, XI, XII e XIII) são vistos em cerca de $25 \%$ dos casos de LES $^{44,76}$. Observamse anticorpos anti-fosfolípides em, aproximadamente, metade dos pacientes. Porém a clínica de sangramento ou fenômenos trombo-embólicos, que ocorre apenas em cerca de $10 \%$ dos pacientes com LES, nem sempre acompanha essa

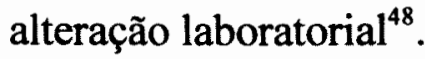

\subsubsection{Manifestações renais}

A nefrite clínica, caracterizada por alterações no sedimento urinário ou por anormalidades funcionais, está presente em cerca de $50 \%$ dos pacientes, porém, alterações histológicas podem ser detectadas em, virtualmente, todos os casos, sem obrigatoriamente ocorrerem manifestações clínicas $^{73}$. $\mathrm{O}$ espectro e a intensidade da doença renal variam de paciente para paciente. Com isso, as opções terapêuticas variam de acordo com o tipo de lesão histológica e com a evolução clínica de cada caso. A classificação mais utilizada é a da Organização 
Mundial da Saúde (OMS), modificada por Pollak e Kant ${ }^{61}$. Nessa classificação, apresentam-se as seguintes categorias histológicas:

- Classe I: rim normal;

- Classe II: glomerulonefrite mesangial (GNMes);

- Classe III: glomerulonefrite proliferativa focal (GNPF);

- Classe IV: glomerulonefrite proliferativa difusa (GNPD);

- Classe V: glomerulonefrite membranosa (GNM) e

- Classe VI: nefrite crônica esclerosante.

Vale salientar que formas mistas podem se desenvolver. As formas mais graves, com maiores possibilidades de perda total da função do rim, são as proliferativas difusas, especialmente quando predominam lesões crônicas sobre as lesões ativas na biópsia renal ${ }^{5}$. O quadro 1 descreve as alterações histológicas de atividade e de cronicidade na nefrite lúpica.

Quadro 1. Lesões histológicas na nefrite lúpica, segundo estadio.

\begin{tabular}{|l|l|}
\hline \multicolumn{1}{|c|}{ ATIVAS } & \multicolumn{1}{|c|}{ CRÔNICAS } \\
\hline - Proliferação celular & - Esclerose glomerular \\
- Necrose fibrionóide/cariorrexis & - Crescentes fibrosos \\
- Crescentes celulares & - Atrofia tubular \\
- Infiltrado leucocitário & - Fibrose intersticial \\
- Trombos hialinos & \\
\hline
\end{tabular}

Fonte: Balow, $1981^{6}$

\subsubsection{Manifestações gastrintestinais}

Os sintomas mais comuns são náusea, vômito, anorexia e dor abdominal. Uma série de fatores pode ser responsável por esses sintomas: medicamentos, peritonite, vasculite intestinal, pancreatite, entre outros. Hepatopatia com elevação de enzimas pode ocorrer como manifestação da doença ou conseqüente a medicamentos, especialmente salicilatos e imunossupressores ${ }^{73}$. 


\subsubsection{Manifestações neuro-psiquiátricas}

Sintomas neuro-psiquiátricos ocorrem em 25 a $80 \%$ dos pacientes, podendo, às vezes, precederem o diagnóstico do $\mathrm{LES}^{73}$. Os sintomas podem ser decorrentes de uma anormalidade orgânica, funcional ou mista, sendo o diagnóstico diferencial, muitas vezes, difícil de realizar, uma vez que, mesmo nos distúrbios orgânicos, a propedêutica clínica e laboratorial pode ser normal. $O$ quadro 2 resume as manifestações neuro-psiquiátricas no LES.

Quadro 2. Manifestações neuro-psiquiátricas no LES, segundo origem.

\begin{tabular}{|l|l|l|}
\hline \multicolumn{3}{|c|}{ ORIGEM } \\
\hline Geralmente funcional & Funcional ou orgânica & Orgânica \\
\hline - Depressão & - Psicose & - Convulsões \\
- Mania & - Distúrbios cognitivos & - Acidente Vascular Cerebral \\
- Ansiedade & - Disestesias & - Paralisias \\
- Distúrbios afetivos & - Cefaléia & - Distúrbios do movimento \\
- Variações do humor & & - Sindrome orgânica cerebral \\
- Distürbios comportamentais & & - Coma \\
& & - Meningite \\
& & - Mielite transversa \\
\hline
\end{tabular}

Fonte: Schur, $1993^{73}$

\subsection{CONSIDERAÇÕES TERAPÊUTICAS ${ }^{28}$}

\subsubsection{Medidas profiláticas}

Até o momento, por não ser possível identificar indivíduos susceptíveis, bem como o(s) agente(s) etiológico(s), a profilaxia primária não pode ser executada. É recomendado evitar fatores sabidamente de risco na exacerbação da doença, como o sol, drogas e gestação durante a doença ativa. A profilaxia antibiótica quando de intervenções cirúrgicas, entre outras, também é importante. 


\subsubsection{Medidas de apoio}

Muito importante é a orientação do paciente sobre a sua doença, alertando sobre os sinais iniciais de atividade, riscos e prognóstico da mesma. A boa relação médico-paciente e o suporte psíquico são fundamentais.

\subsubsection{Terapêutica com drogas}

Basicamente são utilizados protetores solares, anti-maláricos, antiinflamatórios não hormonais, corticosteróides e imunossupressores em combinações e dosagens variadas, de acordo com o local e a intensidade das manifestações clínicas.

\subsection{DIAGNÓSTICO}

O diagnóstico da doença é baseado em uma série de critérios clínicos e laboratoriais, conforme descrito abaixo:

\section{CRITÉRIOS DIAGNÓSTICOS DO LES $^{85}$}

- eritema malar ("asa de borboleta"): eritema fixo sobre as eminências malares e/ou pregas naso-labiais;

- lesões discóides: placas eritematosas com descamação, podendo ocorrer atrofia nas lesões antigas;

- ulcerações em mucosa oral e/ou nasal: ulceração oral e/ou em nasofaringe, geralmente dolorosas, observadas por médico;

- fotossensibilidade: rash cutâneo resultado de exposição à luz solar, relatado na história clínica ou observado por médico;

- artrite (habitualmente não deformante): artrite não erosiva em duas ou mais articulações periféricas;

serosite: pleurite e/ou pericardite, documentada no exame clínico e provas laboratoriais ;

nefropatia: proteinúria persistente (acima de $0,5 \mathrm{~g} / \mathrm{dia}$ ) e/ou cilindros celulares ao exame do sedimento urinário (hemáticos, granulares, leucocitários, tubulares ou mistos); 
alteracões hematológicas: anemia hemolítica (com reticulocitose), leucopenia (menos de $4000 / \mathrm{mm}^{3}$ ), linfopenia (menos que $1500 / \mathrm{mm}^{3}$ ), trombocitopenia (menos que $100.000 / \mathrm{mm}^{3}$ );

alterações do sistema nervoso central: psicose e/ou convulsão, na ausência de drogas ou distúrbios metabólicos associados a essas alterações;

alteraç̃̃es imunológicas: fenômeno da célula LE positivo, anticorpos antiDNA nativo, anticorpos anti-Sm ou sorologia falsamente positiva para sífilis por mais de seis meses;

presenca de fator anti-nuclear (FAN):por imunofluorescência ou método equivalente, sem estar associado a drogas indutoras desse anticorpo.

A presença de quatro ou mais critérios, em qualquer época de observação, é fortemente sugestiva de LES.

\subsection{EPIDEMIOLOGIA}

\subsubsection{Prevalência}

O coeficiente de prevalência do LES varia de 4 a 50 casos por 100000 habitantes ${ }^{33,46}$ sendo mais comum em áreas urbanas do que nas rurais ${ }^{88}$. Essa ampla variação explica-se, provavelmente, pelas diferenças genéticas e ambientais existentes entre as várias populações, bem como por critérios não uniformes utilizados no diagnóstico da doença. Nos Estados Unidos, o coeficiente de prevalência é maior nos asiáticos (20 por 100000), em mulheres negras (9 por 100000), se comparado com o dos hispânicos (1 por 100000 habitantes) e das mulheres brancas (4 por 100000) $)^{32,55,73,75}$. Na Nova Zelândia, a taxa de prevalência é de 15 por 100000 brancos e 51 por 100000 polinésios, sendo, estes, os que apresentam, também, maiores coeficientes de mortalidade ${ }^{53}$. A prevalência na Suécia é de 39 por $100000^{57}$, na Finlândia é de 28 por $100000^{31}$ e é infreqüente na África ${ }^{49}$. Na França, é mais comum entre migrantes da Espanha, Portugal, África do Norte e Itália ${ }^{64}$. No Reino Unido ${ }^{34}$, a prevalência do LES é, também, bastante influenciada pelo grupo étnico, com coeficientes de 36 por 100000 mulheres brancas, 91 por 100000 mulheres asiáticas e 206 por 100000 mulheres negras. A distribuição dos casos no sexo feminino é de, aproximadamente, $65 \%$ na faixa etária de 16 a 55 anos, $20 \%$ nas menores de 16 anos e $15 \%$ nas acima de 55 anos $^{16,64,70}$. A razão entre os sexos é, em média, de 5 
a 10 mulheres para 1 homem, entre 16 e 55 anos, caindo a 2 para 1 fora destes limites de idade $^{20,50}$.

Alguns autores, no entanto, encontraram uma prevalência maior na raça branca do que em negros ou asiáticos, em estudo recente realizado em Boston, Estados Unidos (crianças) e em Londres, Inglaterra (adultos) ${ }^{87}$.

Sato $^{68}$, em estudo na Escola Paulista de Medicina (atual Universidade Federal de São Paulo) encontrou, em sua casuística de 201 pacientes, proporções de $66 \%$ de brancos e $34 \%$ de não brancos.

\subsubsection{Incidência}

Nos Estados Unidos a incidência varia de 1,8 a 7,6 casos por 100000 pessoas por ano, segundo vários estudos apresentados na tabela 1:

Tabela 1 : Incidência do lúpus, segundo sexo e raça*, Estados Unidos

\begin{tabular}{|c|c|c|c|c|c|c|c|}
\hline \multirow[t]{2}{*}{ Autor } & \multirow[t]{2}{*}{ Local } & \multirow[t]{2}{*}{ Período } & \multicolumn{2}{|c|}{ brancos } & \multicolumn{2}{|c|}{ negros } & \multirow[t]{2}{*}{ Geral } \\
\hline & & & homem & mulher & homem & mulher & \\
\hline Siegel and Lee ${ }^{78}$ & New York & $1956-65$ & 0,3 & 2,5 & 1,1 & 8,1 & 2,0 \\
\hline Fessel $^{20}$ & S.Francisco & $1965-73$ & $\ldots$ & $\ldots$ & $\ldots$ & ... & 7,6 \\
\hline \multirow[t]{2}{*}{ Michet 55} & Rochester & $1950-79$ & 0,9 & 2,5 & $\cdots$ & ... & 1,8 \\
\hline & & $1970-79$ & 0,8 & 3,4 & $\ldots$ & $\ldots$ & 2,2 \\
\hline Hochberg $^{32}$ & Baltimore & $1970-77$ & 0,4 & 3,9 & 2,5 & 11,4 & 4,6 \\
\hline McCarty ${ }^{51}$ & Pennsylvania & $1985-90$ & 0,4 & 3,5 & 0,7 & 9,2 & 2,4 \\
\hline
\end{tabular}

Fonte: Hochberg, $1992^{33}$ (modificada)

*coeficiente de incidência por 100000 pessoas/ano

\subsubsection{Efeitos da idade, sexo e raça na gravidade da doença}

Com relação à gravidade da doença, crianças apresentam quadros mais severos com maior incidência de nefrite, pericardite e alterações hematológicas ${ }^{70}$. Do mesmo modo, o acometimento no sexo masculino tende a ser mais grave, com trombocitopenia e nefrite ${ }^{37}$. Nos indivíduos idosos, o LES tende a ser mais benigno, com pouco acometimento renal e de sistema nervoso central ${ }^{90}$. Recentemente, Costallat \& Coimbra ${ }^{12}$, em Campinas-São Paulo, confirmaram o 
pior prognóstico clínico para indivíduos abaixo dos 16 anos de idade e uma doença mais leve quando iniciada após os 50 anos. O estado clínico bem como o prognóstico, também, parecem ser piores em negros e nos indivíduos de baixa condição sócio-econômica, ${ }^{9,47,62,91}$. Alguns autores, no entanto, têm notado que é muito difícil separar raça de condição sócio-econômica na influência do prognóstico do LES. Pistiner e colaboradores ${ }^{60}$, em 1991, por exemplo, encontraram o mesmo prognóstico para brancos e negros, dando importância maior às condiçðes sócio-econômicas, tais como facilidades na procura do serviço médico e no tratamento da doença.

Ainda, em nosso meio, Sato e colaboradores ${ }^{69}$ encontraram, em análise univariada, riscos para desenvolvimento de insuficiência renal terminal 3,5 vezes maior nos pacientes com proteinúria e 8,2 vezes maior nos com hematúria.

\subsubsection{Mortalidade}

As causas de morte no LES podem ser divididas naquelas relacionadas à atividade da doença, naquelas relacionadas às complicações do seu tratamento $\mathrm{e}$ causas não relacionadas à patologia ${ }^{25,29}$. No que se refere à atividade da doença, o acometimento de órgão nobre, especialmente sistema nervoso central e rim, tem sido associado a um pior prognóstico ${ }^{23,69,77}$. A nefrite, além de ser uma complicação freqüente na doença, é importante fator preditor da mortalidade. Cerca de $50 \%$ dos pacientes apresentam nefrite clínica por ocasião do diagnóstico, podendo chegar a $75 \%$, após o primeiro ano da doença ${ }^{61,65}$. A nefropatia, na maioria dos estudos, tem implicado um pior prognóstico ${ }^{25,60,74}$. A associação de lesões ativas e crônicas encontradas na biópsia renal tem se mostrado relacionada a um maior risco de morte ${ }^{52}$, especialmente na presença de hipertensão arterial sistêmica ${ }^{74}$.

Com relação à raça, recentemente, Stephen e colaboradores ${ }^{83}$ encontraram diferenças no comportamento da mortalidade entre mulheres brancas e negras, nos Estados Unidos, entre 1968 e 1991. Nas brancas houve um risco decrescente abaixo dos 45 anos e crescente após os 45 anos (média de 4,6 óbitos por milhão). Nas negras, houve um risco constante abaixo dos 45 anos e progressivo acima dos 55 (média de 18,7 óbitos por milhão). 
Sato e colaboradores ${ }^{69}$ descreveram como fatores de risco para o óbito os pacientes de cor não branca, do sexo masculino, com vasculite digital, comprometimento neurológico como um todo, convulsão, hipertensão arterial e insuficiência renal terminal.

No que se refere às causas de óbito relacionadas ao tratamento do LES, a infecção, freqüentemente associada à imunossupressão, tem sido implicada como a principal causa conseqüente de óbito nesta patologia ${ }^{25,30,60}$.

Recentemente, Abu-Shakra e colaboradores ${ }^{1}$ detectaram 124 óbitos $(18,6 \%)$ em uma coorte de 665 pacientes com LES, observados entre 1970 e 1993. Quarenta pacientes (32\%) morreram tendo a infecção como uma causa associada e vinte (16\%) faleceran por causas relacionadas à atividade da doença. Os óbitos por atividade foram mais comuns nos primeiros cinco anos do diagnóstico e aqueles relacionados às complicações da doença, não associadas à atividade da mesma, foram mais comuns após cinco anos de evolução. Concluíram, ainda, que o risco padronizado de morte comparado com a população geral de Ontário (SMR) foi de $4,9\left(\mathrm{IC}_{95 \%}=[4,1 ; 5,9]\right)$. Esse risco foi maior nas idades abaixo dos 54 anos, quando comparado com o risco acima dessa faixa etária.

Em outra publicação, os mesmos autores relatam que a insuficiência renal terminal, trombocitopenia, envolvimento pulmonar e o grau de atividade da doença por ocasião do diagnóstico estão associados à mortalidade no LES, em análise multivariada mediante o modelo de riscos proporcionais de Cox. Já a hipertensão e a doença isquêmica cardíaca estão associadas com o óbito apenas na análise univariada ${ }^{2}$.

\subsubsection{Sobrevida}

O prognóstico dos pacientes com LES tem melhorado muito nos últimos 40 anos. Em 1954, 78\% dos casos sobreviviam ao $1^{\circ}$ ano da doença e apenas $52 \%$ chegavam ao quarto ano ${ }^{29,54}$. Em 1982, as porcentagens de sobrevida de 1 ano, 4 anos e 10 anos passaram a ser de $95 \%, 88 \%$ e $76 \%$, respectivamente ${ }^{23}$. Publicações recentes têm mostrado taxas de sobrevida de $95 \%$ aos 5 anos, $90 \%$ 
aos 10 anos e 79 a $83 \%$ aos 15 anos $^{1,26,60,62}$. Abu-Shakra e colaboradores ${ }^{1}$ encontraram taxas de $68 \%$ após 20 anos.

O Quadro 3 apresenta alguns trabalhos mostrando a melhora da sobrevida do LES nas últimas quatro décadas.

Quadro 3. Taxa de sobrevida aos 5, 10 e 15 anos de pacientes com LES, segundo estudo, ano de publicação, centro de estudo, nos últimos 40 anos.

\begin{tabular}{|c|c|c|c|c|c|c|c|}
\hline \multirow[t]{2}{*}{ ESTUDO } & \multirow[t]{2}{*}{ ANO } & \multirow[t]{2}{*}{ CENTRO } & \multirow{2}{*}{$\begin{array}{c}\mathrm{N}^{\circ} \text { de } \\
\text { pacientes }\end{array}$} & \multirow{2}{*}{$\begin{array}{l}\mathrm{N}^{\circ} \text { de } \\
\text { óbitos }\end{array}$} & \multicolumn{3}{|c|}{ TAXA DE SOBREVIDA (\%) } \\
\hline & & & & & 5 anos & 10 anos & 15 anos \\
\hline Merrel \& Shulman ${ }^{54}$ & 1955 & Baltimore* & 99 & 30 & 50 & ... & $\cdots$ \\
\hline Kellum \& Hasericke ${ }^{38}$ & 1964 & Cleveland* & 299 & 86 & 69 & 54 & ... \\
\hline Estes \& Christian ${ }^{19}$ & 1971 & New York* & 150 & 53 & 77 & 60 & 50 \\
\hline Fries et $\mathrm{al}^{21}$ & 1974 & Stanford* & 146 & 8 & 94 & 90 & $\ldots$ \\
\hline Wallace el al ${ }^{89}$ & 1981 & Los Angeles* & 609 & 128 & 88 & 79 & 74 \\
\hline Ginzler et $\mathrm{al}^{23}$ & 1982 & multicêntrico & 1103 & 222 & 86 & 76 & ... \\
\hline Stafford-Brady et al ${ }^{80}$ & 1988 & Toronto** & 550 & $\cdots$ & 84 & 75 & 64 \\
\hline Jonsson et $\mathrm{al}^{35}$ & 1989 & Suécia & 86 & 9 & 97 & $\ldots$ & $\ldots$ \\
\hline Swaak et al ${ }^{84}$ & 1989 & Holanda & 110 & 14 & 94 & 87 & ... \\
\hline Reveille et $\mathrm{a}^{62}$ & 1990 & Alabama* & 389 & 89 & 89 & 83 & 79 \\
\hline Gripenberg \& Helve ${ }^{26}$ & 1991 & Suécia & 66 & 12 & $\ldots$ & 91 & 81 \\
\hline Pistiner et $\mathrm{al}^{60}$ & 1991 & Los Angeles* & 570 & 154 & 97 & 93 & 83 \\
\hline Seleznick \& Fries ${ }^{74}$ & 1991 & Stanford* & 310 & 51 & 88 & 64 & $\ldots$ \\
\hline Abu-Shakra et al ${ }^{1}$ & 1995 & Toronto** & 665 & 124 & 93 & 85 & 79 \\
\hline
\end{tabular}

*: Estados Unidos

Fonte: Gladman, $1992^{25}$ (modificada)

O prognóstico nos pacientes com nefrite, também, tem melhorado muito nos últimos anos. Enquanto que, há vinte anos, a sobrevida era de 1 a 2 anos, atualmente $80 \%$ dos pacientes com nefrite sobrevivem mais que 10 anos ${ }^{73}$. Nos pacientes que, por insuficiência renal terminal (IRT), são submetidos a transplante, a sobrevida do enxerto é, em $70 \%$ dos casos, maior que 5 anos ${ }^{8}$, sendo rara a recidiva da doença no rim transplantado ${ }^{42}$. A melhora da sobrevida renal (tempo entre o início da nefrite clínica e o desenvolvimento de IRT) implica um maior tempo sob boas condições de vida e, também, está relacionada com 
uma maior eficácia no tratamento destes pacientes, especialmente a terapia com imunossupressores ${ }^{28}$.

$\mathrm{O}$ aumento das taxas de sobrevida tem sido atribuído a vários fatores como diagnóstico precoce, melhores opções terapêuticas (corticosteróides, imunossupressores, anti-maláricos) e no controle das condições mórbidas associadas (avanços na antibioticoterapia, agentes anti-hipertensivos modernos, melhora nas técnicas de diálise e transplante $)^{25}$.

Vale lembrar que, embora a tendência atual dos estudos seja considerar o início da doença como sendo a data do diagnóstico, alguns, ainda, utilizam a data de início dos sintomas. Tal fato pode ocasionar vício, com taxas de sobrevida super estimadas, visto que o início dos sintomas nem sempre é o início da doença, pois alguns sintomas são comuns a várias patologias. Outro ponto importante a ser mencionado é que a memória do paciente pode levar, também, a erros com relação à data do início da doença ${ }^{22}$.

Em nível nacional, do ponto de vista epidemiológico, existe uma escassez de dados e publicações relativas ao LES, especialmente com a utilização de técnicas estatísticas apropriadas. Este foi o estímulo maior ao desenvolvimento deste trabalho. A caracterização, bem como a quantificação dos fatores de risco nessa doença, fornece subsídios para decisões no acompanhamento clínico destes pacientes. 


\section{OBJETIVOS}

\subsection{GERAL}

Analisar a sobrevida dos pacientes portadores de LES assistidos em um hospital público de grande porte.

\subsection{ESPECÍFICOS}

- Estimar e analisar a probabilidade de sobrevida acumulada até o óbito.

- Estimar e analisar a probabilidade de sobrevida acumulada até o acometimento de insuficiência renal terminal.

- Estimar e analisar a probabilidade de sobrevida acumulada até o óbito nos pacientes que apresentaram nefrite lúpica, a partir da data do diagnóstico da nefrite.

- Estimar e analisar a probabilidade de sobrevida acumulada até o acometimento de insuficiência renal terminal, nos pacientes que apresentaram nefrite lúpica, a partir da data do diagnóstico da nefrite.

- Estimar e analisar a probabilidade de sobrevida acumulada até o óbito dos pacientes que apresentaram insuficiência renal terminal, a partir da data do desenvolvimento da insuficiência renal terminal.

- Estudar a relação entre as variáveis independentes: sexo, raça, idade, presença de hipertensão arterial sistêmica, acometimento pulmonar, acometimento cardíaco, ulcerações em mucosas, alterações hematológicas, alterações do sistema nervoso central, no início da doença, bem como acometimento renal e uso de imunossupressores, com os respectivos riscos de mortalidade, para o total de pacientes, para os pacientes com nefrite e para os pacientes com insuficiência renal crônica.

- Estudar a relação entre as variáveis independentes: sexo, raça, idade, presença de hipertensão arterial sistêmica, acometimento pulmonar, acometimento cardíaco, ulcerações em mucosas, alterações hematológicas, alterações do sistema nervoso central, no início da doença, bem como acometimento renal e uso de imunossupressores, com os respectivos riscos para a insuficiência renal terminal, para o total de pacientes e para os pacientes com nefrite. 


\section{MATERIAL E MÉTODOS}

\subsection{CASUÍSTICA}

Foram estudados todos os pacientes internados e/ou acompanhados ambulatorialmente no Serviço de Reumatologia do Hospital Heliópolis - São Paulo, com diagnóstico de LES, definido segundo critérios do Colégio Americano de Reumatologia ${ }^{85}$, no período de $1^{\circ}$ de janeiro de 1978 a 30 de junho de 1994. Foram incluídos os pacientes com pelo menos um retorno médico após o diagnóstico. No anexo 1 encontra-se o número de pacientes, segundo ano de diagnóstico.

\subsection{DELINEAMENTO}

O estudo foi do tipo coorte, sendo que os pacientes foram acompanhados desde a data do diagnóstico firmado por médico, com base nos critérios já mencionados, até a data da última consulta em consultório (ou contato telefônico) ou até a data do óbito. A data final de seguimento, para este trabalho, foi 30 de junho de 1995.

\subsection{INSTRUMENTO DE COLETA}

Todos os prontuários de pacientes do Serviço de Reumatologia foram transcritos em protocolo padronizado do próprio Serviço onde são anotados dados completos de história clínica, exames subsidiários, tratamento e evolução a cada consulta (em média, com intervalos de 2 a 3 meses). Tal protocolo completo (anexo 2) é normalmente utilizado desde 1982. As informações dos pacientes, cuja doença foi diagnosticada em outro local, foram coletadas através de contato médico direto ou por carta. Pacientes com informações duvidosas foram excluídos do estudo.

O preenchimento dos prontuários é feito por residentes da especialidade e supervisionado pelo mesmo assistente responsável pelo ambulatório dessa patologia, autor desse trabalho. Desse protocolo completo, o autor elaborou um segundo protocolo, simplificado (anexo 3), com ênfase nas variáveis em estudo. 
As causas de óbito foram definidas a partir das informações médicas do registro hospitalar (óbitos no próprio hospital) ou usando a causa relacionada nos atestados de óbito (óbitos fora do serviço), fornecidos pelos parentes.

A data da última observação foi registrada na última consulta ou mediante contato telefônico com o paciente. Pacientes sem contato por mais de um ano antes do término da coleta foram considerados com tempo de observação incompleto (denominados como censura) e a data da última observação foi a do último contato.

\subsection{VARIÁVEIS}

Foram analisadas as seguintes variáveis, com as respectivas categorias:

- sexo: masculino e feminino.

- raça: branca e não branca.

- idade: considerada a idade de início do diagnóstico médico da doença. Foram analisadas em três faixas etárias: 7 a 15 anos, 16 anos a 34 anos e 35 a 60 anos.

- presença de nefrite: considerada quando ocorreram uma ou mais das seguintes alterações: sedimento urinário alterado (hematúria e/ou cilindrúria) sem outra causa, proteinúria de 24 horas acima de $0,5 \mathrm{~g}$, creatinina sérica acima de $1,5 \mathrm{mg} / \mathrm{dl}$ e clearence de creatinina abaixo de $50 \mathrm{ml} / \mathrm{min}$.

- presença de insuficiência renal terminal (IRT): considerada quando o paciente apresentou perda total da função renal, necessitando de diálise.

- presença de neuropatia central: psicose e/ou convulsão diagnosticadas por médicos, desenvolvidas durante o primeiro ano da doença.

- uso de imunossupressores: quaisquer das drogas dessa linha, utilizadas para o tratamento da atividade da doença por mais de três meses, em qualquer período após o diagnóstico da mesma.

- presença de hipertensão arterial: definida como pressão sistólica igual ou maior de $150 \mathrm{~mm} / \mathrm{Hg}$ e pressão diastólica acima de $100 \mathrm{~mm} / \mathrm{Hg}$, desenvolvida no primeiro ano da doença.

- presença de ulceração de mucosas: enantema em mucosa oral e/ou nasal que apareceram no primeiro ano da doença.

- envolvimento cárdio-pulmonar: envolvimento pulmonar (pleurite, infiltrado pulmonar não relacionado a infecção nem a insuficiência cardíaca, ou hemorragia pulmonar) e/ou envolvimento cardíaco (pericardite ou miocardite 
não associadas à infecção, insuficiência cardíaca ou alterações metabólicas) ocorridas no primeiro ano da doença

- presença de alterações hematológicas: anemia hemolítica e/ou leuco/linfopenia e/ou plaquetopenia desenvolvidas durante o primeiro ano da doença.

- variáveis imunológicas laboratoriais: presença de testes positivos para os seguintes auto-anticorpos: anti-DNA (imunofluorescência), anti-Sm, antiRNP, anti-SSA, anti-SSB (imunodifusão dupla), bem como a presença do fenômeno da célula LE. As análises aqui feitas referem-se aos resultados dos exames realizados durante o primeiro ano da doença.

Os critérios de diagnóstico do LES foram analisados de duas maneiras. Primeiramente na descrição dos pacientes, foram contabilizados quais os critérios presentes em qualquer momento do seguimento e, na análise de sobrevida, foi analisada a presença do critério apenas no início do seguimento, com exceção da presença de nefrite. $\mathrm{O}$ critério FAN positivo, detectado através de imunofluorescência, tendo como substrato o fígado de camundongo e o Hep-2, não foi estudado na análise de sobrevida uma vez que todos os pacientes apresentaram este teste positivo, considerado quando os títulos foram maiores ou iguais a $1 / 100$.

\subsection{ANÁLISE ESTATÍSTICA}

\section{- Total de pacientes (253)}

Primeiramente foi feita a análise descritiva das características dos pacientes. Depois foram realizados testes de associação pela distribuição do $\chi^{2}$ ou de Fisher $^{40}$ para avaliar o relacionamento entre a presença de óbito, ou a presença de IRT e as variáveis de estudo. Em seguida, prosseguiu-se com a análise de sobrevida. Para esse grupo de pacientes foram realizadas duas análises de sobrevivência. A primeira constou da análise de sobrevida até o óbito (sobrevida global) e, a outra, foi analisar a sobrevida até o surgimento da insuficiência renal terminal (sobrevida para IRT).

Para a análise da sobrevida até o óbito (global), os pacientes foram acompanhados desde a data do diagnóstico até a data de seu óbito. Foram 
consideradas censuras os pacientes que foram perdidos de observação (pacientes que não compareceram ao serviço havia mais de um ano), aqueles que estavam vivos na data do término do estudo (30 de junho de 1995), bem como os pacientes que foram a óbito por causas seguramente não relacionadas, direta ou indiretamente, à doença de base.

Para a análise da sobrevida até a IRT os pacientes foram acompanhados desde a data do diagnóstico até a data do surgimento da insuficiência renal terminal (IRT), definida como o início da diálise. Foram consideradas censuras do seguimento os pacientes que não estavam em diálise até a data do óbito ou até 30 de junho de 1995, além dos perdidos de observação.

A análise da sobrevida foi, inicialmente, univariada, através do estimador produto limite de Kaplan-Meier ${ }^{36,54}$, para se avaliar dentre as variáveis de estudo quais foram os fatores prognósticos mais significantes para o óbito. A comparação entre as curvas de sobrevivência acumulada foi feita pelo teste estatístico do log-rank ${ }^{14}$.

A seguir, foi feita a análise multivariada mediante o modelo de riscos proporcionais de $\operatorname{Cox}^{14}$ (modelo de Cox) para se verificar a atuação conjunta de todos os fatores prognósticos. No modelo de Cox multivariado a função de riscos $\underline{\mathrm{h}(\mathrm{t})}$ é escrita como função de $\underline{\mathrm{k}}$ variáveis independentes ${ }^{14,43}$ :

$$
h\left(t / X_{1}, X_{2}, \ldots . X_{k}\right)=h_{0}(t) \cdot \exp \left(\beta_{1} X_{1}+\beta_{2} X_{2}+\ldots+\beta_{k} X_{k}\right)
$$

A função $h_{0}(t)$ é a parte não paramétrica do modelo de Cox e, em estudos onde o objetivo é estimar fatores prognósticos, não há interesse em definí-la, pois é comum a todos os indivíduos. Os coeficientes de regressão $\left(\beta_{j}, j=1, . . k\right)$ são estimados pelo método da máxima verossimilhança parcial.

A partir da fórmula (O pode-se estimar a razão das funções de riscos (hazard ratio - HR) para cada uma das variáveis independentes $\left(X_{i}\right)$, supondose todas as outras variáveis independentes $\left(X_{j \neq i}\right)$ como constantes. Essa razão compara as funções de riscos de duas categorias de uma determinada variável. 
Para uma específica variável independente $\left(X_{i}\right)$, dicotômica (isto é, $X_{i}$ pode assumir apenas dois valores, por exemplo, 0 e 1 ), pode-se escrever o modelo de $\operatorname{Cox}(\mathbf{0})$ da seguinte maneira:

para $X_{i}=1 \Rightarrow h\left(t / X_{i}=1, X_{j \neq i}\right)=h_{0}(t) \cdot \exp \left(\beta_{1} X_{1}+\beta_{2} X_{2}+\ldots+\beta_{j} X_{j}+\beta_{i} .1\right)$

2

para $X_{i}=0 \Rightarrow h\left(t / X_{i}=0, X_{j \neq i}\right)=h_{0}(t) \cdot \exp \left(\beta_{1} X_{1}+\beta_{2} X_{2}+\ldots+\beta_{j} X_{j}+\beta_{i} .0\right)$

3

Dividindo-se a função 2 pela função 3 tem-se a razão das funções de riscos (HR):

$H R\left(X_{i}\right)=\frac{h\left(t / X_{i}=1, X_{j \neq i}\right)}{h\left(t / X_{i}=0, X_{j \neq i}\right)}=\frac{h_{0}(t) \cdot \exp \left(\beta_{1} X_{1}+\beta_{2} X_{2}+\ldots+\beta_{j} X_{j}+\beta_{i}\right)}{h_{0}(t) \cdot \exp \left(\beta_{1} X_{1}+\beta_{2} X_{2}+\ldots+\beta_{j} X_{j}\right)}$

$$
\text { logo, } \quad H R\left(X_{i}\right)=\exp \left(\beta_{i}\right)
$$

Neste trabalho, primeiramente, elaboraram-se modelos de Cox univariados para cada uma das variáveis de estudo. $\mathrm{Na}$ análise multivariada, iniciou-se o processo de modelagem pela variável mais significante, do ponto de vista estatístico, no modelo univariado de Cox; a seguir foram acrescentadas, no modelo, as outras variáveis, uma a uma, seguindo a ordem decrescente de significância estatística. Este procedimento é denominado stepwise forward selection procedure ${ }^{40}$. A nova variável era mantida no modelo multivariado caso fosse considerada estatisticamente significante e/ou melhorasse significantemente a precisão do modelo e/ou fosse variável de confusão para a(s) variável(eis) já existente(s) no modelo; além disso, era levada em conta a importância clínica da variável. Uma variável era considerada de confusão quando alterava o(s) coeficiente(s) de regressão de outra(s) variável(eis) já existente(s) no modelo ${ }^{40}$. Após a introdução de todas as variáveis no modelo testou-se o efeito de interação dentre aquelas em que se verificou o efeito de confusão.

Para se avaliar a proporcionalidade das razões de risco foram utilizados os gráficos de $\ln (-\ln (\mathrm{S}(\mathrm{t})))$ em função do tempo de observação para cada uma das 
variáveis $^{15,43}$. Não foi utilizado o modelo de Cox incorporando o termo tempodependente, porque em todos os casos se observou proporcionalidade entre os riscos.

Como resultado final da análise multivariada, foram estimadas as razões das funções de riscos (HR) para cada uma das variáveis constantes no modelo final (estimativa por ponto e por intervalo de confiança de 95\%).

Foi adotado o nível de significância de $5 \%(\alpha=5 \%)$.

\section{- Pacientes com nefrite (118)}

A segunda parte do trabalho consistiu na análise dos fatores de risco para o óbito e para a IRT, mas apenas nos pacientes que desenvolveram nefrite. Também foram realizados testes de associação pela distribuição do $\chi^{2}$ ou de Fisher $^{40}$ para avaliar o relacionamento entre a presença de óbito, ou a presença de IRT e as variáveis de estudo e a análise de sobrevida global e para IRT.

Para a análise da sobrevida global dos pacientes após nefrite clínica foram considerados apenas aqueles pacientes que apresentaram as manifestações persistentes por mais de 3 meses, sendo que o início de acompanhamento foi a data do diagnóstico da nefrite e prosseguiu até o óbito ou última consulta. Adotaram-se os mesmos critérios de censura descritos anteriormente.

Para a análise da sobrevida renal, os pacientes com nefrite foram acompanhados desde o diagnóstico da nefrite clínica até a evolução para a insuficiência renal terminal (IRT). Foram consideradas censuras aqueles pacientes que no momento do término do estudo, ou foram a óbito ou foram perdidos de observação, sem apresentar a perda total da função renal.

Como resultado final da análise multivariada, estimaram-se as razões de riscos (HR) para cada uma das variáveis constantes no modelo final, seja para a sobrevida até o óbito ou até a IRT (estimativa no ponto e por intervalo de confiança) dado que o paciente tenha apresentado nefrite. 
- Pacientes com insuficiência renal terminal (21)

A última parte do trabalho referiu-se apenas àqueles pacientes que desenvolveram IRT. Embora houvesse intenção de fazer a análise de sobrevida global desses pacientes a partir da data de início da diálise, essa análise tornou-se inviável pelo pequeno número de casos (21) e de óbitos (8). Por isso foram apenas realizados testes de associação pelo $\chi^{2}$ ou de Fisher $^{40}$ para avaliar o relacionamento entre a presença de óbito e as variáveis de estudo. 


\section{RESULTADOS E DISCUSSÃO}

\subsection{Descrição dos pacientes}

A casuística deste estudo compreendeu um total de 253 pacientes, sendo que o tempo de seguimento variou de 2 meses a 204 meses, com valor mediano de 65 meses. As características demográficas desses pacientes encontram-se apresentadas na tabela 2 .

Tabela 2. Distribuição dos pacientes com LES, segundo características demográficas.

Clínica de Reumatologia do Hospital Heliópolis. São Paulo - 1978 a 1995

\begin{tabular}{l|l|rr}
\hline \multicolumn{1}{c|}{ Variável } & \multicolumn{1}{c|}{ categoria } & \multicolumn{1}{c}{$\mathbf{n}^{\circ}$} & \multicolumn{1}{c}{$\%$} \\
\hline sexo & masculino & 18 & 7,1 \\
& feminino & 235 & 92,9 \\
raça & não branco & 89 & 35,2 \\
& branco & 164 & 64,8 \\
idade no diagnóstico & & & \\
(anos) & até 15 & 15 & 5,9 \\
& 16 a 34 & 170 & 67,2 \\
& 35 e mais & 68 & 26,9 \\
\hline Total & & 253 & 100,0 \\
\hline
\end{tabular}

A faixa etária de maior ocorrência, no momento do diagnóstico da doença, foi a de 16 aos 34 anos (67,2\%) (gráfico 1). A idade dos pacientes variou de 7 a 60 anos, sendo a idade média igual a 29,1 anos (desvio padrão de 10,2 anos). A idade mediana foi igual a 27 anos e $75 \%$ dos pacientes tinham idade até 35 anos. 


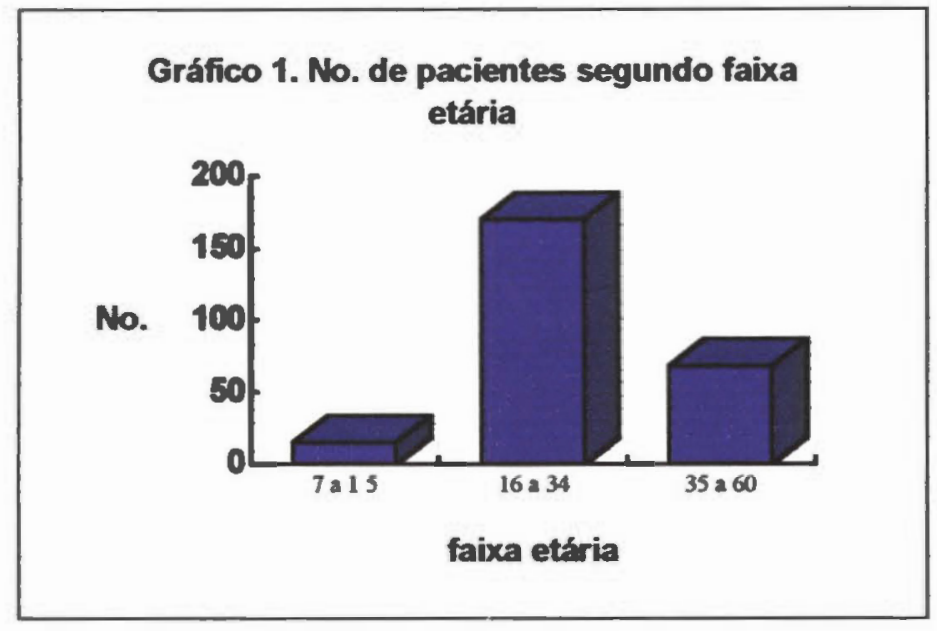

Esta casuística, como pode ser salientado, é baseada em um hospital predominantemente de adultos; logo, o pequeno número de crianças observadas, muito provavelmente, deve ser função desse aspecto. A divisão das faixas etárias neste estudo baseou-se na literatura para a faixa etária dos menores de 16 anos ${ }^{70}$; já as faixas de 16 a 34 e de 35 anos e mais foram definidas baseando-se no número de falhas (óbitos) acontecidas; se fosse analisada a faixa etária acima de 55 anos, conforme vários trabalhos, o estudo estatístico estaria prejudicado, devido à pequena frequiência de óbitos nesta faixa. Optou-se como ponto de corte os 34 anos devido ao fato de ser esta idade a relativa ao percentil 75.

A maioria dos pacientes foi do sexo feminino (92,9\%), sendo apenas 18 pacientes do sexo masculino $(7,1 \%)$ como mostra o gráfico 2 .

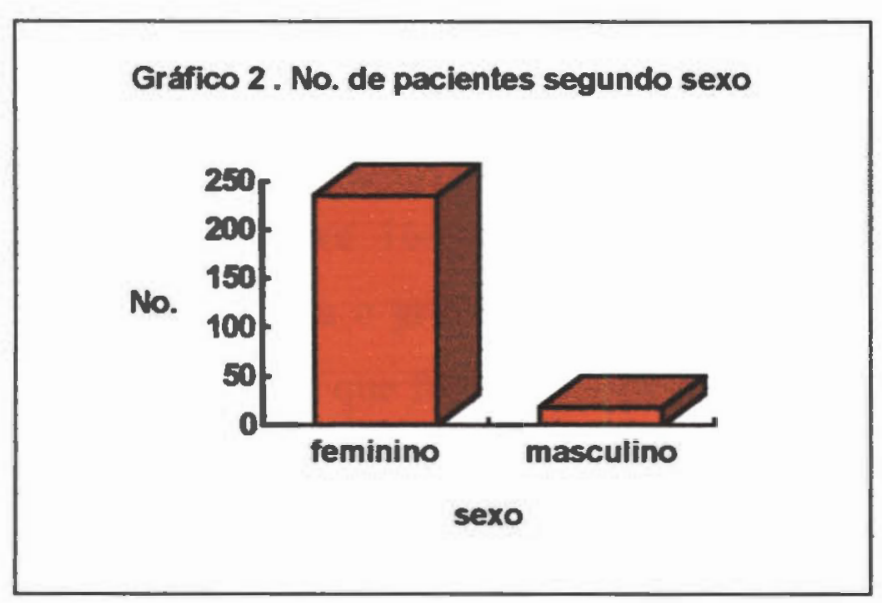


A razão global entre os sexos foi de 13 mulheres para 1 homem. As razões entre os sexos, segundo as faixas etárias, estão apresentadas no gráfico 3 . Na faixa etária de 7 a 15 anos, é igual a 2,7 mulheres para 1 homem, entre 16 e 34 anos é de 16 mulheres para 1 homem, dos 35 aos 54 anos, a razão passa para 20,7 mulheres para cada homem e, acima dos 54 anos, cai novamente para 2 mulheres para cada homem.

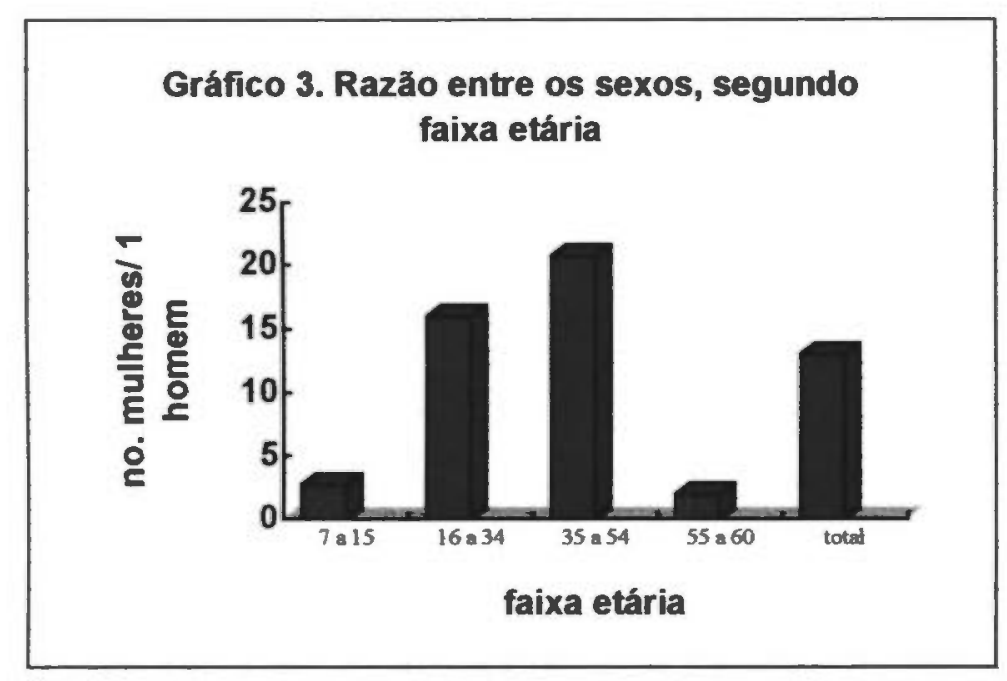

A distribuição dos pacientes segundo sexo, nesta casuística, acompanha o relatado em literatura ${ }^{13,20,50}$, com a predominância no sexo feminino quando analisadas todas as faixas etárias (13 mulheres: 1 homem); esta relação diminui aos serem analisados os pacientes mais jovens no início da doença ( 7 a 15 anos) e os mais velhos (dos 55 anos aos 60 anos de idade). Vale ressaltar a alta ocorrência no sexo feminino, nas faixas etárias intermediárias, chegando a uma proporção de 20 mulheres para cada homem de 35 a 54 anos.

Com relação à raça, houve 164 pacientes brancos $(64,8 \%)$ e 89 não brancos $(35,2 \%)$, conforme mostra o gráfico 4 . Neste estudo havia apenas dois pacientes de ascendência japonesa que foram categorizados como não brancos. 


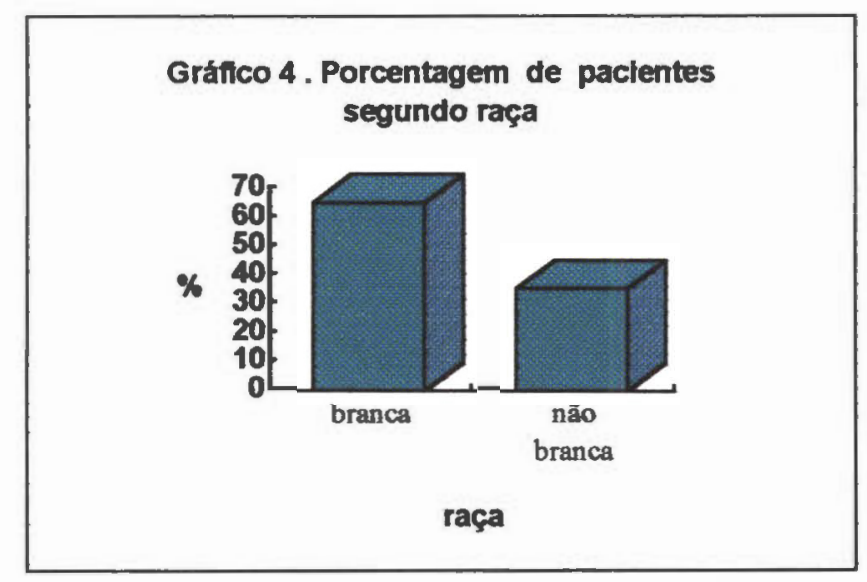

No Brasil encontra-se alguma dificuldade na caracterização da raça. A opção por brancos e não brancos ajuda a diminuir a possibilidade de vício de classificação. A maior ocorrência na raça branca discorda de boa parte da literatura americana ${ }^{20,32,51,55,78}$. Vários autores, entretanto, também observaram um predomínio de brancos sobre outras raças ${ }^{2,13,69,87}$. Vale destacar o número baixo de orientais nesta casuística, fato também encontrado em Campinas-São Paulo por Costallat \& Coimbra ${ }^{13}$.

Na tabela 3, podem ser apreciadas as distribuições de freqüência dos pacientes segundo as alterações clínicas e laboratoriais que preenchem os critérios diagnósticos para o LES. Vale relembrar que a presença desses critérios é considerada em qualquer momento do seguimento do paciente.

A quase totalidade dos pacientes apresentou queixa articular $(98,8 \%)$, seguindo-se, em freqüência, eritema malar (80,2\%), fotossensibilidade (78,3\%), alterações imunológicas laboratoriais $(66,0 \%)$, alterações de mucosas $(47,0 \%)$, nefropatia (46,6\%), serosite $(35,6 \%)$, alterações hematológicas $(30,4 \%)$, lesões discóides $(26,5 \%)$ e alteração do sistema nervoso central $(22,1 \%)$. Todos os pacientes apresentaram fator anti-nuclear (FAN) positivo em algum momento de seu seguimento (gráfico 5). 
Tabela 3. Distribuição dos pacientes com LES segundo os critérios diagnósticos. Clínica de Reumatologia do Hospital Heliópolis. São Paulo - 1978 a 1995

\begin{tabular}{|c|c|c|c|}
\hline Critério & presença & $n^{\circ}$ & $\%$ \\
\hline eritema malar & $\begin{array}{l}\text { sim } \\
\text { não }\end{array}$ & $\begin{array}{c}203 \\
50\end{array}$ & $\begin{array}{l}80,2 \\
19,8\end{array}$ \\
\hline lesões discóides & $\begin{array}{l}\text { sim } \\
\text { não }\end{array}$ & $\begin{array}{c}67 \\
186\end{array}$ & $\begin{array}{l}26,5 \\
73,5\end{array}$ \\
\hline $\begin{array}{l}\text { ulcerações } \\
\text { de mucosas }\end{array}$ & $\begin{array}{l}\text { sim } \\
\text { não } \\
\text { ignorado }\end{array}$ & $\begin{array}{c}119 \\
133 \\
1\end{array}$ & $\begin{array}{c}47,0 \\
52,6 \\
0,4\end{array}$ \\
\hline fotossensibilidade & $\begin{array}{l}\text { sim } \\
\text { não }\end{array}$ & $\begin{array}{c}198 \\
55\end{array}$ & $\begin{array}{l}78,3 \\
21,7\end{array}$ \\
\hline queixa articular & $\begin{array}{l}\text { sim } \\
\text { não }\end{array}$ & $\begin{array}{c}250 \\
3\end{array}$ & $\begin{array}{c}98,8 \\
1,2\end{array}$ \\
\hline serosite & $\begin{array}{l}\text { sim } \\
\text { não }\end{array}$ & $\begin{array}{c}90 \\
163\end{array}$ & $\begin{array}{l}35,6 \\
64,4\end{array}$ \\
\hline nefropatia & $\begin{array}{l}\text { sim } \\
\text { não }\end{array}$ & $\begin{array}{l}118 \\
135\end{array}$ & $\begin{array}{l}46,6 \\
53,4\end{array}$ \\
\hline $\begin{array}{l}\text { alterações } \\
\text { hematológicas }\end{array}$ & $\begin{array}{l}\text { sim } \\
\text { não }\end{array}$ & $\begin{array}{c}77 \\
176\end{array}$ & $\begin{array}{l}30,4 \\
69,6\end{array}$ \\
\hline $\begin{array}{l}\text { alterações do sistema } \\
\text { nervoso central }\end{array}$ & $\begin{array}{l}\text { sim } \\
\text { não }\end{array}$ & $\begin{array}{c}56 \\
197\end{array}$ & $\begin{array}{l}22,1 \\
77,9\end{array}$ \\
\hline $\begin{array}{l}\text { alterações } \\
\text { imunológicas }\end{array}$ & $\begin{array}{l}\text { sim } \\
\text { não }\end{array}$ & $\begin{array}{c}167 \\
86\end{array}$ & $\begin{array}{l}66,0 \\
34,0\end{array}$ \\
\hline fator anti-nuclear (FAN) & $\begin{array}{l}\text { sim } \\
\text { não }\end{array}$ & $\begin{array}{c}253 \\
-\end{array}$ & $\begin{array}{c}100,0 \\
-\end{array}$ \\
\hline Total & & 253 & 100,0 \\
\hline
\end{tabular}


Gráfico 5. Pacientes com LES, segundo presença dos critérios diagnósticos (\%)

Critérios diagnósticos

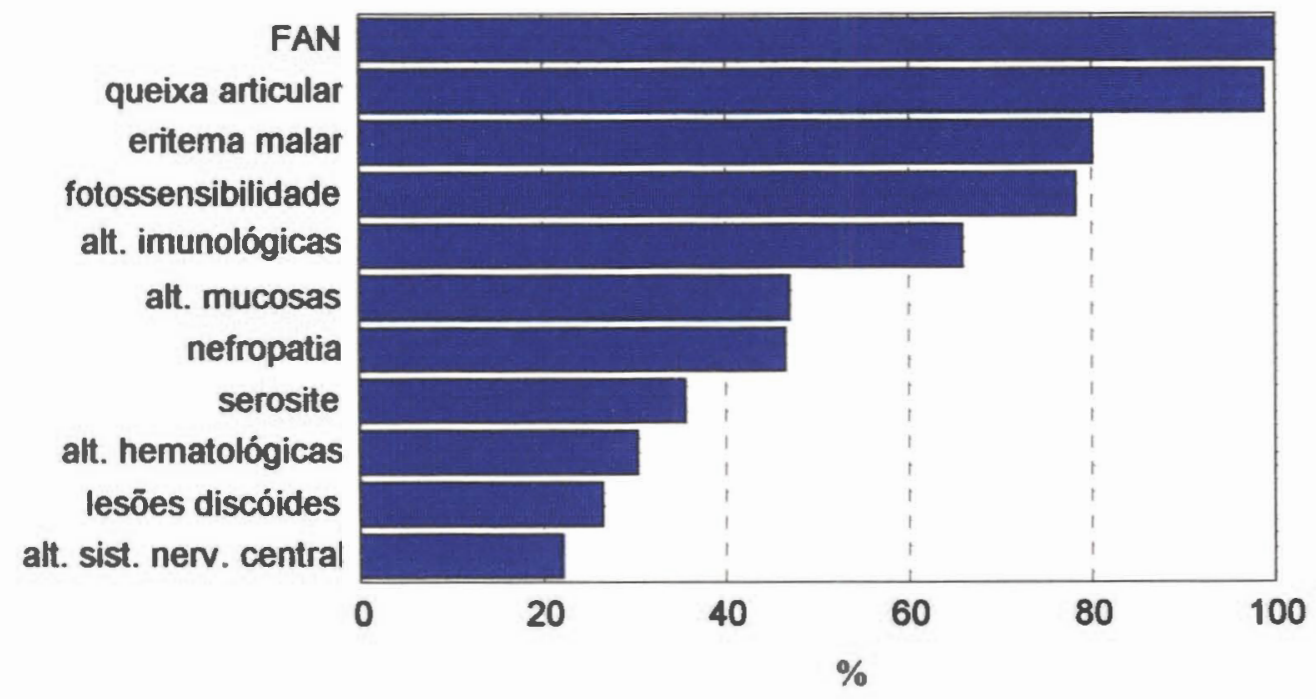

A presença do FAN, detectado por imunofluorescência, em todos os pacientes, em algum momento do acompanhamento, confirma que, quando são utilizados, como substratos, o figado de camundongo e o Hep-2, a sensibilidade deste teste é muito alta. Outro ponto a ser destacado foi a alta freqüência de queixa articular, fato este explicado por englobar não apenas artrite, mas, também, quaisquer queixas álgicas ocorridas nas articulações e estruturas próximas. O eritema malar ocorreu em cerca de $\mathbf{8 0} \%$ dos casos, sempre durante o primeiro ano da doença e essa freqüência é superior a relatos de literatura ${ }^{18,73}$. Talvez uma explicação para esse achado seja a maior exposição solar que ocorre no nosso meio, quando comparada à de países da América do Norte ou Europa. As ocorrências dos demais critérios diagnósticos do LES são semelhantes às descritas na maioria dos trabalhos de literatura ${ }^{13,39,44,66,68,73,76}$.

Na tabela 4 podem ser visualisados os resultados referentes às variáveis clínicas e laboratoriais presentes durante o primeiro ano do acompanhamento. 
Tabela 4. Distribuição dos pacientes com LES segundo variáveis clínicas e laboratoriais. Clínica de Reumatologia do Hospital Heliópolis. São Paulo - 1978 a 1995

\begin{tabular}{|c|c|c|c|}
\hline Variável & categoria & $\mathbf{n}^{\circ}$ & $\%$ \\
\hline $\begin{array}{l}\text { ulcerações de } \\
\text { mucosas }\end{array}$ & $\begin{array}{l}\text { sim } \\
\text { não } \\
\text { ignorado }\end{array}$ & $\begin{array}{r}119 \\
133 \\
1\end{array}$ & $\begin{array}{r}47,0 \\
52,6 \\
0,4\end{array}$ \\
\hline $\begin{array}{l}\text { envolvimento } \\
\text { cárdio-pulmonar }\end{array}$ & $\begin{array}{l}\text { pulmão } \\
\text { coração } \\
\text { pulmão e coração } \\
\text { não }\end{array}$ & $\begin{array}{r}48 \\
18 \\
24 \\
163\end{array}$ & $\begin{array}{r}19,0 \\
7,1 \\
9,5 \\
64,4\end{array}$ \\
\hline $\begin{array}{l}\text { hipertensão } \\
\text { arterial }\end{array}$ & $\begin{array}{l}\text { sim } \\
\text { não }\end{array}$ & $\begin{array}{r}72 \\
181\end{array}$ & $\begin{array}{l}28,5 \\
71,5\end{array}$ \\
\hline $\begin{array}{l}\text { acometimento de } \\
\text { sistema nervoso } \\
\text { central }\end{array}$ & $\begin{array}{l}\text { psicose } \\
\text { convulsão } \\
\text { psicose e convulsão } \\
\text { não }\end{array}$ & $\begin{array}{r}18 \\
28 \\
10 \\
197\end{array}$ & $\begin{array}{r}7,1 \\
11,1 \\
3,9 \\
77,9\end{array}$ \\
\hline $\begin{array}{l}\text { alterações } \\
\text { hematológicas }\end{array}$ & $\begin{array}{l}\text { anemia } \\
\text { leucopenia } \\
\text { plaquetopenia } \\
\text { múltiplas } \\
\text { não }\end{array}$ & $\begin{array}{r}10 \\
52 \\
7 \\
8 \\
176\end{array}$ & $\begin{array}{r}3,9 \\
20,5 \\
2,8 \\
3,2 \\
69,6\end{array}$ \\
\hline nefrite & $\begin{array}{l}\text { sim } \\
\text { não }\end{array}$ & $\begin{array}{l}118 \\
135\end{array}$ & $\begin{array}{l}46,6 \\
53,4\end{array}$ \\
\hline $\begin{array}{l}\text { insuficiência } \\
\text { renal } \\
\text { terminal }\end{array}$ & $\begin{array}{l}\text { sim } \\
\text { não }\end{array}$ & 232 & $\begin{array}{r}8,3 \\
91,7\end{array}$ \\
\hline imunossupressor & $\begin{array}{l}\text { sim } \\
\text { não }\end{array}$ & $\begin{array}{r}200 \\
53\end{array}$ & $\begin{array}{l}79,1 \\
20,9\end{array}$ \\
\hline \multicolumn{2}{|l|}{ Total } & 253 & 100,0 \\
\hline
\end{tabular}

Ulcerações de mucosas orais ou nasais ocorreram em $47 \%$ dos casos (119 pacientes); envolvimento pulmonar isolado ocorreu em 48 pacientes (19\%); envolvimento cardíaco isolado, em 18 casos $(7,1 \%)$ e associado com o pulmonar 
em 24 pacientes (9,5\%). A hipertensão arterial sistêmica se desenvolveu em 72 casos $(28,5 \%)$ e psicose ocorreu em 18 casos $(7,1 \%)$, convulsão em 28 (11\%) e ambos associados em $10(4 \%)$.

Alterações hematológicas ocorreram em 77 pacientes (30,4\%), sendo 10 pacientes com anemia hemolítica (13\%), 52 casos com leucopenia $(67,5 \%)$, sete com plaquetopenia $(9,1 \%)$ e oito casos com alterações mistas $(10,4 \%)$.

A nefrite ocorreu em $46,6 \%$ dos pacientes (118 casos) e a insuficiência renal terminal, em 8,3\% (21 casos). Esses dados são referentes a qualquer época do estudo, tendo sido anotadas as datas de início das mesmas para a análise. A maioria dos pacientes $(79,1 \%)$ foi tratada por três meses ou mais com imunossupressores. Vale comentar a alta freqüência de pacientes que utilizaram, em determinada época, medicamento imunossupressor. Deve-se ressaltar a possibilidade de que, em muitas ocasiões, essa terapêutica tenha sido usada em casos não obrigatoriamente graves. Vários pacientes receberam o medicamento durante pouco tempo e com a finalidade de auxiliar no controle de quadro articular ou cutâneo rebeldes às outras drogas habitualmente utilizadas nestes casos.

Observa-se que neste estudo praticamente não houve dados ignorados com relação às variáveis demográficas, clínicas e laboratoriais estudadas. Tal fato pode ser explicado uma vez que as variáveis escolhidas para o estudo fazem parte da rotina no preenchimento de qualquer protocolo de LES, pois através delas firma-se o diagnóstico. O preenchimento de todos os protocolos de forma completa, sob a supervisão do autor deste trabalho, desde 1981, auxiliou a obtenção dos dados.

Em relação às alterações imunológicas laboratoriais dos pacientes, os resultados podem ser analisados na tabela 5. O fenômeno da célula LE esteve positivo em $61,3 \%$ dos pacientes testados, seguindo-se, em freqüência de 
positividade, por anti-SSA $(46,5 \%)$, anti-RNP $(38,9 \%)$, anti-DNA $(38,0 \%)$, antiSm $(30,2 \%)$ e anti-SSB $(7,9 \%)$. Os achados referentes aos testes imunológicos apresentaram distribuição de freqüências concordante com as descritas na literatura $^{13,58,68,86}$ e, embora úteis como um dos critérios diagnósticos, apresentaram sensibilidade baixa, bem menor do que o FAN. Como se nota, diferentemente das outras variáveis, houve um grande número de testes não realizados; as hipóteses explicativas seriam: dificuldades técnicas do serviço público e o fato de que, no início do estudo, estes testes não eram realizados de rotina.

Tabela 5. Distribuição do número de pacientes com LES segundo alterações imunológicas laboratoriais. Clínica de Reumatologia do Hospital Heliópolis. São Paulo 1978 a 1995

\begin{tabular}{l|l|rr}
\hline \multicolumn{1}{c|}{ Variável } & \multicolumn{1}{|c}{ categoria } & \multicolumn{1}{c}{$\mathbf{n}^{\circ}$} & $\%^{\star}$ \\
\hline anti-DNA & positivo & 81 & 38,0 \\
& negativo & 132 & 62,0 \\
anti-Sm & não realizado & 40 & 15,8 \\
& positivo & 49 & 30,2 \\
& negativo & 113 & 69,8 \\
não realizado & 91 & 36,0 \\
anti-RNP & positivo & 63 & 38,9 \\
& negativo & 99 & 61,1 \\
& não realizado & 91 & 36,0 \\
anti-SSA & positivo & 54 & 46,5 \\
& negativo & 62 & 53,5 \\
& não realizado & 137 & 54,2 \\
anti-SSB & positivo & 9 & 7,9 \\
& negativo & 105 & 92,1 \\
& não realizado & 139 & 54,9 \\
Células LE & positivo & 92 & 61,3 \\
& negativo & 58 & 38,7 \\
& não realizado & 103 & 40,7 \\
\hline \multicolumn{1}{c}{ Total } & & & \\
\hline
\end{tabular}

*: as porcentagens das categorias positivo ou negativo foram calculadas com a exclusão dos pacientes que não realizaram o exame, enquanto que para a categoria "não realizado" as porcentagens referem-se ao total de pacientes. 
Nesta casuística ocorreram 39 óbitos $(15,4 \%)$ durante o período de estudo; as causas conseqüenciais de óbito encontram-se na tabela 6 . A principal causa conseqüente de óbito foi a infecção que ocorreu em 16 pacientes $(41,0 \%)$, sendo 11 casos por septicemia, um caso por pneumonia e quatro casos por broncopneumonia. A atividade da doença como causa direta do óbito, sem evidência de processo infeccioso, ocorreu em 15 pacientes $(38,5 \%)$ e morte decorrente de insuficiência renal terminal ocorreu em 6 casos $(15,4 \%)$. Os dois pacientes com causa mal definida foram considerados como censura na análise de sobrevida até o óbito (gráfico 6). Neste estudo não ocorreram óbitos decorrentes de neoplasias ou doença coronariana, comumente referido por alguns autores $^{1,62,63,92}$.

Tabela 6. Número e porcentagem de óbitos segundo causas conseqüenciais de óbito. Clínica de Reumatologia do Hospital Heliópolis. São Paulo - 1978 a 1995

\begin{tabular}{c|cc}
\hline Causa conseqüencial & $n^{\circ}$ & $\%$ \\
\hline - infeção : septicemia \\
broncopneumonia \\
pneumonia & 11 & 28,1 \\
sub-total & 1 & 10,3 \\
- atividade da doença & 16 & 4,6 \\
- insuficiência renal & 15 & 38,5 \\
terminal & 6 & 15,4 \\
- mal definida & 2 & 5,1 \\
\hline \multicolumn{1}{c|}{ Total } & 39 & 100,0 \\
\hline
\end{tabular}


Gráfico 6. No. de óbitos, segundo causa consequiencial de óbito

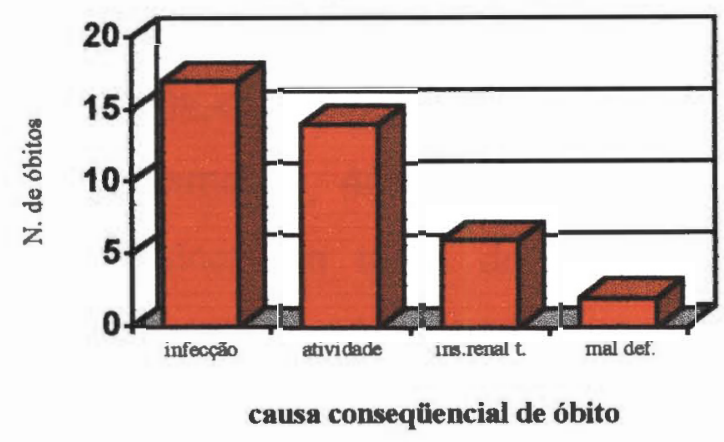

Em relação às causas de óbito, os achados de predomínio de complicações infecciosas concordam com parte da literatura. Abu-Shakra', por exemplo, encontrou $32 \%$ de óbitos decorrentes de infecção e $16 \%$ devido à atividade do lúpus, sendo que estes por atividade foram mais comuns nos pacientes dentro dos primeiros cinco anos da doença e aqueles conseqüentes à insuficiência de órgão nobre, mais comuns nos casos com mais de cinco anos de evolução. Nesse mesmo estudo a ocorrência de infecção foi constante durante todo o acompanhamento. Ward e colaboradores ${ }^{92}$, entretanto, encontraram a atividade do lúpus como causa mais comum de óbito (34\%) seguida de infecção em $22 \%$ (32/144 óbitos). Mortes pelo lúpus e por infecção foram mais comuns em pacientes jovens e o risco de morte por atividade foi maior nos primeiros 3 anos da doença, embora tenham ocorrido durante todo o curso da doença. Rosner e

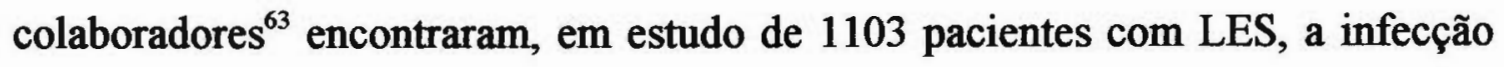
como principal causa de óbito ( $33 \%$ dos 222 óbitos). No presente estudo, complicações da insuficiência renal terminal foram causas conseqüentes de óbito em $15,4 \%$ desses, confirmando sua importância no prognóstico da doença, como já descrito em literatura ${ }^{23}$. Entretanto, óbito decorrente de acometimento no sistema nervoso central ocorreu em apenas um dos 15 casos de morte por atividade da doença, contrariando o observado em literatura, como causa conseqüente importante ${ }^{77}$. 
Outro dado a relatar foi a ausência de óbitos conseqüentes a câncer, salientando-se que neste estudo não foram encontrados óbitos em pacientes cuja doença se iniciou após os 50 anos de idade. Este fato difere do encontrado por Ward e colaboradores ${ }^{92}$ e Abu-Shakra e colaboradores ${ }^{1}$. Nesses trabalhos, além da casuística maior (respectivamente, 408 e 665 pacientes), foi descrita porcentagem de óbitos por câncer em torno de 6\%. Esses dois estudos concordam que os riscos de óbito por atividade da doença são muito maiores nos primeiros 5 anos do início e que os riscos de morte decorrentes de complicações crônicas ou câncer tornam-se mais importantes após 5 anos da doença.

\subsection{Análise de sobrevida até o óbito (global)}

Ocorreram 39 óbitos nesta coorte e, para dois deles, a causa de óbito foi "mal definida". Com isso, a análise de sobrevivência foi feita considerando-se 37 óbitos dentre os 253 pacientes acompanhados e os demais foram considerados censura. Foram registradas 65 perdas durante o seguimento $(25,7 \%$ do total de pacientes). A tabela 7 apresenta as distribuições dos casos segundo a ocorrência de óbito e variáveis demográficas.

Tabela 7. Distribuição dos pacientes com LES, segundo a ocorrência de óbito e variáveis demográficas. Clínica de Reumatologia do Hospital Heliópolis. São Paulo - 1978 a 1995

\begin{tabular}{|c|c|c|c|c|c|c|c|c|}
\hline \multirow[t]{2}{*}{ Variável } & \multirow[t]{2}{*}{ categoria } & \multicolumn{2}{|c|}{ censura } & \multicolumn{2}{|c|}{ óbito } & \multicolumn{2}{|c|}{ Total } & \multirow{2}{*}{$\begin{array}{l}\text { valor } \\
\text { de } p^{*}\end{array}$} \\
\hline & & $\mathbf{n}^{\circ}$ & $\%$ & $n^{\circ}$ & $\%$ & $n^{\circ}$ & $\%$ & \\
\hline Sexo & $\begin{array}{l}\text { feminino } \\
\text { masculino }\end{array}$ & $\begin{array}{r}203 \\
13\end{array}$ & $\begin{array}{l}86,4 \\
72,2\end{array}$ & $\begin{array}{r}32 \\
5\end{array}$ & $\begin{array}{l}13,6 \\
27,8\end{array}$ & $\begin{array}{r}235 \\
18\end{array}$ & $\begin{array}{l}100,0 \\
100,0\end{array}$ & 0,1551 \\
\hline Raça & $\begin{array}{l}\text { não branco } \\
\text { branco }\end{array}$ & $\begin{array}{r}79 \\
137\end{array}$ & $\begin{array}{l}88,8 \\
83,5\end{array}$ & $\begin{array}{l}10 \\
27\end{array}$ & $\begin{array}{l}11,2 \\
16.5\end{array}$ & $\begin{array}{r}89 \\
164\end{array}$ & $\begin{array}{l}100,0 \\
1000\end{array}$ & 0,3486 \\
\hline Idade no momento & 7 a 15 & 11 & 73,3 & 4 & 26,7 & 15 & 100,0 & 0,1503 \\
\hline do diagnóstico & 16 a 34 & 143 & 84,1 & 27 & 15,9 & 170 & 100,0 & \\
\hline (anos) & 35 a 60 & 62 & 91,2 & 6 & 8,8 & 68 & 100,0 & \\
\hline Total & & 216 & 85,4 & 37 & 14,6 & 253 & 100,0 & \\
\hline
\end{tabular}

${ }^{*}$ p: nível descritivo do teste de associação pelo $\chi^{2}$ ou Fisher. 
Ocorreram, proporcionalmente, mais óbitos no sexo masculino do que no feminino (respectivamente, $27,8 \%$ e 13,6\%), como pode ser visto no gráfico 7 . Também os pacientes com início da doença entre 7 e 15 anos tiveram uma proporção de óbitos maior do que os mais velhos (gráfico 8); entretanto não houve evidências para detectar associação estatisticamente significante entre a ocorrência de óbito e as variáveis demográficas. O pior prognóstico do LES, no sexo masculino e em crianças, tem sido amplamente relatado em literatura ${ }^{37,7087}$, no entanto, nesta casuística, os resultados dos testes de associação não foram estatisticamente significantes. A baixa freqüência de pacientes, bem como de óbitos nessas categorias, eventualmente, poderiam explicar esses achados.
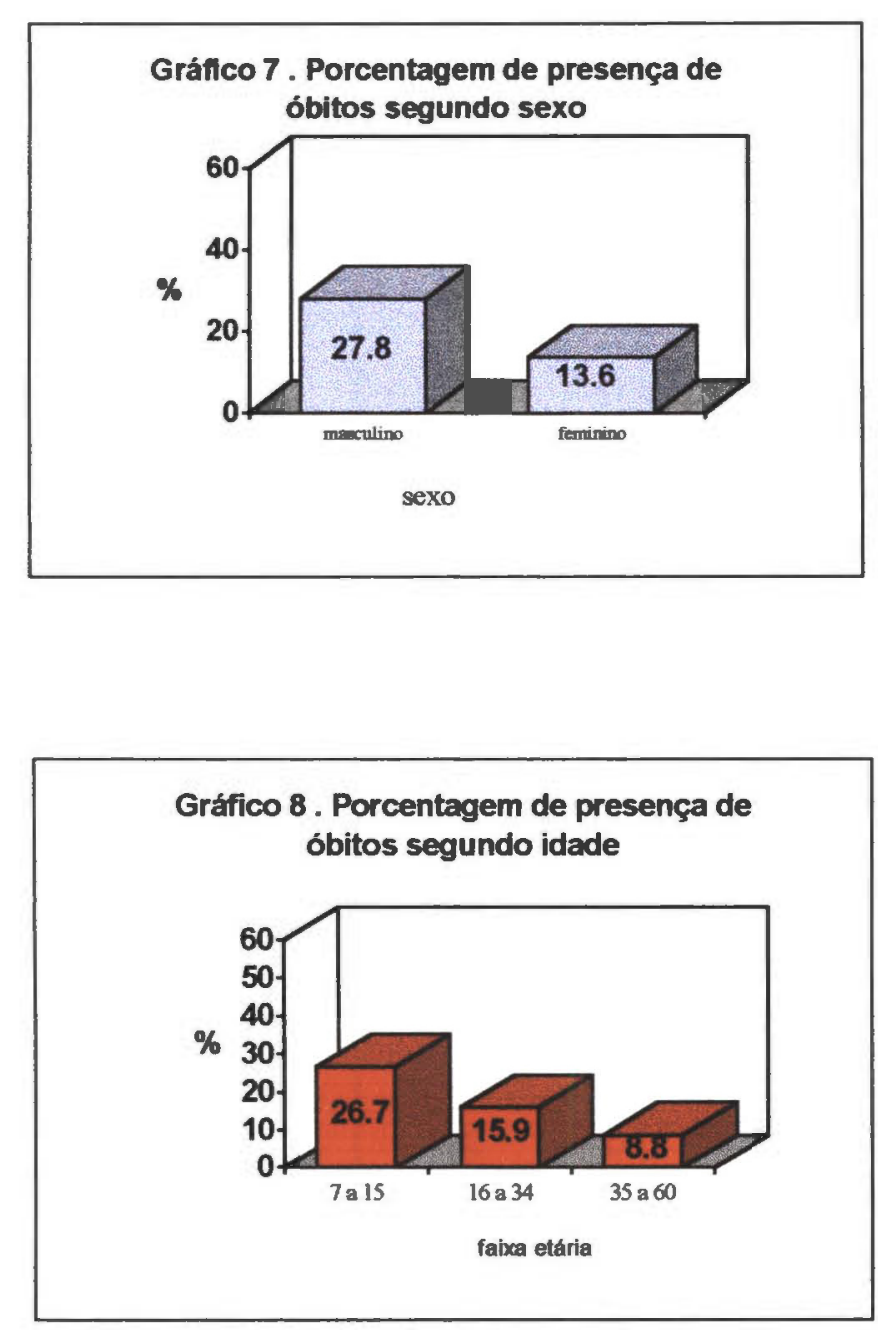
A tabela 8 apresenta a distribuição dos pacientes, segundo ocorrência de óbito e as variáveis clínicas e laboratoriais. A presença e localização do envolvimento cárdio-pulmonar esteve estatisticamente associada à ocorrência do óbito $(\mathrm{p}=0,0103)$. Os pacientes com acometimento isolado do pulmão, bem como associado ao acometimento cardíaco, revelaram as maiores porcentagens de óbito (respectivamente, $20,8 \%$ e $33,3 \%$ ); já aqueles com acometimento isolado no coração ou sem envolvimento cárdio-pulmonar apresentaram, respectivamente, $16,7 \%$ e $9,8 \%$ de óbito (gráfico 9 ).

Tabela 8. Distribuição dos pacientes com LES, segundo a ocorrência de óbito e as variáveis clínicas e laboratoriais.Clínica de Reumatologia do Hospital Heliópolis. São Paulo - 1978 a 1995

\begin{tabular}{|c|c|c|c|c|c|c|c|c|}
\hline \multirow[t]{2}{*}{ Variável } & \multirow[t]{2}{*}{ categoria } & \multicolumn{2}{|c|}{ censura } & \multicolumn{2}{|c|}{ óbito } & \multicolumn{2}{|c|}{ Total } & \multirow{2}{*}{$\begin{array}{l}\text { valor } \\
\text { de } p^{*}\end{array}$} \\
\hline & & $\mathrm{n}^{\circ}$ & $\%$ & $n^{\circ}$ & $\%$ & $n^{\circ}$ & $\%$ & \\
\hline ulcerações & não & 103 & 86,6 & 16 & 13,4 & 119 & 100,0 & 0,7289 \\
\hline \multirow[t]{2}{*}{ de mucosas } & $\operatorname{sim}$ & 112 & 84,2 & 21 & 15,8 & 133 & 100,0 & \\
\hline & ignorado & 1 & 100,0 & - & 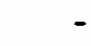 & 1 & 100,0 & \\
\hline envolvimento & não & 147 & 90,2 & 16 & 9,8 & 163 & 100,0 & 0,0103 \\
\hline \multirow[t]{3}{*}{ cárdio-pulmonar } & pulmão & 38 & 79,2 & 10 & 20,8 & 48 & 100,0 & \\
\hline & coração & 15 & 83,3 & 3 & 16,7 & 18 & 100,0 & \\
\hline & pulmão e coração & 16 & 66,7 & 8 & 33,3 & 24 & 100,0 & \\
\hline hipertensão & não & 154 & 85,1 & 27 & 14,9 & 181 & 100,0 & 0,9907 \\
\hline arterial & $\operatorname{sim}$ & 62 & 86,1 & 10 & 13,9 & 72 & 100,0 & \\
\hline acometimento de & não & 170 & 86,3 & 27 & 13,7 & 197 & 100,0 & 0,3616 \\
\hline sistema nervoso & psicose & 14 & 77,8 & 4 & 22,2 & 18 & 100,0 & \\
\hline \multirow[t]{2}{*}{ central } & convulsão & 25 & 89,3 & 3 & 10,7 & 28 & 100,0 & \\
\hline & psicose e convulsão & 7 & 70,0 & 3 & 30,0 & 10 & 100,0 & \\
\hline alterações & não & 147 & 83,5 & 29 & 16,5 & 176 & 100,0 & 0,2720 \\
\hline \multirow[t]{4}{*}{ hematológicas } & anemia & 9 & 90,0 & 1 & 10,0 & 10 & 100,0 & \\
\hline & leucopenia & 47 & 90,4 & 5 & 9,6 & 52 & 100,0 & \\
\hline & plaquetopenia & 6 & 85,7 & 1 & 14,3 & 7 & 100,0 & \\
\hline & múltiplos & 7 & 87,5 & 1 & 12,5 & 8 & 100,0 & \\
\hline \multirow[t]{2}{*}{ nefrite } & não & 120 & 88,9 & 15 & 11,1 & 135 & 100,0 & 0,1302 \\
\hline & sim & 96 & 81,4 & 22 & 18,6 & 118 & 100,0 & \\
\hline insuficiência & não & 203 & 87,5 & 29 & 12,5 & 232 & 100,0 & 0,0049 \\
\hline renal terminal & $\operatorname{sim}$ & 13 & 61,9 & 8 & 38,1 & 21 & 100,0 & \\
\hline \multirow[t]{2}{*}{ imunossupressor } & não & 170 & 85,0 & 30 & 15,0 & 200 & 100,0 & 0,9126 \\
\hline & $\operatorname{sim}$ & 46 & 86,8 & 7 & 13,2 & 53 & 100,0 & \\
\hline \multicolumn{2}{|l|}{ Total } & 216 & 85,4 & 37 & 14,6 & 253 & 100,0 & \\
\hline
\end{tabular}

*p: nivel descritivo do teste de associação pelo $\chi^{2}$ ou Fisher. Na realização do teste foi excluída a categoria "ignorado" 


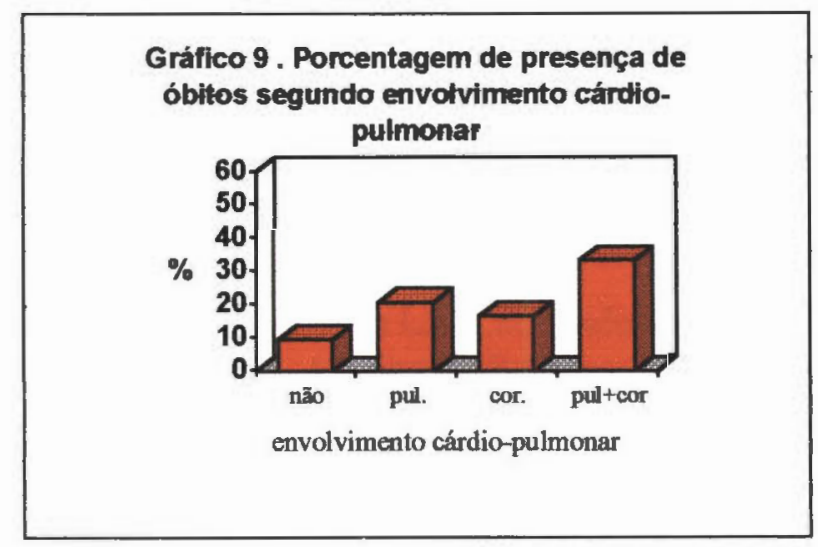

A insuficiência renal terminal esteve associada, de forma estatisticamente significante, com o óbito ( $p=0,0049)$. Em $38,1 \%$ dos casos com IRT ocorreu o óbito, mas apenas $12,5 \%$ dos pacientes sem insuficiência renal terminal morreram (gráfico 10). Quanto à nefrite, não foi detectada associação estatisticamente significante com o óbito $(\mathrm{p}=0,1302)$, embora a porcentagem de óbito em pacientes com nefrite tenha sido maior do que aqueles sem essa alteração (respectivamente $18,6 \%$ e 11,1\%), como se observa no gráfico 11 .
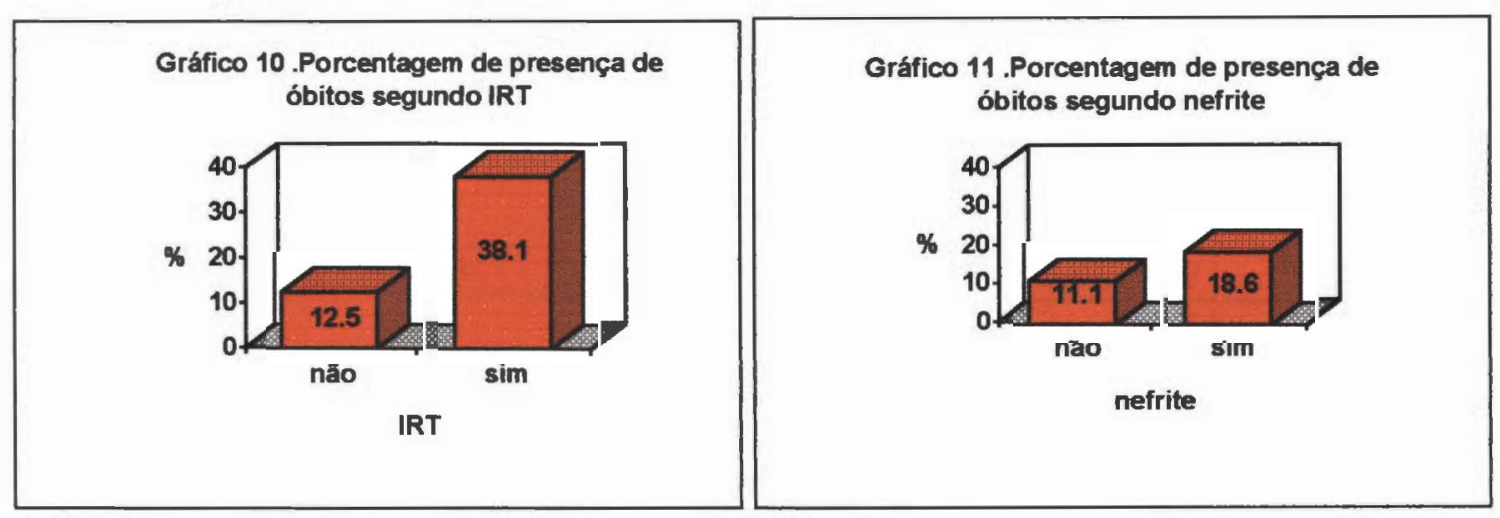

Verifica-se que não houve associação estatisticamente significante entre qualquer das alterações imunológicas laboratoriais testadas e o óbito (tabela 9). Vale observar, novamente, que em muitos casos os exames não foram realizados por dificuldades técnicas. Na literatura, de todos esses auto-anticorpos, aquele 
que está mais relacionado com a atividade clínica da doença, bem como com o acometimento renal no LES, é o anti-DNA ${ }^{67}$. No entanto, nada tem sido relatado em relação à sua associação com o óbito. Neste estudo, também, não se observou tal associação.

Tabela 9. Distribuição dos pacientes com LES, segundo a ocorrência de óbito e as alterações imunológicas laboratoriais. Clínica de Reumatologia do Hospital Heliópolis.

São Paulo - 1978 a 1995

\begin{tabular}{|c|c|c|c|c|c|c|c|c|}
\hline \multirow[t]{2}{*}{ Variável } & \multirow[t]{2}{*}{ categoria } & \multicolumn{2}{|c|}{ censura } & \multicolumn{2}{|c|}{ óbito } & \multicolumn{2}{|c|}{ Total } & \multirow{2}{*}{$\begin{array}{c}\text { valor } \\
\text { de } p^{*}\end{array}$} \\
\hline & & $\mathrm{n}^{\circ}$ & $\%$ & $n^{\circ}$ & $\%$ & $\mathrm{n}^{\circ}$ & $\%$ & \\
\hline \multirow[t]{3}{*}{ anti DNA } & negativo & 111 & $\overline{84,1}$ & 21 & $\overline{15,9}$ & 132 & 100,0 & 0,6060 \\
\hline & positivo & 71 & 87,7 & 10 & 12,3 & 81 & 100,0 & \\
\hline & não realizado & 34 & 85,0 & 6 & 15,0 & 40 & 100,0 & \\
\hline \multirow[t]{3}{*}{ anti-Sm } & negativo & 100 & $\mathbf{8 8 , 5}$ & 13 & 11,5 & 113 & 100,0 & 0,3568 \\
\hline & positivo & 40 & 81,6 & 9 & 18,4 & 49 & 100,0 & \\
\hline & não realizado & 76 & 83,5 & 15 & 16,5 & 91 & 100,0 & \\
\hline \multirow[t]{3}{*}{ anti-RNP } & negativo & 84 & 84,8 & 15 & 15,2 & 99 & 100,0 & 0,6195 \\
\hline & positivo & 56 & 88,9 & 7 & 11,1 & 63 & 100,0 & \\
\hline & não realizado & 76 & 83,5 & 15 & 16,5 & 91 & 100,0 & \\
\hline \multirow[t]{3}{*}{ anti-SSA } & negativo & 54 & 87,1 & 8 & 12,9 & 62 & 100,0 & 0,7577 \\
\hline & positivo & 45 & 83,3 & 9 & 16,7 & 54 & 100,0 & \\
\hline & não realizado & 117 & 85,4 & 20 & 14,6 & 137 & 100,0 & \\
\hline \multirow[t]{3}{*}{ anti-SSB } & negativo & 89 & 84,8 & 16 & 15,2 & 105 & 100,0 & 0,8776 \\
\hline & positivo & 8 & 88,9 & 1 & 11,1 & 9 & 100,0 & \\
\hline & não realizado & 119 & 85,6 & 20 & 14,4 & 139 & 100,0 & \\
\hline \multirow[t]{3}{*}{ Células LE } & negativo & 45 & 77,6 & 13 & 22,4 & 58 & 100,0 & 0,3687 \\
\hline & positivo & 78 & 84,8 & 14 & 15,2 & 92 & 100,0 & \\
\hline & não realizado & 93 & 90,3 & 10 & 9,7 & 103 & 100,0 & \\
\hline \multicolumn{2}{|l|}{ Total } & 216 & 85,4 & 37 & 14,6 & 253 & 100,0 & \\
\hline
\end{tabular}

*p: nível descritivo do teste de associação pelo $\chi^{2}$ ou Fisher. Na realização do teste foi excluída a categoria "não realizado"

Na análise da sobrevida até o óbito dos pacientes com LES, primeiramente são apresentados os resultados referentes à análise pelo método de Kaplan-Meier. No gráfico 12 pode-se visualizar a curva de sobrevida global para o período de estudo. Os valores estimados das proporções de sobrevida global foram $96,4 \%$ 
após um ano, $89,9 \%$ aos 5 anos, $79,6 \%$ aos 10 anos e $71,8 \%$ aos 15 anos de seguimento da coorte.

Gráfico 12 . Probabilidade de sobrevida acumulada total

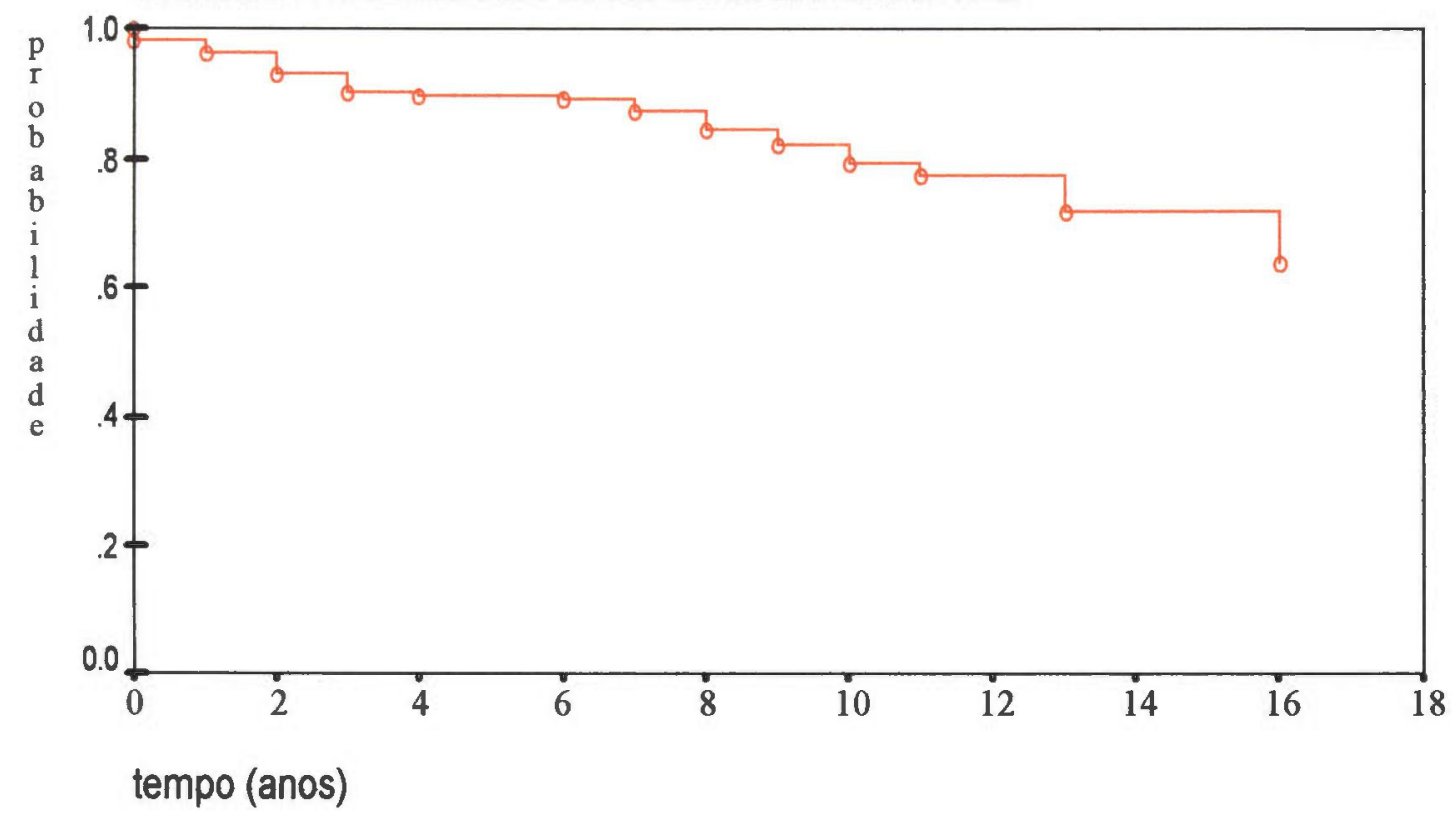

Estas estimativas são semelhantes às relatadas em trabalhos recentes de literatura, conforme já apresentado no quadro 3 da introdução deste trabalho (pg 12). Ao se analisar esse quadro, nota-se que desde os primeiros trabalhos de tábua de vida com pacientes com LES, como o de Merrel \& Shulman ${ }^{54}$, a taxa de sobrevida tem aumentado consideravelmente até nossos dias. Tal aumento nas estimativas das probabilidades de sobrevivência foi notadamente marcante a partir da década de 70, como mostra o trabalho de Fries e colaboradores ${ }^{21}$, onde em seguimento por 10 anos de 146 pacientes (oito óbitos e cinco perdas) as taxas de sobrevida subiram para próximo de $\mathbf{9 5 \%}$ aos cinco anos e $90 \%$ aos 10 anos. Nesse mesmo trabalho, os autores discutem que métodos clínicos e laboratoriais mais padronizados e conhecidos, ajudando no diagnóstico precoce, bem como um maior suporte terapêutico, têm contribuído para essas taxas maiores de sobrevida. É importante salientar a possibilidade da existência de vício relacionado ao tempo (lead time bias), isto é, o fato de estarem sendo feitos diagnósticos mais precocemente, na atualidade, redundaria, de forma artificial, em um aumento da 
sobrevida, sem, entretanto, refletir, obrigatoriamente, uma real melhora da mesma, mas, apenas, um tempo de observação maior, em virtude da deteç̧ão precoce do LES.

$\mathrm{Na}$ década de 90 essas porcentagens se mantiveram, aproximadamente, dentro desses valores ${ }^{1,26,60,62}$, com exceção do trabalho de Seleznick $\&$ Fries $^{74}$, que encontraram taxas de sobrevida em 310 pacientes (51 óbitos) de $88 \%$ aos cinco anos e $64 \%$ aos 10 anos de seguimento. Nesse mesmo trabalho, quando considerada a data de início dos sintomas, as taxas eram maiores (respectivamente, 96 e 89\%), embora as duas curvas não tenham sido estatisticamente diferentes.

Os resultados da análise da sobrevida global pelo método de KaplanMeier, segundo as características demográficas dos pacientes, estão apresentados na tabela 10.

Tabela 10. Probabilidade de sobrevida acumulada para o óbito pelo método de Kaplan-Meier, segundo as características demográficas. Clínica de Reumatologia do Hospital Heliópolis. São Paulo - 1978 a 1995

\begin{tabular}{|c|c|c|c|c|c|c|}
\hline \multirow[t]{2}{*}{ Variável } & \multirow{2}{*}{ categoria } & \multicolumn{3}{|c|}{ prob. sobrevida acumulada } & \multirow{2}{*}{\begin{tabular}{|l|}
$(\%)$ \\
15 anos \\
\end{tabular}} & \multirow{2}{*}{$\begin{array}{c}\text { log rank } \\
\text { (p) }\end{array}$} \\
\hline & & 1 ano & 5 anos & 10 anos & & \\
\hline Sexo & feminino & 98,2 & 92,1 & 82,0 & 73,6 & 0,2377 \\
\hline Raça & $\begin{array}{l}\text { não branco } \\
\text { branco }\end{array}$ & $\begin{array}{l}97,6 \\
98,1\end{array}$ & $\begin{array}{l}93,4 \\
90,4\end{array}$ & $\begin{array}{l}86,4 \\
78,6\end{array}$ & $\begin{array}{l}86,4 \\
68,0\end{array}$ & 0,1824 \\
\hline $\begin{array}{l}\text { Idade } \\
\text { no diagnóstico } \\
\text { (em anos) }\end{array}$ & $\begin{array}{l}7 \text { a } 15 \\
16 \text { a } 34 \\
35 \text { a } 60\end{array}$ & $\begin{array}{r}100,0 \\
97,0 \\
100,0\end{array}$ & $\begin{array}{l}92,3 \\
89,3 \\
96,4\end{array}$ & $\begin{array}{l}92,3 \\
79,1 \\
82,4\end{array}$ & $\begin{array}{l}57,7 \\
74,9 \\
82,4\end{array}$ & 0,5203 \\
\hline Total & & 96,4 & 89,9 & 79,6 & 71,8 & \\
\hline
\end{tabular}

Ao se compararem as curvas da probabilidade de sobrevida acumulada entre os sexos masculino e feminino, não foi detectada diferença estatisticamente 
significante entre elas $(p=0,2377)$, embora a sobrevida masculina tenha sido sempre inferior quando comparada à feminina, nesta amostra (gráfico 13). Após 5 e 10 anos de seguimento, as proporções acumuladas de sobrevivência entre os homens foram, respectivamente, de $81,9 \%$ e $68,3 \%$ enquanto que para as mulheres essas proporções foram de $92,1 \%$ e $82,0 \%$.

Gráfico 13 - Probabilidade de sobrevida acumulada, segundo sexo

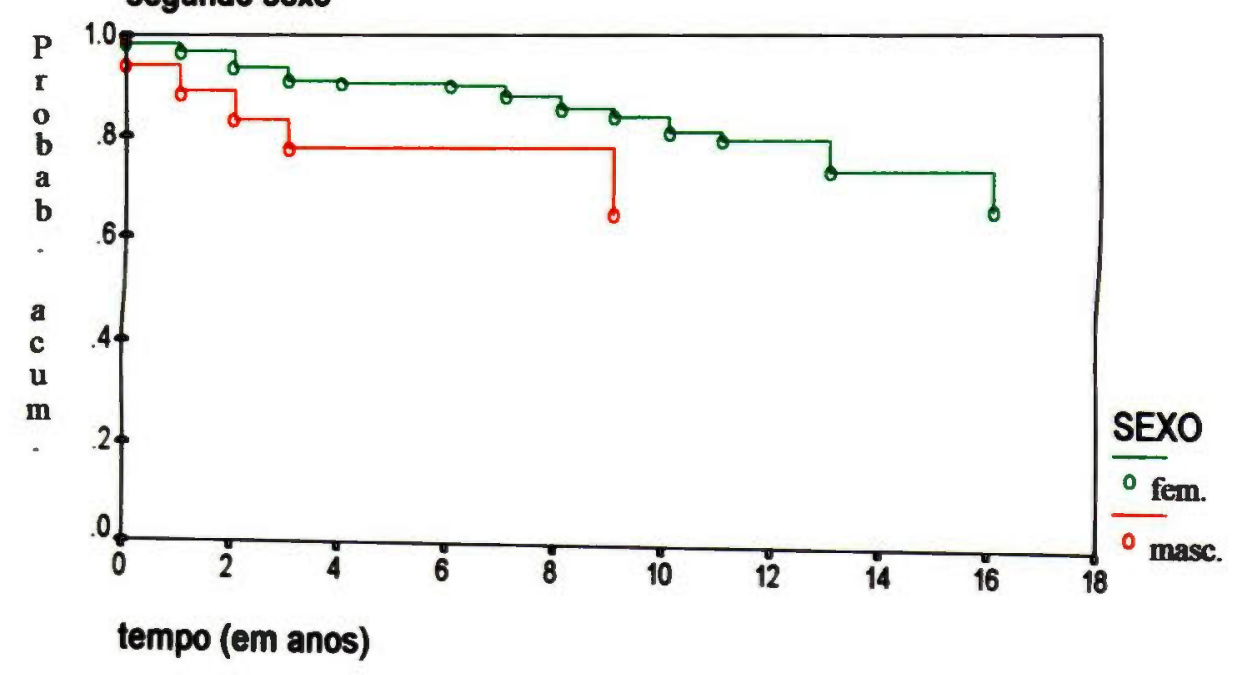

O mesmo aconteceu em relação à idade dos pacientes, isto é, não se detectou diferença estatisticamente significante $(p=0,5203)$ entre as curvas de probabilidade de sobrevida acumulada (gráfico 14), mesmo ao serem comparadas duas a duas. Porém, após 15 anos de seguimento, dos pacientes com até 15 anos, no momento do diagnóstico, $57,7 \%$ estavam vivos, contra $74,9 \%$ e $82,4 \%$ dos pacientes mais velhos (respectivamente, 16 a 34 anos e 35 a 60 anos). 
Gráfico 14. Probabilidade de sobrevida acumulada,

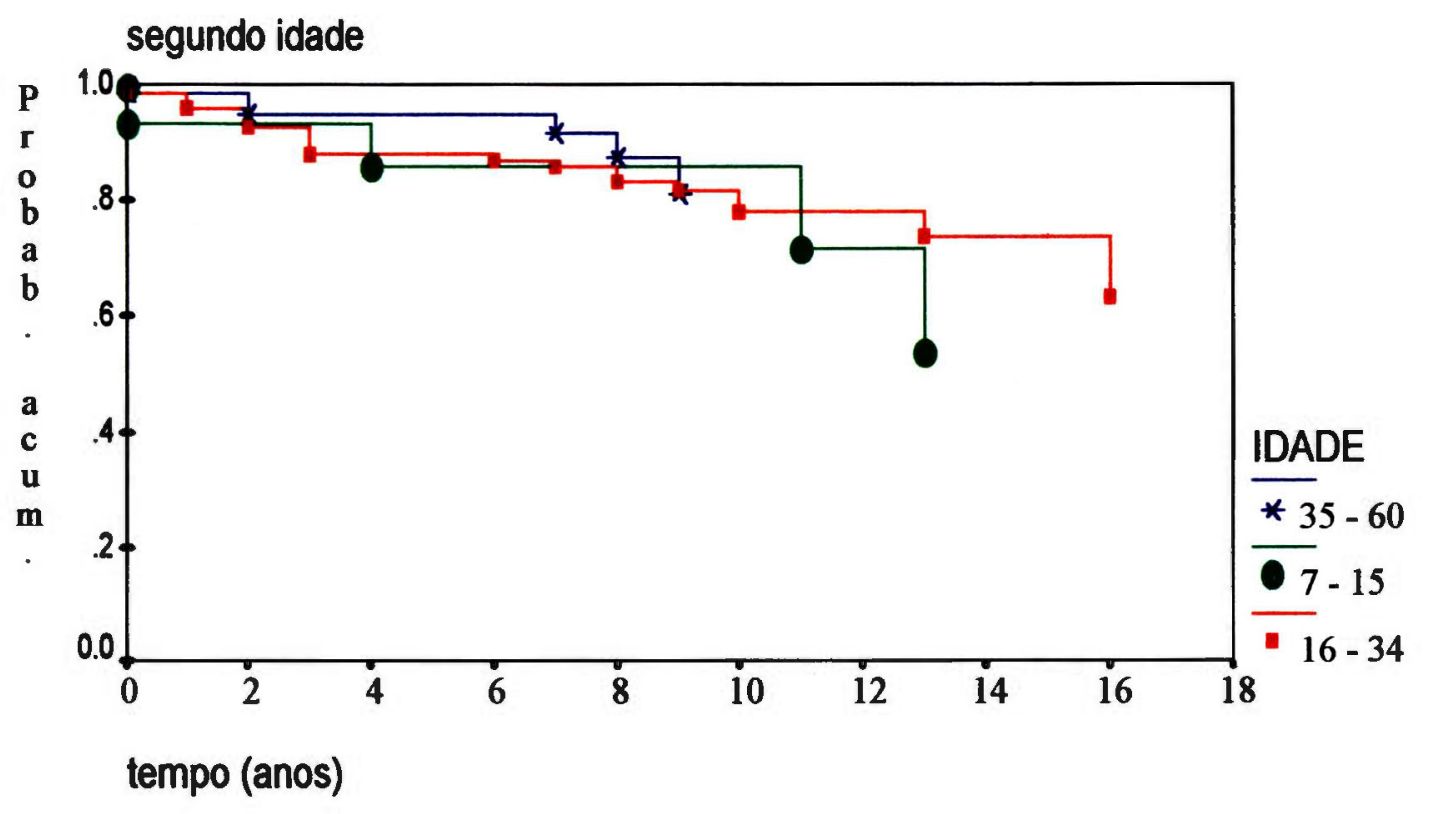

Portanto, com relação às curvas de probabilidade de sobrevida acumulada das variáveis demográficas, os achados foram semelhantes àqueles encontrados nos testes de associação, valendo as mesmas considerações já apresentadas, ou seja, não houve associação significante entre essas variáveis e o óbito.

A tabela 11 apresenta os resultados da análise da sobrevida global pelo método de Kaplan-Meier, para as variáveis clínicas e laboratoriais. Dos pacientes deste estudo com nefrite lúpica, 98,3\% sobreviveram após um ano de seguimento, contra $97,7 \%$ dos demais pacientes; porém, com o decorrer do tempo, essa proporção foi sempre menor entre os pacientes com nefrite, quando comparados com os sem nefrite (gráfico 15). Entretanto, as curvas de probabilidade de sobrevida acumulada não apresentaram diferenças significantes estatisticamente $(p=0,1000)$. 
Tabela 11. Probabilidade de sobrevida acumulada para o óbito (\%), pelo método de KaplanMeier, segundo as variáveis clínicas e laboratoriais. Clínica de Reumatologia do Hospital Heliópolis. São Paulo - 1978 a 1995

\begin{tabular}{|c|c|c|c|c|c|c|}
\hline \multirow{2}{*}{ Variável } & \multirow{2}{*}{ categoria } & \multicolumn{4}{|c|}{ prob.de sobrevida acumulada (\%) } & \multirow{2}{*}{$\begin{array}{c}\text { log rank } \\
\text { (p) }\end{array}$} \\
\hline & & 1 ano & 5 anos & 10 anos & $15 \operatorname{anos}$ & \\
\hline ulcerações & não & 97,4 & 90,1 & 76,7 & 71,1 & 0,3091 \\
\hline de mucosas & $\operatorname{sim}$ & 98,4 & 92,4 & 83,8 & 76,5 & \\
\hline envolvimento & não & 98,7 & 93,7 & 90,6 & 87,5 & 0,0074 \\
\hline \multirow[t]{3}{*}{ cárdio-pulmonar } & pulmão & 97,9 & 87,5 & 62,0 & 62,0 & \\
\hline & coração & 100,0 & 100,0 & 75,0 & 0,0 & \\
\hline & pulmão e coração & 91,3 & 76,9 & 62,1 & 46,6 & \\
\hline hipertensão & não & 97,7 & 89,9 & 81,0 & 74,3 & 0,6766 \\
\hline arterial & $\operatorname{sim}$ & 98,6 & 95,1 & 80,0 & 68,6 & \\
\hline acometimento de & não & 98,4 & 91,9 & 85,1 & 73,2 & 0,1920 \\
\hline sistema nervoso & psicose & 88,2 & 80,9 & 64,7 & 64,7 & \\
\hline \multirow[t]{2}{*}{ central } & convulsão & 100,0 & 95,7 & 76,5 & 76,5 & \\
\hline & psicose e convulsão & 100,0 & 87,5 & 36,5 & 36,5 & \\
\hline alterações & não & 97,6 & 90,0 & 78,0 & 66,8 & 0,7206 \\
\hline \multirow{4}{*}{ hematológicas } & anemia & 100,0 & 87,5 & 87,5 & 87,5 & \\
\hline & leucopenia & 98,0 & 95,7 & 88,5 & 88,5 & \\
\hline & plaquetopenia & 100,0 & 85,7 & 85,7 & 85,7 & \\
\hline & múltiplos & 100,0 & 100,0 & 83,3 & 83,3 & \\
\hline \multirow[t]{2}{*}{ nefrite } & não & 97,7 & 94,1 & 83,1 & 76,7 & 0,1000 \\
\hline & $\operatorname{sim}$ & 98,3 & 88,2 & 77,9 & 68,6 & \\
\hline insuficiência & não & 97,8 & 92,6 & 82,7 & 78,8 & 0,0051 \\
\hline renal terminal & $\operatorname{sim}$ & 100,0 & 78,8 & 63,0 & 42,0 & \\
\hline \multirow[t]{2}{*}{ imunossupressor } & não & 97,4 & 89,4 & 79,3 & 76,5 & 0,4449 \\
\hline & $\operatorname{sim}$ & 100,0 & 97,9 & 86,7 & 70,9 & \\
\hline \multicolumn{2}{|l|}{ Total } & 96,4 & 89,9 & 79,6 & 71,8 & \\
\hline
\end{tabular}


Gráfico 15 - Probabilidade de sobrevida acumulada, segundo presença de nefrite

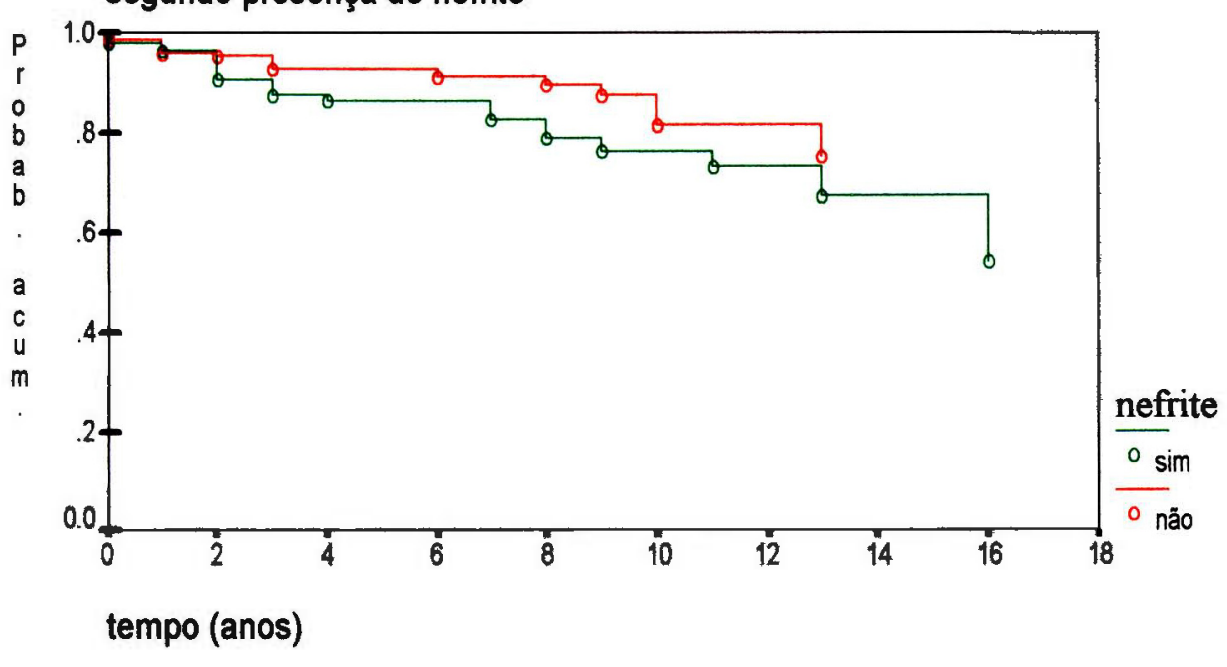

Abu-Shakra e colaboradores ${ }^{2}$ concluiram que as curvas de sobrevida dos pacientes com nefrite (sem insuficiência renal terminal) foram significantemente diferentes daquelas dos pacientes sem nefrite, com taxas de sobrevida sempre superiores no primeiro grupo de pacientes; justificando o fato pela possibilidade de que o tratamento da inflamação renal auxiliaria no controle da doença como um todo, influenciando na melhora do prognóstico.

Reveille e colaboradores ${ }^{62}$, entretanto, descreveram curva de sobrevida inferior nos pacientes com nefrite, quando comparada a de pacientes sem essa alteração. Tal significância não se confirmou na análise multivariada.

Observa-se que os resultados relativos à presença de nefrite na análise de sobrevida pelo método de Kaplan-Meier são inconclusivos. No presente estudo não se encontrou significância estatística da mesma, como fator de risco para o óbito.

Os pacientes com insuficiência renal terminal tiveram uma sobrevida menor quando comparados com aqueles que não apresentaram essa complicação (gráfico 16). Dos pacientes com insuficiência renal terminal, respectivamente, 
$63,0 \%$ e $42,0 \%$ estavam vivos após 10 e 15 anos. As curvas de probabilidade de sobrevida acumulada apresentaram diferenças estatisticamente significantes $(\mathrm{p}=0,0051)$. Esses achados são semelhantes aos encontrados por uma série de autores que concordam que indicadores clínicos, laboratoriais e histológicos de insuficiência renal terminal são marcadores de prognóstico ruim ${ }^{2,19,23,60,74,89}$.

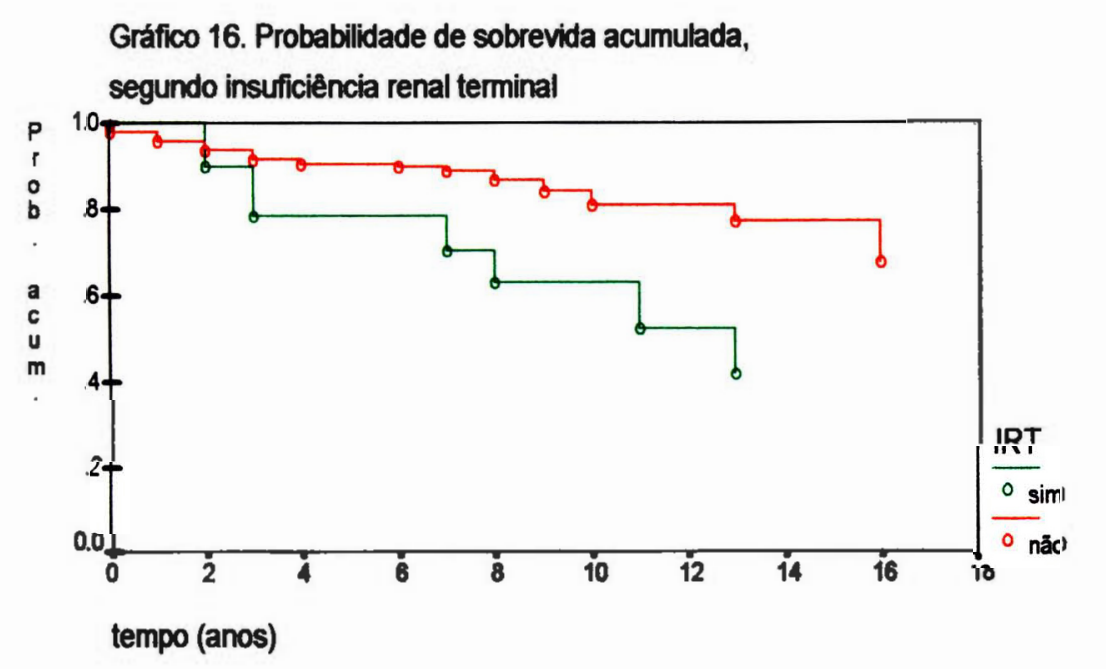

Quando se analisa o envolvimento cárdio-pulmonar, verifica-se que a probabilidade de sobrevida acumulada depende não só da presença ou não do mesmo, mas da sua localização (gráfico 17). As proporções de sobreviventes após 5 e 10 anos de seguimento, nos pacientes sem envolvimento cárdiopulmonar, foram, respectivamente, $93,7 \%$ e $90,6 \%$. Essas proporções diminuiram para $87,5 \%$ e $62 \%$ quando o acometimento foi pulmonar; tornam-se $100 \%$ e $75 \%$ quando o acometimento foi no coração; quando o acometimento se deu nos dois órgãos, as proporções foram de $76,9 \%$ e $62,1 \%$. As quatro curvas de probabilidade de sobrevida acumulada diferiram estatisticamente $(\mathrm{p}=0,0074)$. Ao serem comparadas duas a duas, o grupo com acometimento no coração não diferiu estatisticamente do grupo sem acometimento $(p=0,2857)$, porém as curvas relativas aos pacientes com acometimentos no pulmão apresentam-se diferentes ( $p=0,0411$ e $p=0,0021$, respectivamente, para pulmão e pulmão+coração). Abu- 
Shakra e colaboradores ${ }^{2}$ encontraram curvas de sobrevida semelhantes nos pacientes com e sem acometimento pulmonar, sendo que esse acometimento foi definido, por esses autores, como não apenas serosite, mas, também, doença parenquimatosa e/ou vascular no pulmão. Seus achados na análise multivariada foram, porém diferentes, como se verá.

Gráfico 17. Probabilidade de sobrevida acumulada,

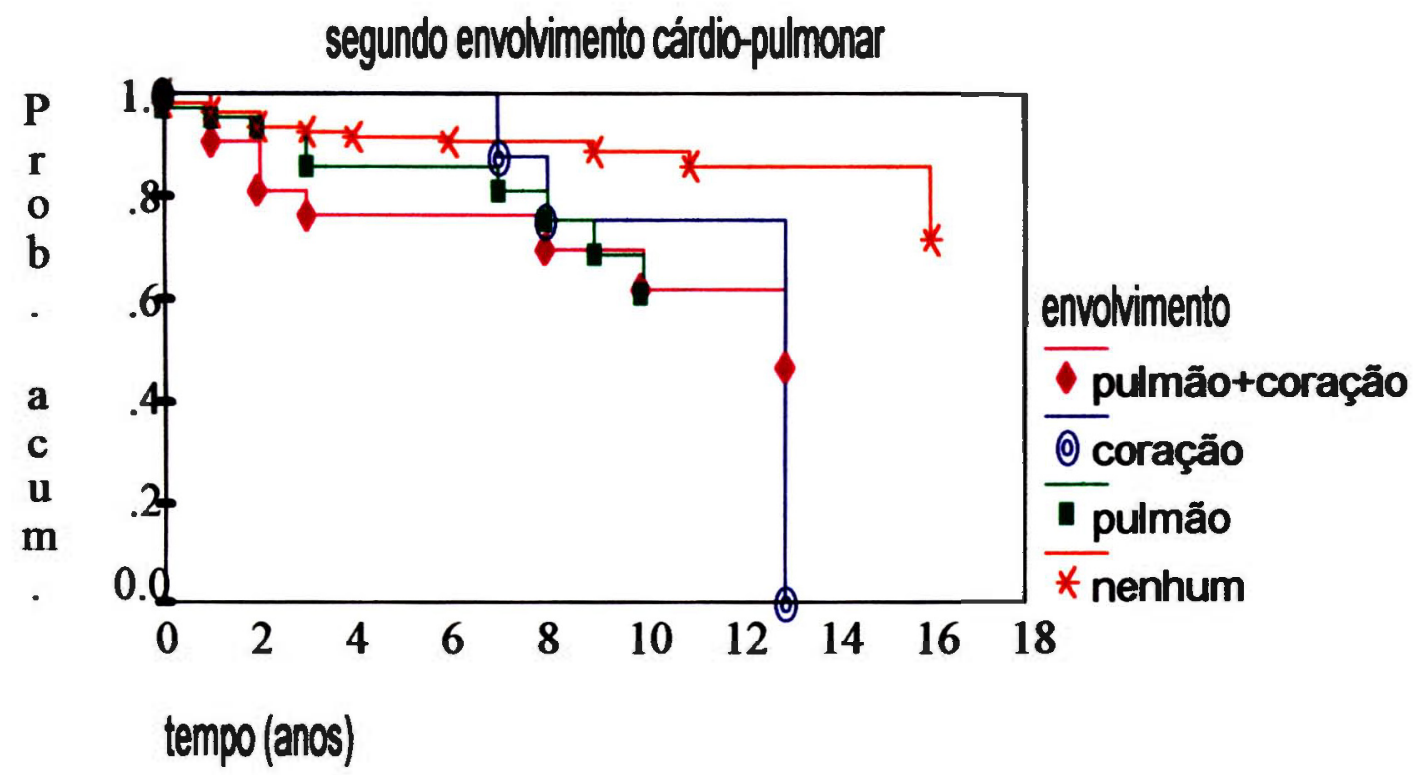

Ao se compararem as curvas de probabilidade de sobrevida acumulada segundo o acometimento do sistema nervoso central (gráfico 18) verifica-se que elas estatisticamente não são diferentes $(\mathrm{p}=0,1920)$. Mesmo quando as categorias foram comparadas duas a duas, não foi detectada significância estatística ( $\mathrm{p}=0,2238, \mathrm{p}=0,6914$ e $\mathrm{p}=0,1928$, respectivamente, para psicose, convulsão e psicose mais convulsão quando comparadas com o grupo sem acometimento no sistema nervoso central). Esses achados não concordam com um pior prognóstico do acometimento do sistema nervoso central no LES conforme relatado por Reveille ${ }^{62}$ e Sibley ${ }^{7}$. Vale salientar que nesta coorte não foram analisadas alterações neuro-psiquiátricas crônicas, como plegias, paresias, mielite transversa e neuropatias fixas centrais ou periféricas. 
Gráfico 18. Probabilidade de sobrevida acumulada,

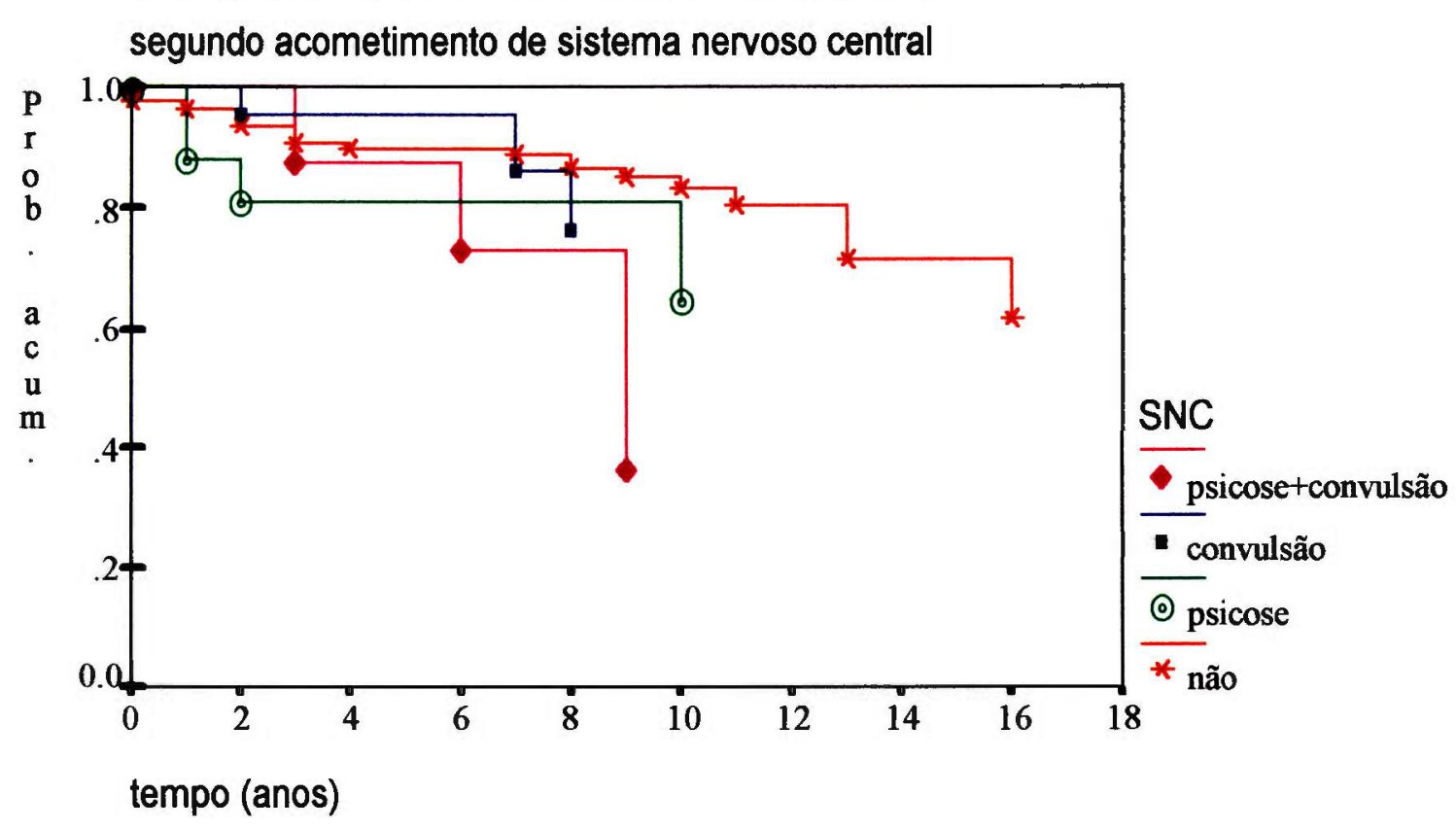

O grupo de pacientes com alterações hematológicas apresentou sobrevida menor que os demais, após 10 anos de seguimento (gráfico 19), porém as curvas não diferiram estatisticamente $(p=0,7206)$. Mesmo quando os diversos tipos de alteração foram comparados individualmente com a curva sem a presença de alteração hematológica $(\mathrm{p}=0,7554, \mathrm{p}=0,0972, \mathrm{p}=0,9739$ e $\mathrm{p}=0,5903$, respectivamente para anemia, leucopenia e plaquetopenia). Muito embora a plaquetopenia tenha sido descrita como um fator de mau prognóstico no $\mathrm{LES}^{2,62}$, não foi encontrada essa associação. Miller ${ }^{56}$, no entanto, refere que em pacientes com trombocitopenia e que morreram, a mortalidade estava associada a complicações não trombocitopênicas da doença ou sua terapia. 
Gráfico 19. Probabilidade de sobrevida acumulada,

segundo alteraçőes hematológicas

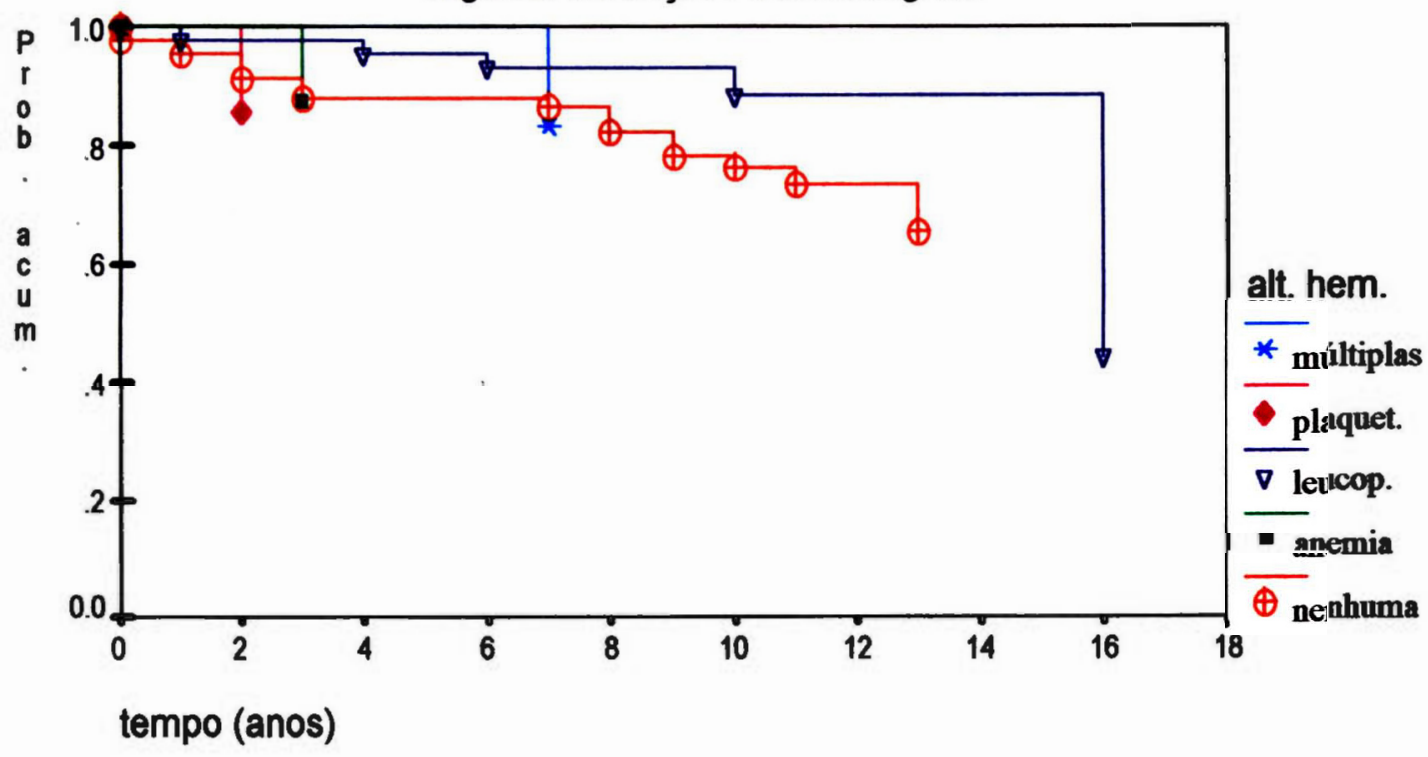

A tabela 12 apresenta os resultados da análise da sobrevida global pelo método de Kaplan-Meier, para as alterações imunológicas laboratoriais.

Tabela 12. Probabilidade de sobrevida acumulada para o óbito pelo método de Kaplan-Meier, segundo as alterações imunológicas laboratoriais. Clínica de Reumatologia do Hospital Heliópolis. São Paulo - 1978 a 1995

\begin{tabular}{|c|c|c|c|c|c|c|}
\hline \multirow[t]{2}{*}{ Variável } & \multirow[t]{2}{*}{ categoria } & \multicolumn{4}{|c|}{ prob. sobrevida acumulada (\%) } & \multirow{2}{*}{$\begin{array}{c}\log \text { rank } \\
\text { (p) }\end{array}$} \\
\hline & & 1 ano & 5 anos & 10 anos & 15 anos & \\
\hline anti DNA & $\begin{array}{l}\text { negativo } \\
\text { positivo }\end{array}$ & $\begin{array}{l}97,6 \\
98,7\end{array}$ & $\begin{array}{l}92,2 \\
91,1\end{array}$ & $\begin{array}{l}82,6 \\
80,9\end{array}$ & $\begin{array}{l}69,5 \\
80,9\end{array}$ & 0,7830 \\
\hline anti-Sm & $\begin{array}{l}\text { negativo } \\
\text { positivo }\end{array}$ & $\begin{array}{r}100,0 \\
95,6\end{array}$ & $\begin{array}{l}95,9 \\
84,2\end{array}$ & $\begin{array}{l}86,9 \\
73,7\end{array}$ & $\begin{array}{l}74,5 \\
73,7\end{array}$ & 0,0355 \\
\hline anti-RNP & $\begin{array}{l}\text { negativo } \\
\text { positivo }\end{array}$ & $\begin{array}{r}100,0 \\
96,7\end{array}$ & $\begin{array}{l}95,3 \\
88,5\end{array}$ & $\begin{array}{l}82,1 \\
88,5\end{array}$ & $\begin{array}{l}74,7 \\
73,7\end{array}$ & 0,6778 \\
\hline anti-SSA & $\begin{array}{l}\text { negativo } \\
\text { positivo }\end{array}$ & $\begin{array}{l}98,3 \\
98,1\end{array}$ & $\begin{array}{l}90,7 \\
93,3\end{array}$ & $\begin{array}{l}85,4 \\
80,2\end{array}$ & $\begin{array}{l}71,2 \\
70,1\end{array}$ & 0,8731 \\
\hline anti-SSB & $\begin{array}{l}\text { negativo } \\
\text { positivo }\end{array}$ & $\begin{array}{r}98,0 \\
100,0\end{array}$ & $\begin{array}{r}91,3 \\
100,0\end{array}$ & $\begin{array}{r}83,4 \\
100,0\end{array}$ & $\begin{array}{r}71,4 \\
100,0\end{array}$ & 0,5199 \\
\hline Células LE & $\begin{array}{l}\text { negativo } \\
\text { positivo }\end{array}$ & $\begin{array}{l}98,2 \\
98,9\end{array}$ & $\begin{array}{l}94,2 \\
90,0\end{array}$ & $\begin{array}{l}69,0 \\
79,2\end{array}$ & $\begin{array}{l}51,7 \\
79,2\end{array}$ & 0,2786 \\
\hline Total & & 96,4 & 89,9 & 79,6 & 71,8 & \\
\hline
\end{tabular}


Apenas o anti-Sm mostrou significância estatistica, pois verificou-se que quando positivo, a proporção de pacientes sobreviventes era sempre inferior à de pacientes negativos (gráfico 20). Houve diferenças estatisticamente significantes entre as curvas de sobrevida $(\mathrm{p}=0,0355)$ e, após 10 anos de seguimento, a proporção de era de $73,7 \%$ para os pacientes positivos e $86,9 \%$ para os negativos. Porém, após 15 anos de seguimento, os dois grupos se apresentavam semelhantes (porcentagens próximas a $74 \%$ ).

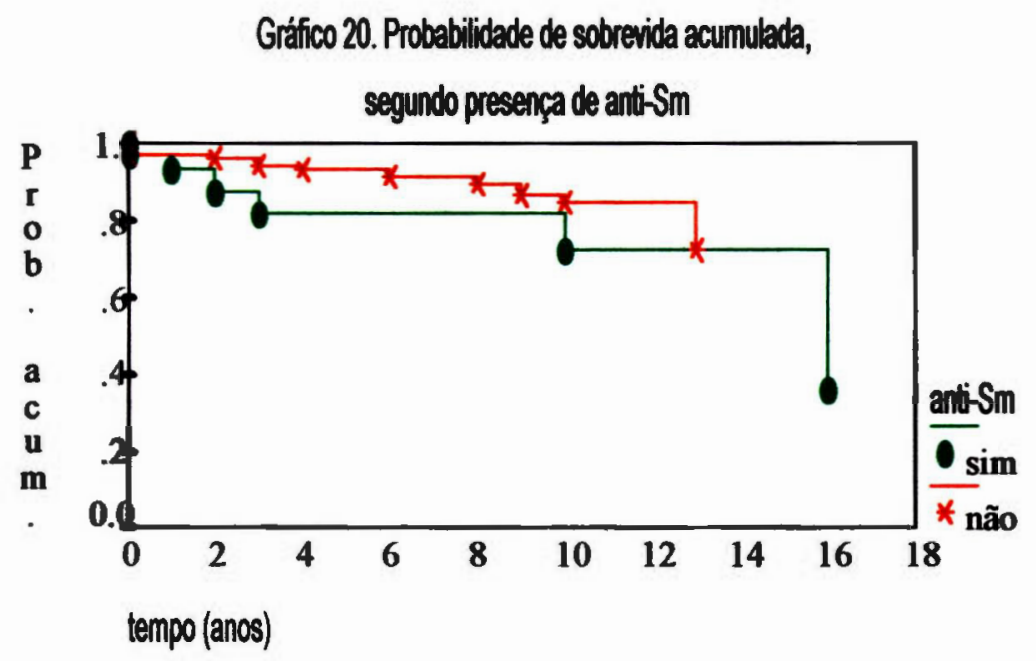

Embora alguns autores tenham encontrado uma associação da presença de anticorpos anti-Sm com doença mais grave ${ }^{7,41,95}$, de consenso mesmo é apenas o papel marcador de diagnóstico desse auto-anticorpo. Não foram encontrados, em literatura, relatos de diferenças significantes entre curvas de probabilidade de sobrevida dos pacientes positivos e negativos para este teste. Recentemente, Gulko e colaboradores ${ }^{27}$, em análise de sobrevida pelo método de Kaplan-Meier, também não encontraram efeito de risco ou protetor, desses auto-anticorpos, para o óbito.

Para se elaborar o modelo de riscos proporcionais de Cox multivariado, primeiramente, fez-se a análise univariada para a seleção das variáveis que 
entrariam no processo de modelagem multivariada. A tabela 13 apresenta os resultados da análise univariada da sobrevida global pelo modelo de riscos proporcionais de Cox.

Tabela 13. Análise univariada dos fatores prognósticos para o óbito através do modelo de riscos proporcionais de Cox. Clínica de Reumatologia do Hospital Heliópolis. São Paulo - 1978 a 1995

\begin{tabular}{|c|c|c|c|c|c|c|}
\hline Variável & categoria & coef.( $\beta$ i) & $\mathbf{H R}_{\mathbf{b}}{ }^{*}$ & IC $95 \%(\mathrm{HR})$ & p(categoria) & p(variável) \\
\hline sexo & $\begin{array}{l}\text { feminino } \\
\text { masculino }\end{array}$ & $\begin{array}{c}-0,7386 \\
\text { ref. }\end{array}$ & $\begin{array}{l}0,48 \\
1,00\end{array}$ & {$[0,19 ; 1,23]$} & 0,1260 & 0,1615 \\
\hline raça & ăo branco & ref. & 1,00 & & & 0,4881 \\
\hline idade no & $\begin{array}{l}\text { branco } \\
7 \text { a } 15\end{array}$ & $\begin{array}{l}0, \angle D L L \\
0,7823\end{array}$ & $\begin{array}{l}1,29 \\
2,19\end{array}$ & $\begin{array}{l}{[0,62 ; 2,66]} \\
{[0,61 ; 7,83]}\end{array}$ & $\begin{array}{l}0,4961 \\
0,2295\end{array}$ & 0,4426 \\
\hline diagnóstico & 34 & ref. & 1,00 & & & \\
\hline (anos) & a 60 & 0,4416 & 1,56 & {$[0,64 ; 3,78]$} & 0,3294 & \\
\hline ulcerações & 10 & ref. & 1,00 & & & 0,7609 \\
\hline de mucosas & sim & $-0,1030$ & 0,90 & {$[0,47 ; 1,75]$} & 0,7604 & \\
\hline envolvimento & & ref. & 1,00 & & & 0,0414 \\
\hline \multirow[t]{3}{*}{ cádio-pulmonar } & Imão & 0,7842 & 2,19 & {$[0,99 ; 4,84]$} & 0,0524 & \\
\hline & ração & 0,6249 & 1,87 & {$[0,54 ; 6,43]$} & 0,3215 & \\
\hline & pulmão e coração & 1,1885 & 3,28 & {$[1,40 ; 7,71]$} & 0,0064 & \\
\hline hipertensão & não & ref. & 1,00 & & & 0,9423 \\
\hline arterial & S & $-0,0267$ & 0,97 & {$[0,47 ; 2,01]$} & 0,9424 & \\
\hline acometimento de & não & ref. & 1,00 & & & 0,4333 \\
\hline sistema nervoso & psicose & 0,6505 & 1,92 & {$[0,67 ; 5,50]$} & 0,2262 & \\
\hline \multirow[t]{2}{*}{ central } & convulsão & $-0,2200$ & 0,80 & {$[0,24 ; 2,65]$} & 0,7184 & \\
\hline & psicose e convulsão & 0,7803 & 2,18 & {$[0,66 ; 7,23]$} & 0,2017 & \\
\hline alterações & não & ref. & 1,00 & & & 0,5102 \\
\hline \multirow[t]{4}{*}{ hematológicas } & emia & $-0,2863$ & 0,75 & {$[0,10 ; 5,55]$} & 0,7790 & \\
\hline & leucopenia & $-0,7783$ & 0,46 & {$[0,18 ; 1,19]$} & 0,1090 & \\
\hline & plaquetopenia & $-0,0182$ & 0,98 & {$[0,13 ; 7,24]$} & 0,9858 & \\
\hline & múltiplos & $-0,5859$ & 0,56 & {$[0,08 ; 4,10]$} & 0,5652 & \\
\hline \multirow[t]{2}{*}{ nefrite } & não & ref. & 1,00 & & & 0,1138 \\
\hline & $\sin$ & 0,5242 & 1,69 & {$[0,88 ; 3,26]$} & 0,1178 & \\
\hline insuficiência & não & ref. & 1,00 & & & 0,0313 \\
\hline renal terminal & $\operatorname{sim}$ & 0,9505 & 2,59 & {$[1,18 ; 5,69]$} & 0,0180 & \\
\hline \multirow[t]{2}{*}{ imunossupressor } & não & ref. & 1,00 & & & 0,2839 \\
\hline & sis & $-0,4341$ & 0,65 & {$[0,28 ; 1,48]$} & 0,3042 & \\
\hline \multirow[t]{2}{*}{ anti DNA } & negativo & ref. & 1,00 & & & 0,6500 \\
\hline & positivo & $-0,1734$ & 0,84 & {$[0,40 ; 1,79]$} & 0,6531 & \\
\hline \multirow[t]{2}{*}{ anti-Sm } & negativo & ref. & 1,00 & & & 0,0970 \\
\hline & & 0,7471 & 2,11 & {$[0,90 ; 4,96]$} & 0,0867 & \\
\hline \multirow[t]{2}{*}{ anti-RNP } & negativo & ref. & 1,00 & & & 0,7425 \\
\hline & positivo & $-0,1494$ & 0,86 & {$[0,35 ; 2,12]$} & 0,7447 & \\
\hline \multirow[t]{2}{*}{ anti-SSA } & negativo & ref & 1,00 & & & 0,6606 \\
\hline & positivo & 0,2153 & 1,24 & {$[0,47 ; 3,25]$} & 0,6610 & \\
\hline \multirow[t]{2}{*}{ Células LE } & negativo & ref & 1,00 & & & 0,2501 \\
\hline & positivo & $-0,4490$ & 0.64 & {$[0,30 ; 1,37]$} & 0,2469 & \\
\hline
\end{tabular}

${ }^{*} \mathrm{HR}_{\mathrm{b}}$ : hazard ratio bruta 
As variáveis selecionadas para a elaboração do modelo multivariado foram: insuficiência renal terminal $(p=0,0313)$, envolvimento cardio-pulmonar $(\mathrm{p}=0,0414)$, anti-Sm $(\mathrm{p}=0,0970)$, presenca de nefrite $(\mathrm{p}=0,1138)$, sexo $(0,1615)$, imunossupressor $(I S)(p=0,2839)$, acometimento do sistema nervoso central $(\mathrm{p}=0,4333)$, idade $(\mathrm{p}=0,4426)$, raça $(\mathrm{p}=0,4881)$, alteração hematológica ( $p=0,5102)$, ulcerações de mucosas $(p=0,7609)$ e hipertensão arterial $(p=0,9423)$; sendo essa a ordem de entrada no modelo. A variável anti-SSB não foi testada, pois só ocorreram óbitos nos pacientes com resultado positivo, o que inviabilizou a análise.

Foi avaliada visualmente a proporcionalidade das razões de riscos através dos gráficos de $\ln (-\ln (\mathrm{S}(\mathrm{t})))$ e, para todas as variáveis, os riscos foram proporcionais ao longo do tempo (gráficos 21 a 32).
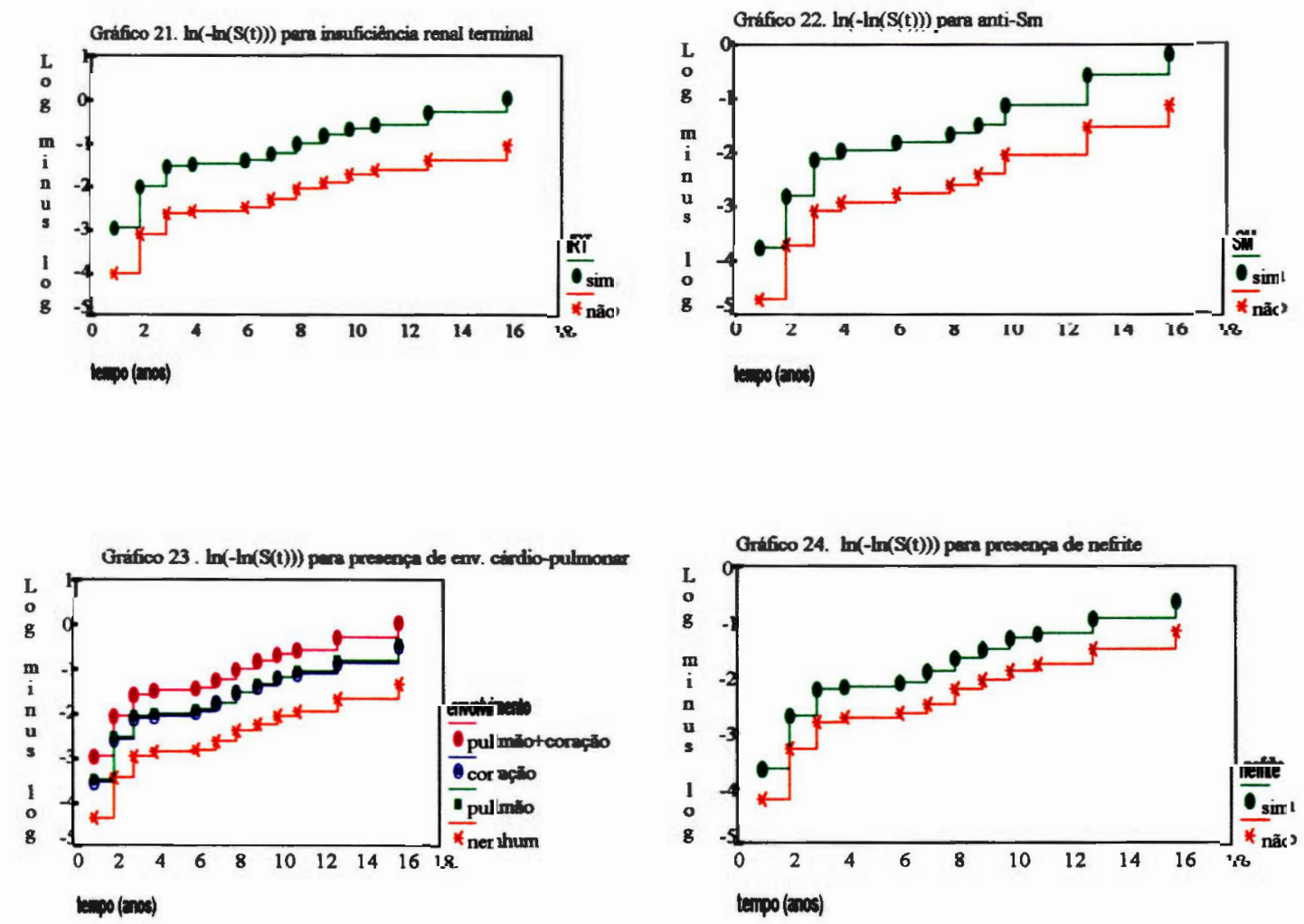

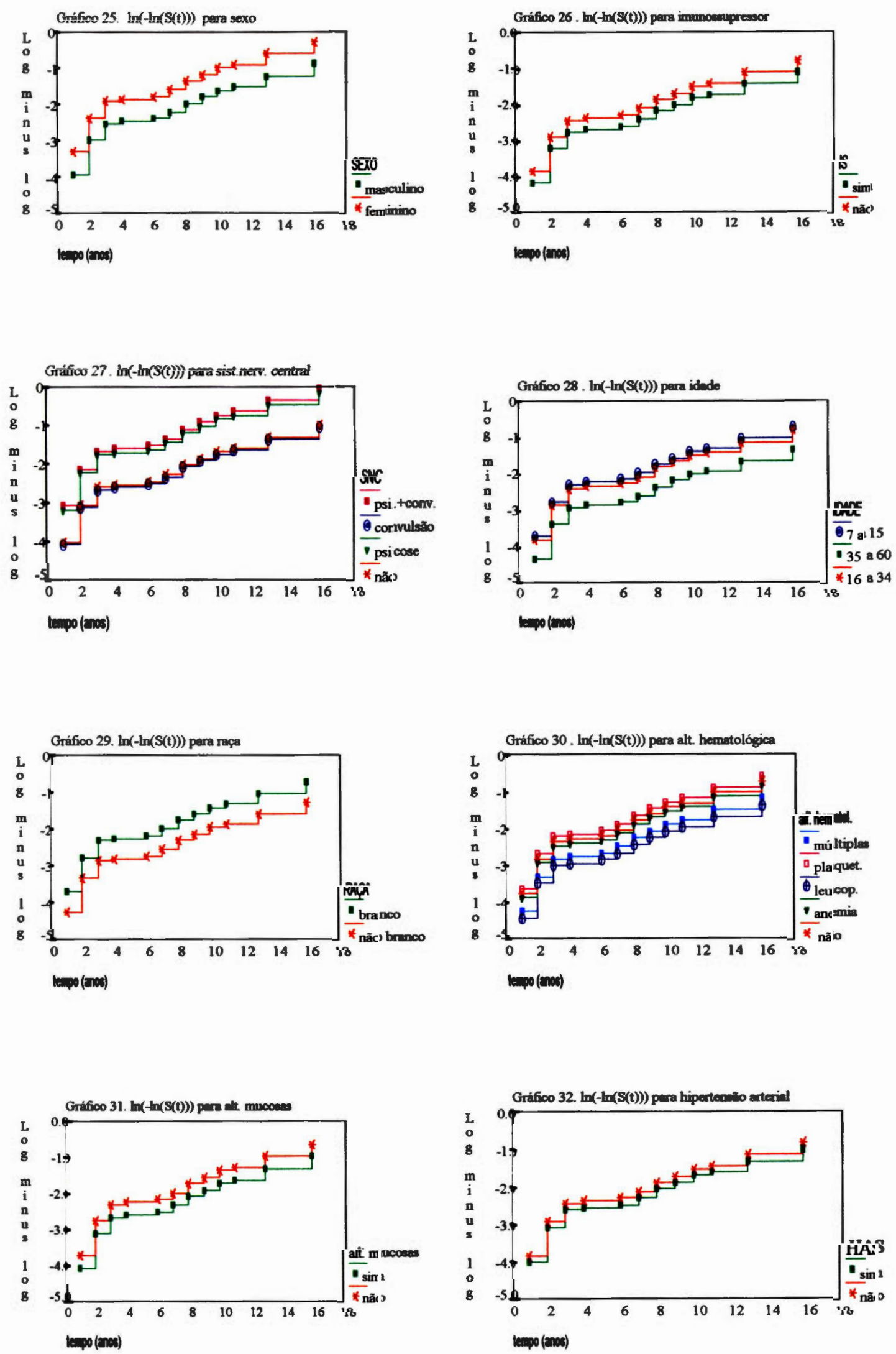
Iniciou-se o processo de modelagem multivariado com a variável IRT e, a seguir, introduziu-se a variável "acometimento cárdio-pulmonar". Essa segunda variável foi mantida no modelo multivariado, pois, além de melhorar a significância estatística do mesmo, também foi significante, estatisticamente, por si só. Pelo fato de ter modificado o valor do coeficiente de regressão $(\beta)$ da IRT, foi considerada variável de confusão para a mesma. As outras variáveis acrescentadas ao modelo multivariado foram, seqüencialmente: presença de anti$\mathrm{Sm}$, presença de nefrite e sexo. Nenhuma dessas variáveis foi mantida no modelo multivariado, pois não foram estatisticamente significantes e nem melhoraram a significância do modelo multivariado, além de não serem variáveis de confusão para as já existentes. Posteriormente, foi introduzida a variável "uso de imunossupressor" que, apesar de não ser estatisticamente significante $(\mathrm{p}=0,0767)$, melhorou significantemente a precisão do modelo multivariado $(\mathrm{p}=0,0411)$. Não foi verificado efeito de confusão entre o uso de imunossupressor com IRT ou com envolvimento cárdio-pulmonar. Por último foram acrescentadas, uma a uma, as variáveis "acometimento do sistema nervoso central", "idade", "raça", "alterações hematológicas" e "hipertenção arterial sistêmica". Nenhuma delas foi mantida no modelo multivariado, pois não foram estatisticamente significantes, não melhoraram a significância do modelo multivariado e não foram variáveis de confusão.

Após essa etapa foi testada a interação das variáveis "IRT" e "envolvimento cárdio-pulmonar", acrescentando-se o produto das mesmas no modelo multivariado. Este termo não foi estatisticamente significante e por isso foi retirado do modelo.

Foi testada a variável IRT como tempo-dependente, acrescentando-se esse termo no modelo multivariado com IRT, envolvimento cárdio-pulmonar e uso de imunossupressor. Ao se acrescentar a IRT como tempo-dependente, verificou-se que esse termo não era estatisticamente significante, não melhorava a significância do modelo total e, ainda, retirava a significância da IRT; por isso 
decidiu-se retirá-lo do modelo multivariado e deixar a IRT sem o termo tempodependente.

A tabela 14 apresenta o modelo multivariado final da análise de sobrevida global pelo modelo de riscos proporcionais de Cox. Dessa análise, notou-se que os importantes fatores prognósticos para o óbito dos pacientes acompanhados na Clínica de Reumatologia do Hospital Heliópolis foram as presenças de insuficiência renal terminal, de envolvimento cárdio-pulmonar e utilização de imunossupressor.

Tabela 14. Modelo multivariado final para os fatores prognósticos do óbito dos pacientes da Clínica de Reumatologia do Hospital Heliópolis. São Paulo - 1978 a 1995

\begin{tabular}{|c|c|c|c|c|c|c|}
\hline Variável & categoria & coef.( $(\beta i)$ & $\mathrm{HR}^{*}$ wrma & $\mathrm{HR}^{*}{ }_{\text {ajmade }}$ & IC $95 \%$ (HRa) & p(variável) \\
\hline $\begin{array}{l}\text { insuficiência } \\
\text { renal terminal }\end{array}$ & $\begin{array}{l}\text { não } \\
\text { sim }\end{array}$ & $\begin{array}{c}\text { ref. } \\
1,0029\end{array}$ & $\begin{array}{l}1,00 \\
2,59\end{array}$ & $\begin{array}{l}1,00 \\
2,73\end{array}$ & {$[1,11 ; 6,67]$} & 0,0281 \\
\hline $\begin{array}{l}\text { envolvimento } \\
\text { cárdio-pulmonar }\end{array}$ & $\begin{array}{l}\text { não } \\
\text { pulmão } \\
\text { coração } \\
\text { pulmão e coração }\end{array}$ & $\begin{array}{c}\text { ref. } \\
1,0779 \\
0,9112 \\
1,3267\end{array}$ & $\begin{array}{l}1,00 \\
2,19 \\
1,87 \\
3,28\end{array}$ & $\begin{array}{l}1,00 \\
2,94 \\
2,49 \\
3,77\end{array}$ & $\begin{array}{l}{[1,23 ; 7,00]} \\
{[0,70 ; 8,77]} \\
{[1,43 ; 9,90]}\end{array}$ & 0,0179 \\
\hline imunossupressor & $\begin{array}{l}\text { não } \\
\text { sim }\end{array}$ & $\begin{array}{c}\text { ref. } \\
-0,8004\end{array}$ & $\begin{array}{l}1,00 \\
0,65\end{array}$ & $\begin{array}{l}1,00 \\
0,45\end{array}$ & {$[0,18 ; 1,08]$} & 0,0767 \\
\hline
\end{tabular}

*HR: hazard ratio

significância do modelo final $\rightarrow \mathrm{p}=0,0039$

A estimativa da razão de riscos de morrer de pacientes com insuficiência renal terminal é igual a 2,73 vezes $(\mathrm{IC}=[1,11 ; 6,67])$ o de pacientes sem essa complicação. Abu-Shakra e colaboradores ${ }^{2}$ encontraram, em análise multivariada, uma razão de riscos de $2,94\left(\mathrm{IC}=\left[2,00 ; ?^{*}\right]\right)$ para IRT. Os mesmos autores mostraram um efeito protetor da nefrite para o óbito, em análise multivariada, com valor da razão de riscos de $0,52(\mathrm{IC}=[0,36 ; 0,77])$, confirmando

\footnotetext{
* ?: limite superior não informado
} 
os seus achados da análise das curvas de Kaplan-Meier. A possível explicação para essa proteção, como já exposta, seria o tratamento da inflamação renal, melhorando o prognóstico da doença como um todo. No presente estudo a nefrite não foi fator estatisticamente significante no modelo multivariado; na análise univariada (tabela 13), a nefrite obteve uma razão de riscos para o óbito não significante, com valor de 1,69 (IC $=[0,88 ; 3,26])$.

McLaughlin $^{52}$, em estudo com biópsias renais, encontrou uma razão de riscos para o óbito de 5,9 (IC=[2,5;13,8]) nos pacientes com lesões crônicas e/ou creatinina sérica elevada, como marcadores de insuficiência renal.

Não só a presença, mas a localização do envolvimento cárdio-pulmonar, foi um importante preditor do óbito. A razão de riscos entre pacientes com o acometimento no coração e aqueles sem alterações cárdio-pulmonares foi igual a $1,87$ (IC $=[0,70 ; 8,77])$, porém esse achado não foi estatisticamente significante $(p=0,1566)$. Já a comparação entre pacientes com acometimento no pulmão e aqueles sem qualquer acometimento levou à razão de riscos de morrer igual a $2,94$ (IC $=[1,23 ; 7,00])$, enquanto que a razão de riscos entre pacientes com e sem acometimento em ambos os órgãos foi igual a 3,77 vezes $(\mathrm{IC}=[1,43 ; 9,90])$. Isto permite dizer que o envolvimento pulmonar isolado e, principalmente, em conjunto com o envolvimento cardíaco, é fator de risco, estatisticamente significante, para o óbito. O primeiro estudo a revelar envolvimento pulmonar (pleurite, doença parenquimatosa ou vascular pulmonar) como um fator de risco para a morte foi o de Abu-Shakra ${ }^{2}$, em 1995, com razão de riscos de 1,72 $(\mathrm{IC}=[1,18 ; 2,49])$. Reveille $^{62}$ não encontrou risco, estatisticamente significante, para essa variável, muito embora tenha estudado apenas a doença parenquimatosa pulmonar. Cabe ressaltar que não há relatos na literatura analisando o envolvimento conjunto desses órgãos, conforme analisado na coorte dos pacientes do Serviço de Reumatologia do Hospital Heliópolis. 
A hipertensão arterial sistêmica não se mostrou como fator de risco para o óbito, estatisticamente significante, na análise uni ou multivariada $\left(\mathrm{HR}_{\mathrm{bruta}}=0,97\right.$; $\mathrm{IC}=[0,47 ; 2,01])$. Seleznick ${ }^{74}$, no entanto, em análise multivariada, encontrou que a única variável significante no modelo de Cox foi a hipertensão arterial sistólica, com um aumento de risco de mortalidade em $2 \%$ para cada milímetro de aumento na pressão arterial sistólica.

Anticorpos anti-Sm que estavam associados a uma curva de sobrevida mais baixa na análise univariada pelo Kaplan-Meier, no modelo de Cox não apresentaram razão de riscos significante $\left(\mathrm{HR}_{\text {bruta }}=2,11\right.$, com $\left.\mathrm{IC}=[0,90 ; 4,96]\right)$.

A utilização de imunossupressor (IS) foi um fator protetor para o óbito do paciente com lúpus, embora acima do limite da significância estatística $(p=0,0767)$. A razão de riscos entre aqueles pacientes com uso de IS e aqueles que não utilizam IS é 0,45 vezes $(\mathrm{IC}=[0,18 ; 1,08])$. Muito embora os imunossupressores sejam utilizados em pacientes mais graves, o prognóstico dos mesmos tem sido melhor, o que sugere uma eficácia terapêutica dos mesmos. A utilização de uma dose menor de corticosteróides nessa situação também poderia estar contribuindo para menores efeitos colateriais destas drogas, melhorando o prognóstico. É preciso, no entanto, ressaltar que em determinados casos essa medicação foi utilizada por pouco tempo e em casos não graves do ponto de vista sistêmico, como já discutido anteriormente. Não se encontrou na literatura dados numéricos que informassem proteção para o óbito com a utilização de IS. 


\subsection{Análise de sobrevida até a evolução para a insuficiência renal terminal (IRT)}

Nesta etapa analisaram-se os fatores de risco para a evolução para a insuficiência renal terminal nos 253 pacientes da coorte. A tabela 15 apresenta as distribuições de freqüência dos pacientes com LES, segundo acometimento de IRT e as variáveis demográficas.

Tabela 15. Distribuição dos pacientes com LES, segundo acometimento de insuficiência renal terminal e as variáveis demográficas. Clínica de Reumatologia do Hospital Heliópolis. São Paulo -1978 a 1995

\begin{tabular}{|c|c|c|c|c|c|c|c|c|}
\hline \multirow[t]{2}{*}{ Variável } & \multirow[t]{2}{*}{ Categoria } & \multicolumn{2}{|c|}{ censura } & \multicolumn{2}{|c|}{ insuf. renal terminal } & \multicolumn{2}{|c|}{ Total } & \multirow{2}{*}{$\begin{array}{l}\text { valor } \\
\text { de } p^{*}\end{array}$} \\
\hline & & $n^{\circ}$ & $\%$ & $\mathrm{n}^{\circ}$ & $\%$ & $n^{\circ}$ & $\%$ & \\
\hline Sexo & $\begin{array}{l}\text { feminino } \\
\text { masculino }\end{array}$ & $\begin{array}{r}217 \\
15\end{array}$ & $\begin{array}{l}85,8 \\
83,3\end{array}$ & $\begin{array}{r}18 \\
3\end{array}$ & $\begin{array}{l}14,2 \\
16,7\end{array}$ & $\begin{array}{r}235 \\
18\end{array}$ & $\begin{array}{l}100,0 \\
100,0\end{array}$ & 0,3725 \\
\hline Raça & $\begin{array}{l}\text { não branco } \\
\text { branco }\end{array}$ & $\begin{array}{r}82 \\
150\end{array}$ & $\begin{array}{l}92,1 \\
91,5\end{array}$ & $\begin{array}{r}7 \\
14\end{array}$ & $\begin{array}{l}7,9 \\
8,5\end{array}$ & $\begin{array}{r}89 \\
164\end{array}$ & $\begin{array}{l}100,0 \\
100,0\end{array}$ & 0,9571 \\
\hline $\begin{array}{l}\text { Idade no } \\
\text { diagnóstico } \\
\text { (anos) }\end{array}$ & $\begin{array}{l}7 \text { a } 15 \\
16 \text { a } 34 \\
35 \text { a } 60\end{array}$ & $\begin{array}{r}10 \\
156 \\
66\end{array}$ & $\begin{array}{l}66,7 \\
91,8 \\
97,1\end{array}$ & $\begin{array}{r}5 \\
14 \\
2\end{array}$ & $\begin{array}{r}33,3 \\
8,2 \\
2,9\end{array}$ & $\begin{array}{r}15 \\
170 \\
68\end{array}$ & $\begin{array}{l}100,0 \\
100,0 \\
100,0\end{array}$ & 0,0006 \\
\hline Total & & 232 & 91,7 & 21 & 8,3 & 253 & 100,0 & \\
\hline
\end{tabular}

*p: nível descritivo do teste de associação pelo $\chi^{2}$.

Das variáveis demográficas apenas a idade esteve estatisticamente associada com IRT $(p=0,0006)$. Entre os pacientes mais jovens (de 7 a 15 anos) há uma proporção maior de IRT $(33,3 \%)$, quando comparada com as outras faixas etárias, onde esta porcentagem foi inferior a 9\% (gráfico 33). 
Gráfico 33. Porcentagem de presença de

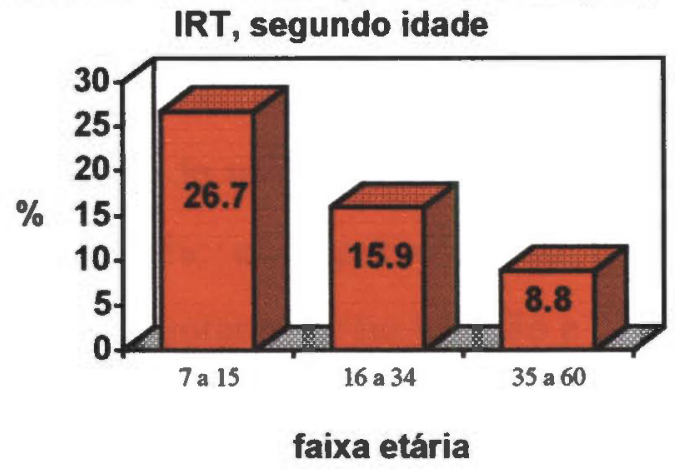

A tabela 16 apresenta a distribuição dos pacientes com LES, segundo o acomentimento de IRT e as variáveis clínicas e laboratoriais.

Tabela 16. Distribuição de pacientes com LES,segundo acometimento de insuficiência renal terminal e as variáveis clinicas e laboratoriais. Clínica de Reumatologia do Hospital Heliópolis.

São Paulo - 1978 a 1995

\begin{tabular}{|c|c|c|c|c|c|c|c|c|}
\hline \multirow[t]{2}{*}{ Variável } & \multirow[t]{2}{*}{ categoria } & \multicolumn{2}{|c|}{ censura } & \multicolumn{2}{|c|}{ ins. renal terminal } & \multicolumn{2}{|c|}{ Total } & \multirow{2}{*}{$\begin{array}{l}\text { valor } \\
\text { de } p^{*}\end{array}$} \\
\hline & & $n^{0}$ & $\%$ & $n^{\circ}$ & $\%$ & $n^{\circ}$ & $\%$ & \\
\hline ulcerações & não & 109 & 91,6 & 10 & 8,4 & 119 & 100,0 & 0,8491 \\
\hline \multirow[t]{2}{*}{ de mucosas } & $\operatorname{sim}$ & 122 & 91,7 & 11 & 8,3 & 133 & 100,0 & \\
\hline & ignorado & 1 & 100,0 & - & - & 1 & 100,0 & \\
\hline envolvimento & não & 150 & 92,0 & 13 & 8,0 & 163 & 100,0 & 0,0096 \\
\hline \multirow[t]{3}{*}{ cárdio-pulmonar } & pulmão & 47 & 97,9 & 1 & 2,1 & 48 & 100,0 & \\
\hline & coração & 17 & 94,4 & 1 & 5,6 & 18 & 100,0 & \\
\hline & pulmão e coração & 18 & 75,0 & 6 & 25,0 & 24 & 100,0 & \\
\hline hipertensão & não & 172 & 95,0 & 9 & 5,0 & 181 & 100,0 & 0,0053 \\
\hline arterial & $\operatorname{sim}$ & 60 & 83,3 & 12 & 16,7 & 72 & 100,0 & \\
\hline acometimento de & não & 181 & 91,9 & 16 & 8,1 & 197 & 100,0 & 0,7257 \\
\hline sistema nervoso & psicose & 16 & 88,9 & 2 & 11,1 & 18 & 100,0 & \\
\hline \multirow[t]{2}{*}{ central } & convulsão & 25 & 89,3 & 3 & 10,7 & 28 & 100,0 & \\
\hline & psicose e convulsão & 10 & 100,0 & - & - & 10 & 100,0 & \\
\hline alterações & não & 163 & 92,6 & 13 & 7,4 & 176 & 100,0 & 0,0197 \\
\hline \multirow[t]{4}{*}{ hematológicas } & anemia & 7 & 70,0 & 3 & 30,0 & 10 & 100,0 & \\
\hline & leucopenia & 50 & 96,2 & 2 & 3,8 & 52 & 100,0 & \\
\hline & plaquetopenia & 5 & 71,4 & 2 & 28,6 & 7 & 100,0 & \\
\hline & múltiplos & 7 & 87,5 & 1 & 12,5 & 8 & 100,0 & \\
\hline \multirow[t]{2}{*}{ imunossupressor } & não & 185 & 92,5 & 15 & 7,5 & 200 & 100,0 & 0,5376 \\
\hline & $\operatorname{sim}$ & 47 & 88,7 & 6 & 11,3 & 53 & 100,0 & \\
\hline \multicolumn{2}{|l|}{ Total } & 232 & 91,7 & 21 & 8,3 & 253 & 100,0 & \\
\hline
\end{tabular}

*p: nível descritivo do teste de associação pelo $\chi^{2}$. Para a realização do teste foi excluída a categoria de "ignorado". 
O envolvimento cárdio-pulmonar revelou associação estatisticamente significante com a presença de IRT $(\mathrm{p}=0,0096)$. Quando o paciente não apresentava essa alteração, ou de um desses órgãos, a porcentagem de pacientes com IRT foi, no máximo, 9\%; essa porcentagem porém eleva-se para $25 \%$ quando o acometimento é conjuntamente no pulmão e no coração (gráfico 34).

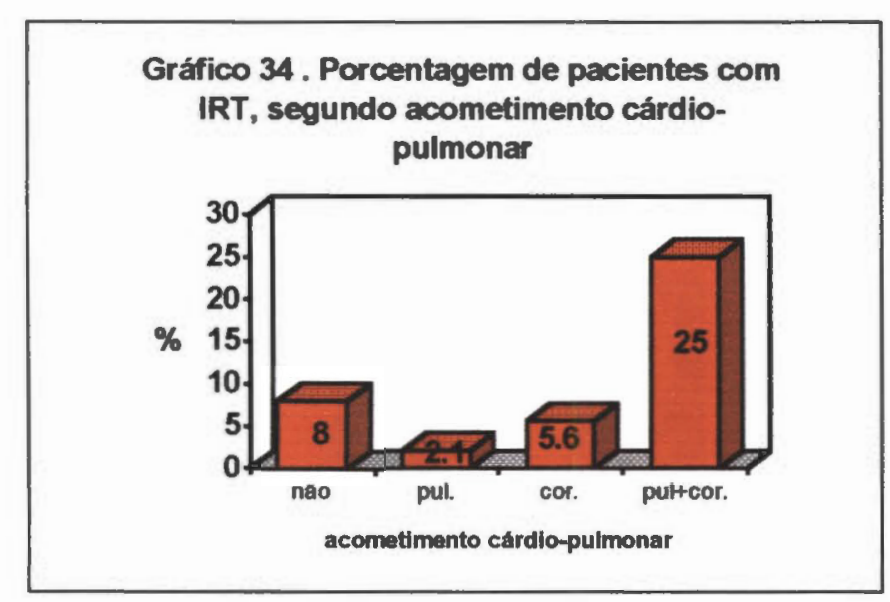

A presença de hipertensão arterial no início do acompanhamento foi estatisticamente associada com o acometimento de IRT $(\mathrm{p}=0,0053)$. Dos pacientes com hipertensão arterial, $16,7 \%$ tiveram IRT, diminuindo essa porcentagem para 5,0\%, na ausência desse agravo (gráfico 35).

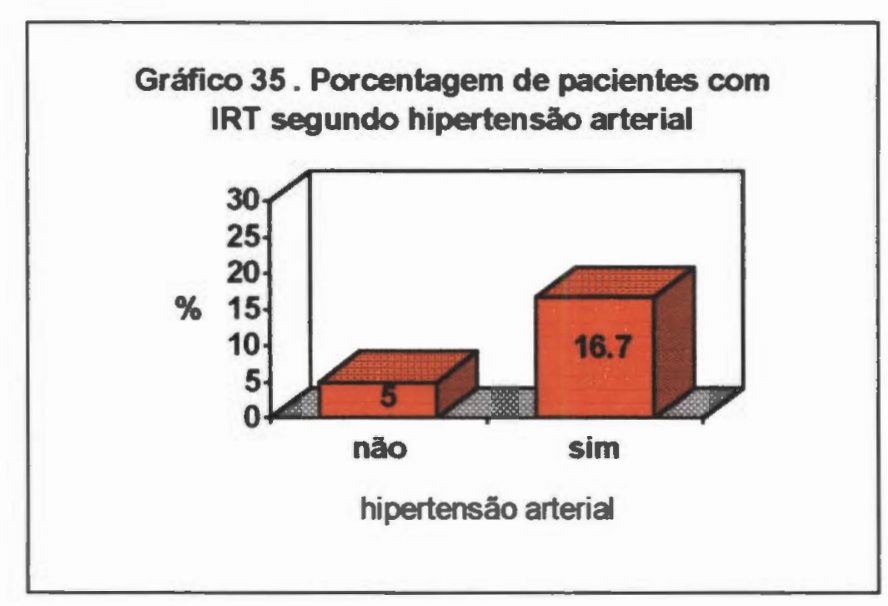


A presença de alteração hematológica apresentou associação estatisticamente significante com a presença de IRT $(\mathrm{p}=0,0197)$; na verdade não é a presença ou não de alteração hematológica que é importante, mas, sim, a presença de anemia ou plaquetopenia, isoladamente. Nestes casos, a porcentagem de IRT elevou-se para $30,0 \%$ e $28,6 \%$, respectivamente, contra menos de $13 \%$, das outras categorias (gráfico 36 ).

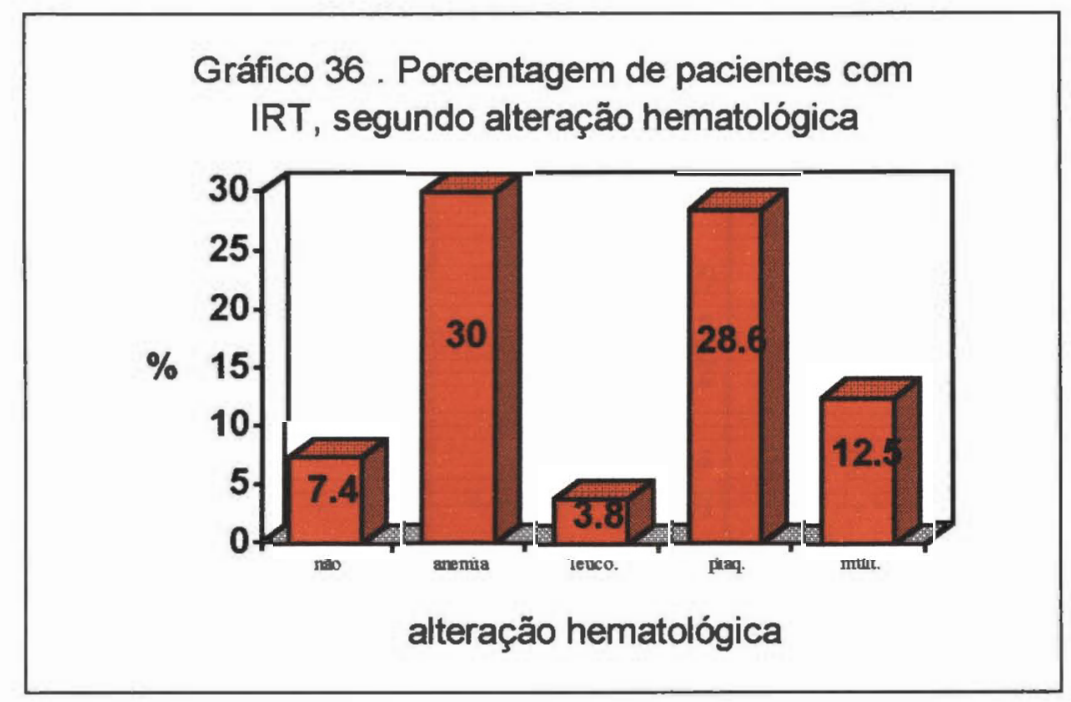

Na tabela 17 podem ser verificadas as distribuições de pacientes com LES, segundo a presença de IRT e as alterações imunológicas laboratoriais. Com nenhuma das variáveis foi detectada associação estatisticamente significante com a ocorrência de IRT. 
Tabela 17. Distribuição de pacientes com LES, segundo acometimento de insuficiência renal terminal e as alteraçoes imunológicas laboratoriais. Clínica de Reumatologia do Hospital Heliópolis.São Paulo - 1978 a 1995

\begin{tabular}{|c|c|c|c|c|c|c|c|c|}
\hline \multirow[t]{2}{*}{ Varifivel } & \multirow[t]{2}{*}{ categoria } & \multicolumn{2}{|c|}{ censura } & \multicolumn{2}{|c|}{ ins. renal terminal } & \multicolumn{2}{|c|}{ Total } & \multirow{2}{*}{$\begin{array}{l}\text { valor } \\
\text { de } p^{\star}\end{array}$} \\
\hline & & $n^{\circ}$ & $\%$ & $n^{\circ}$ & $\%$ & $n^{0}$ & $\%$ & \\
\hline anti DNA & $\begin{array}{l}\text { negativo } \\
\text { positivo } \\
\text { não realizado }\end{array}$ & $\begin{array}{r}120 \\
73 \\
39\end{array}$ & $\begin{array}{l}90,9 \\
90,1 \\
97,5\end{array}$ & $\begin{array}{r}12 \\
8 \\
1\end{array}$ & $\begin{array}{l}9,1 \\
9,9 \\
2,5\end{array}$ & $\begin{array}{r}132 \\
81 \\
40\end{array}$ & $\begin{array}{l}100,0 \\
100,0 \\
100,0\end{array}$ & 0,9592 \\
\hline anti-Sm & $\begin{array}{l}\text { negativo } \\
\text { positivo } \\
\text { não realizado }\end{array}$ & $\begin{array}{r}105 \\
45 \\
82\end{array}$ & $\begin{array}{l}92,9 \\
91,8 \\
90,1\end{array}$ & $\begin{array}{l}8 \\
4 \\
9\end{array}$ & $\begin{array}{l}7,1 \\
8,2 \\
9,9\end{array}$ & $\begin{array}{r}113 \\
49 \\
91\end{array}$ & $\begin{array}{l}100,0 \\
100,0 \\
100,0\end{array}$ & 0,9325 \\
\hline anti-RNP & $\begin{array}{l}\text { negativo } \\
\text { positivo } \\
\text { não realizado }\end{array}$ & $\begin{array}{l}90 \\
60 \\
82\end{array}$ & $\begin{array}{l}90,9 \\
95,2 \\
90,1\end{array}$ & $\begin{array}{l}9 \\
3 \\
9\end{array}$ & $\begin{array}{l}9,1 \\
4,8 \\
9,9\end{array}$ & $\begin{array}{l}99 \\
63 \\
91\end{array}$ & $\begin{array}{l}100,0 \\
100,0 \\
100,0\end{array}$ & 0,4728 \\
\hline anti-SSA & \begin{tabular}{|l} 
negativo \\
positivo \\
não realizado
\end{tabular} & $\begin{array}{r}55 \\
52 \\
125\end{array}$ & $\begin{array}{l}88,7 \\
96,3 \\
91,2\end{array}$ & $\begin{array}{r}7 \\
2 \\
12\end{array}$ & $\begin{array}{r}11,3 \\
3,7 \\
8,8\end{array}$ & $\begin{array}{r}62 \\
54 \\
137\end{array}$ & $\begin{array}{l}100,0 \\
100,0 \\
100,0\end{array}$ & 0,2397 \\
\hline anti-SSB & \begin{tabular}{|l} 
negativo \\
positivo \\
não realizado
\end{tabular} & $\begin{array}{r}96 \\
9 \\
127\end{array}$ & $\begin{array}{r}91,4 \\
100,0 \\
91,4\end{array}$ & $\begin{array}{r}9 \\
- \\
12\end{array}$ & $\begin{array}{r}8,6 \\
- \\
8,6\end{array}$ & $\begin{array}{r}105 \\
9 \\
139\end{array}$ & $\begin{array}{l}100,0 \\
100,0 \\
100,0\end{array}$ & 0,7863 \\
\hline Células LE & $\begin{array}{l}\text { negativo } \\
\text { positivo } \\
\text { não realizado }\end{array}$ & $\begin{array}{l}52 \\
81 \\
99\end{array}$ & $\begin{array}{l}89,7 \\
88,0 \\
96,1\end{array}$ & $\begin{array}{r}6 \\
11 \\
4\end{array}$ & $\begin{array}{r}10,3 \\
12,0 \\
3,9\end{array}$ & $\begin{array}{r}58 \\
92 \\
103\end{array}$ & $\begin{array}{l}100,0 \\
100,0 \\
100,0\end{array}$ & 0,9691 \\
\hline Total & & 232 & 91,7 & 21 & $\overline{8,3}$ & 253 & 100,0 & \\
\hline
\end{tabular}

*p: nivel descritivo do teste de associaçåo pelo $\chi^{2}$. Para a realizaçăo do teste foi excluída a categoria "nào realizado".

A tabela 18 apresenta os resultados da análise de sobrevida para a insuficiência renal terminal, através do método de Kaplan-Meier, para as características demográficas dos pacientes. 
Tabela 18. Probabilidade de sobrevida acumulada para a insuficiência renal terminal pelo método de Kaplan-Meier, segundo as características demográficas. Clínica de Reumatologia do Hospital Heliópolis. São Paulo - 1978 a 1995

\begin{tabular}{|c|c|c|c|c|c|c|}
\hline \multirow{2}{*}{ Variável } & \multirow{2}{*}{ categoria } & \multicolumn{3}{|c|}{ prob. sobrevida acumulada } & \multirow{2}{*}{\begin{tabular}{|c|}
$(\%)$ \\
15 anos
\end{tabular}} & \multirow{2}{*}{$\begin{array}{c}\log \text { rank } \\
\text { (p) }\end{array}$} \\
\hline & & 1 ano & 5 anos & 10 anos & & \\
\hline Sexo & feminino & 98,7 & 95,9 & 90,4 & 77,6 & 0,1404 \\
\hline & masculino & 94,1 & 87,8 & 79,1 & 79,1 & \\
\hline \multirow[t]{2}{*}{ Raça } & não branco & 97,6 & 94,4 & 88,3 & 70,6 & 0,7104 \\
\hline & branco & 98,7 & 95,8 & 91,0 & 79,9 & \\
\hline Idade no & 7 a 15 & 100,0 & 100,0 & 75,0 & 40,0 & 0,0428 \\
\hline diagnóstico & 16 a 34 & 98,2 & 93,7 & 89,7 & 80,6 & \\
\hline (anos) & 35 a 60 & 98,4 & 98,4 & 94,9 & 94,9 & \\
\hline \multicolumn{2}{|l|}{ Total } & 98,0 & 95,0 & 89,7 & 76,9 & \\
\hline
\end{tabular}

Os pacientes do sexo masculino revelaram porcentagens de sobrevida acumulada para IRT sempre menores do que os do sexo feminino, como pode ser visto no gráfico 37 , porém a diferença entre as curvas não foi estatisticamente significante $(\mathrm{p}=0,1404)$. Após 10 anos de seguimento, a proporção de pacientes do sexo masculino sem acometimento de IRT foi de $79,1 \%$, contra $90,4 \%$ das mulheres em igual situação.

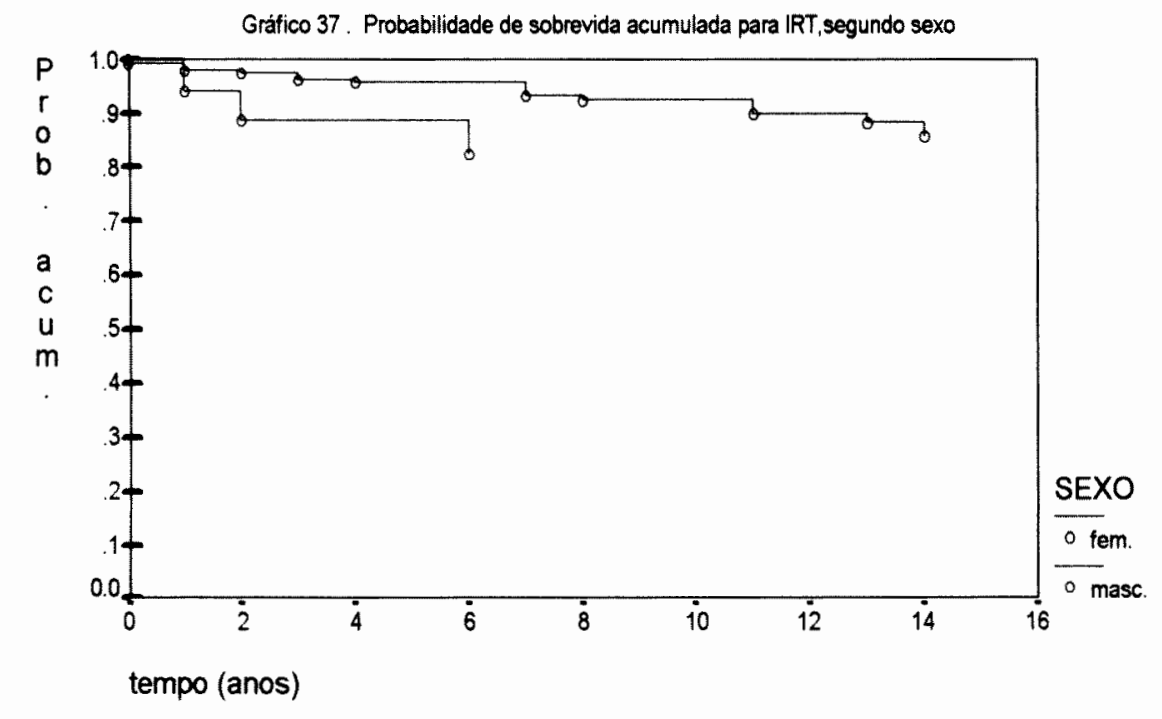


A idade do diagnóstico de lúpus é uma variável importante para o acometimento da IRT. Dos pacientes menores de 16 anos, 75\% não desenvolveram IRT após 10 anos de doença e 40,0\% após 15 anos. Essas porcentagens se elevam para $89,7 \%$ e $80,6 \%$ para os pacientes entre 16 e 34 anos e $94,9 \%$ após os dois períodos de seguimento para os pacientes mais velhos. No gráfico 38 estão apresentadas as curvas de probabilidade de sobrevida acumulada para as diversas faixas etárias; houve diferença estatisticamente significante $(p=0,0428)$ entre as curvas.

Gráfico 38. Probabilidade de sobrevida acumulada

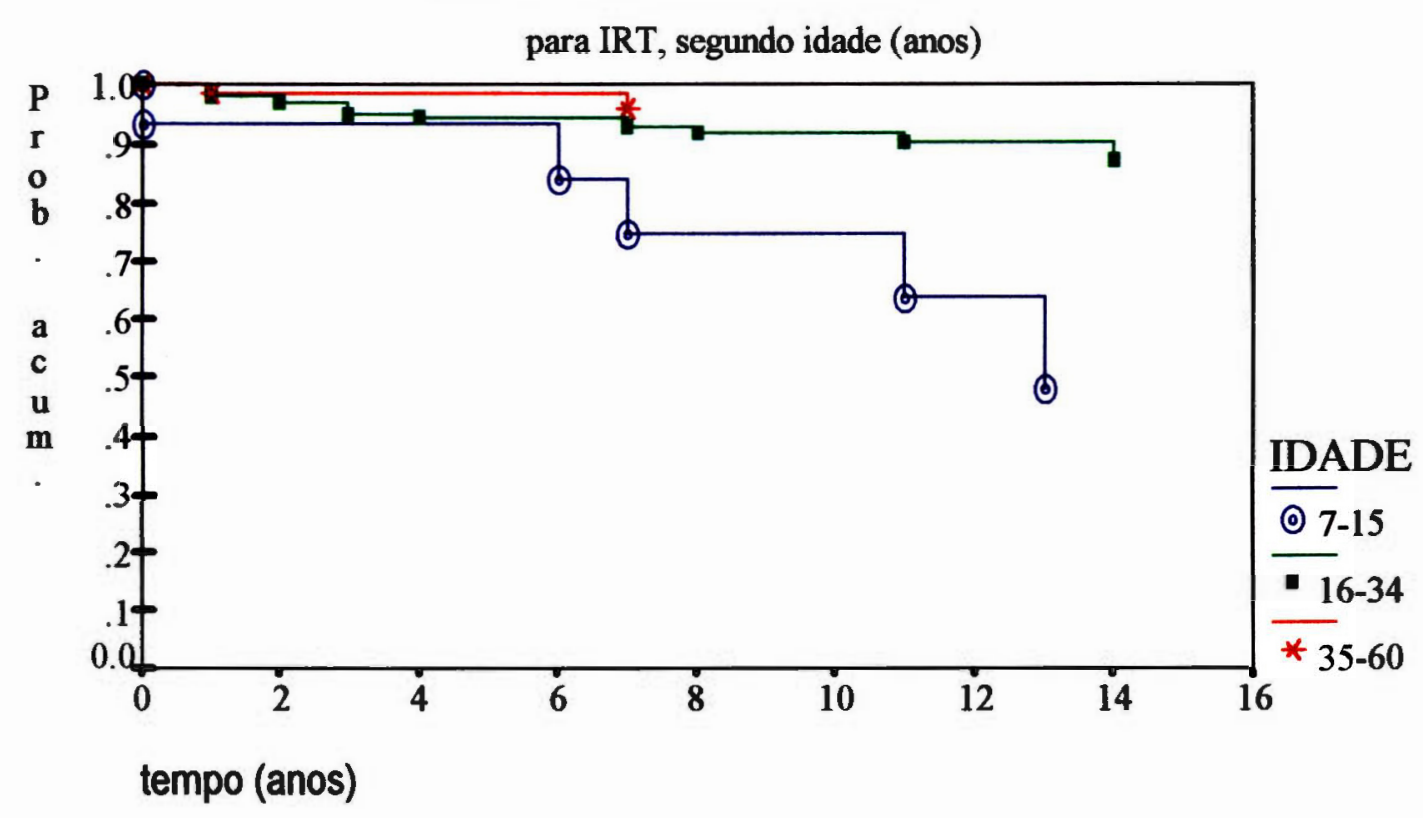

A tabela 19 mostra a análise da sobrevida até a IRT, segundo as variáveis clínicas e laboratoriais. 
Tabela 19. Probabilidade de sobrevida acumulada até o acometimento de insuficiência renal terminal pelo método de Kaplan-Meier, dos pacientes com LES, segundo as variáveis clínicas e laboratoriais. Clínica de Reumatologia do Hospital Heliópolis. São Paulo - 1978 a 1995

\begin{tabular}{|c|c|c|c|c|c|c|}
\hline \multirow[t]{2}{*}{ Variável } & \multirow[t]{2}{*}{ categoria } & \multicolumn{4}{|c|}{$\begin{array}{l}\text { prob. sobrevida acumulada }(\%) \\
\end{array}$} & \multirow{2}{*}{$\begin{array}{c}\log r a n k \\
\text { (p) }\end{array}$} \\
\hline & & 1 ano & 5 anos & 10 anos & 15 anos & \\
\hline ulcerações & não & 97,4 & 95,1 & 86,8 & 80,6 & 0,3682 \\
\hline de mucosas & $\operatorname{sim}$ & 99,2 & 95,7 & 92,6 & 78,7 & \\
\hline envolvimento & não & 98,1 & 95,0 & 92,5 & 78,3 & 0,0079 \\
\hline \multirow[t]{3}{*}{ cárdio-pulmonar } & pulmão & 100,0 & 100,0 & 94,4 & 94,4 & \\
\hline & coração & 100,0 & 100,0 & 87,5 & 87,5 & \\
\hline & pulmão e coração & 95,7 & 85,0 & 68,1 & 45,3 & \\
\hline hipertensão & não & 98,9 & 96,0 & 96,0 & 84,5 & 0,0045 \\
\hline arterial & $\operatorname{sim}$ & 97,1 & 93,9 & 75,9 & 50,6 & \\
\hline acometimento de & não & 98,4 & 95,2 & 91,8 & 73,2 & 0,6825 \\
\hline sistema nervoso & psicose & 94,1 & 86,3 & 86,3 & 86,3 & \\
\hline \multirow[t]{2}{*}{ central } & convulsão & 100,0 & 100,0 & 72,7 & 72,7 & \\
\hline & psicose e convulsão & 100,0 & 100,0 & 100,0 & 100,0 & \\
\hline alteração & não & 98,8 & 96,4 & 91,9 & 73,6 & 0,0005 \\
\hline \multirow[t]{4}{*}{ hematológica } & anemia & 90,0 & 68,6 & 68,6 & 68,6 & \\
\hline & leucopenia & 100,0 & 100,0 & 94,0 & 94,0 & \\
\hline & plaquetopenia & 85,7 & 71,4 & 71,4 & 71,4 & \\
\hline & múltiplos & 100,0 & 100,0 & 83,3 & 83,3 & \\
\hline \multirow[t]{2}{*}{ imunossupressor } & não & 97,9 & 96,0 & 89,9 & 79,6 & 0,6855 \\
\hline & $\operatorname{sim}$ & 100,0 & 93,6 & 90,3 & 73,0 & \\
\hline \multicolumn{2}{|l|}{ Total } & 98,0 & 95,0 & 89,7 & 76,9 & \\
\hline
\end{tabular}

A presença do acometimento conjunto do pulmão e do coração diminuiu a proporção de indivíduos livres de IRT, como se observa no gráfico 39 Após 10 e 15 anos de seguimento, dentre os pacientes com envolvimento simultâneo desses dois órgãos, respectivamente, $68,1 \%$ e $45,3 \%$ não vieram a ter IRT. Nos grupos onde o acometimento ficou restrito a um só desses órgãos, as porcentagens são próximas a $90 \%$. As curvas de probabilidade de sobrevida acumulada apresentaram-se diferentes, estatisticamente $(\mathrm{p}=0,0079)$. Não foram encontrados, na literatura consultada, trabalhos que analisassem o envolvimento conjunto do coração e do pulmão e que pudessem ser comparados com os resultados do presente estudo. 


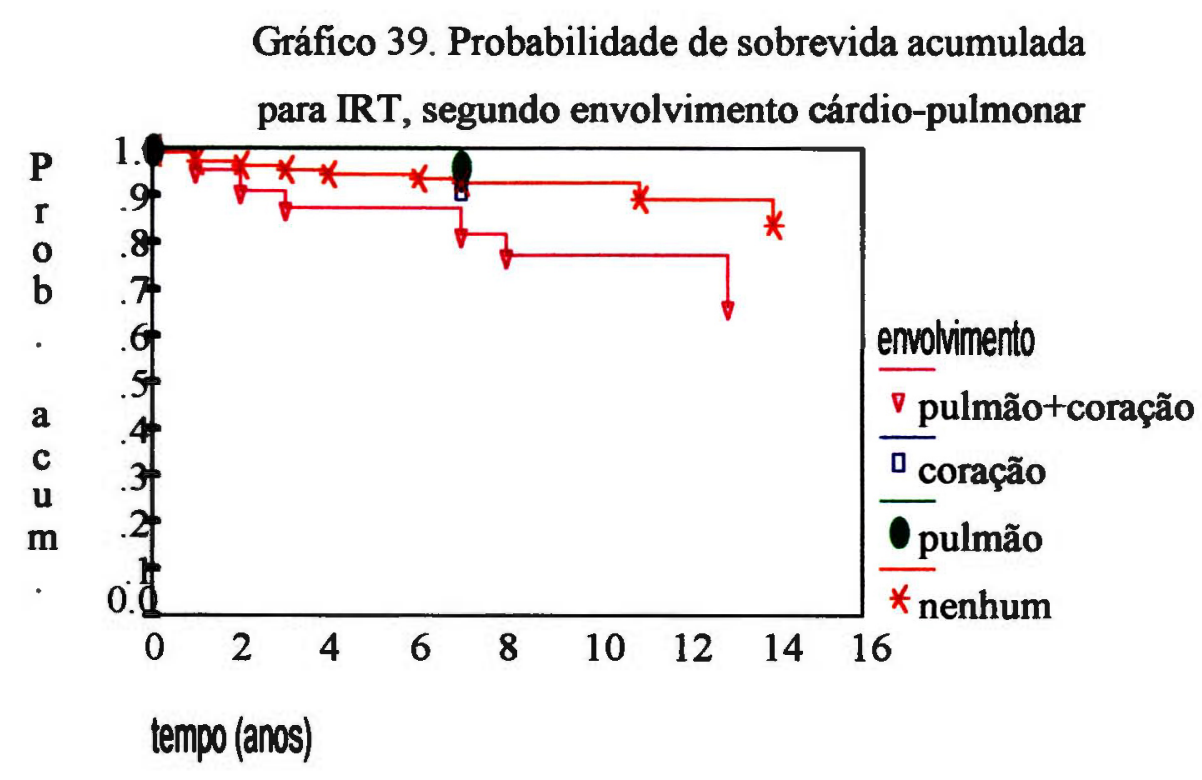

A presença de hipertensão arterial no primeiro ano do diagnóstico do LES pode vir a aumentar a probabilidade de um indivíduo desenvolver IRT ao longo do tempo; foi detectada diferença estatisticamente significante entre as curvas de probabilidade de sobrevida acumulada $(\mathrm{p}=0,0045)$. Até 5 anos de seguimento as curvas se equiparavam, porém, a partir daí, a porcentagem de sobrevida acumulada para IRT foi sempre menor entre os pacientes com hipertensão arterial (gráfico 40).

Gráfico 40. Probabilidade de sobrevida acumulada para IRT,

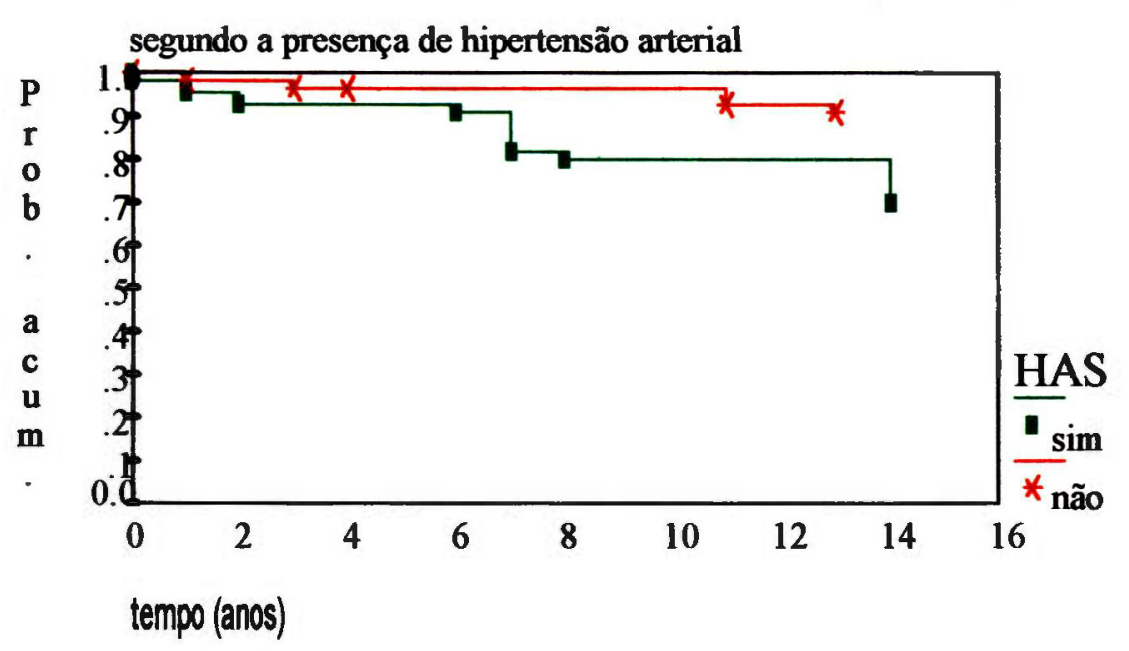


Houve diferença estatisticamente significante $(p=0,0005)$ entre as curvas de probabilidade de sobrevida renal acumulada para a alteração hematológica; especialmente a anemia hemolítica foi $o$ acometimento que esteve estatisticamente associado à menor sobrevida renal, a partir do quinto ano de acompanhamento (gráfico 41).

Gráfico 41. Probabilidade de sobrevida acumulada

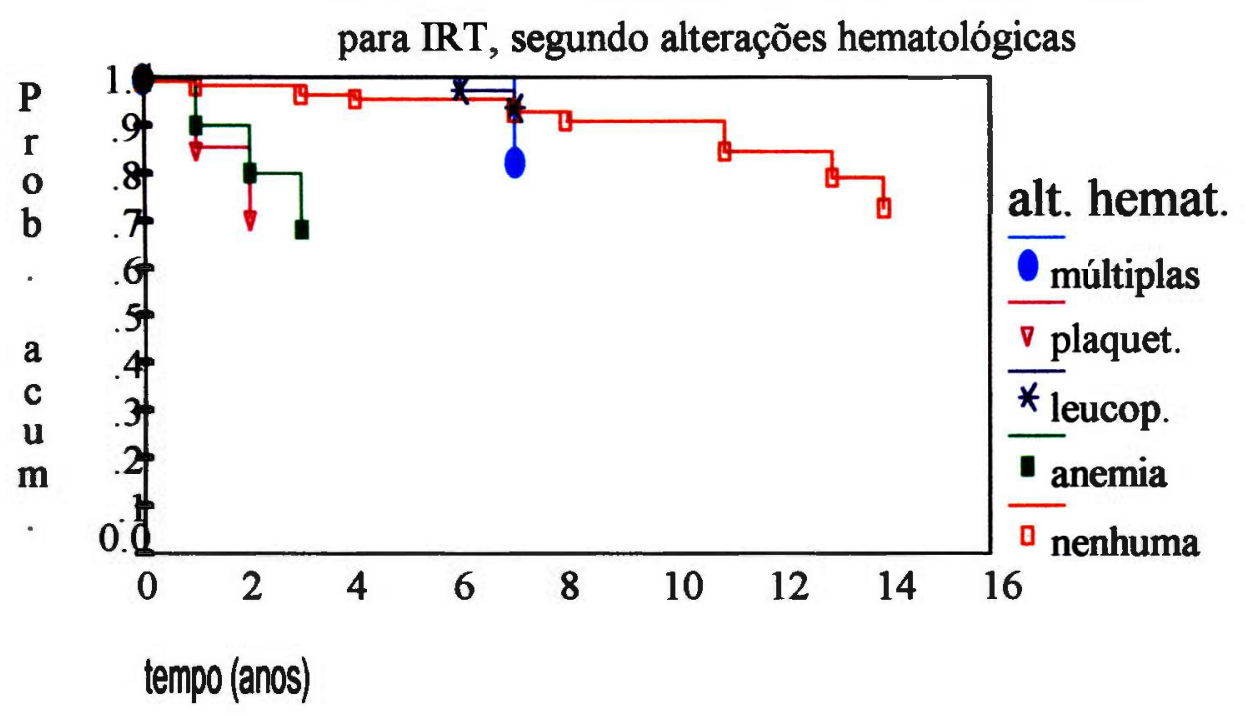

A tabela 20 mostra as estimativas da probabilidade de sobrevida até a ocorrência de IRT, segundo as alterações imunológicas laboratoriais. Nenhuma dessas variáveis apresentou associação estatisticamente significante, na análise de sobrevida pelo método de Kaplan-Meier. Embora a presença de auto-anticorpos anti-DNA seja classicamente associada à presença de nefrite ${ }^{86}$, não foi detectada diferença significante entre as curvas de probabilidade de sobrevida renal acumulada dos pacientes portadores ou não desse auto-anticorpo. 
Tabela 20. Probabilidade de sobrevida acumulada para a insuficiência renal terminal pelo método de Kaplan-Meier, pa a pacientes com LES, segundo as alterações imunológicas laboratoriais. Clínica de Reumatologia do Hospital Heliópolis. São Paulo - 1978 a 1995

\begin{tabular}{|c|c|c|c|c|c|c|}
\hline \multirow[t]{2}{*}{ Variável } & \multirow[t]{2}{*}{ categoria } & \multicolumn{4}{|c|}{ prob. sobrevida acumulada (\%) } & \multirow{2}{*}{$\begin{array}{c}\log \operatorname{ranh} \\
\text { (p) }\end{array}$} \\
\hline & & 1 ano & 5 anos & 10 anos & 15 anos & \\
\hline anti DNA & $\begin{array}{l}\text { negativo } \\
\text { positivo }\end{array}$ & $\begin{array}{l}98,4 \\
97,5\end{array}$ & $\begin{array}{l}94,5 \\
96,0\end{array}$ & $\begin{array}{l}91,4 \\
83,2\end{array}$ & $\begin{array}{l}74,4 \\
76,2\end{array}$ & 0,5083 \\
\hline anti-Sm & $\begin{array}{l}\text { negativo } \\
\text { positivo }\end{array}$ & $\begin{array}{r}100,0 \\
93,2\end{array}$ & $\begin{array}{l}97,9 \\
93,2\end{array}$ & $\begin{array}{l}90,6 \\
93,2\end{array}$ & $\begin{array}{l}79,1 \\
93,2\end{array}$ & 0,8001 \\
\hline anti-RNP & $\begin{array}{l}\text { negativo } \\
\text { positivo }\end{array}$ & $\begin{array}{l}97,8 \\
98,3\end{array}$ & $\begin{array}{l}96,5 \\
96,4\end{array}$ & $\begin{array}{l}90,3 \\
92,0\end{array}$ & $\begin{array}{l}75,6 \\
92,0\end{array}$ & 0,5525 \\
\hline anti-SSA & $\begin{array}{l}\text { negativo } \\
\text { positivo }\end{array}$ & $\begin{array}{r}96,6 \\
100,0\end{array}$ & $\begin{array}{l}94,7 \\
97,4\end{array}$ & $\begin{array}{l}88,2 \\
91,3\end{array}$ & $\begin{array}{l}70,5 \\
91,3\end{array}$ & 0,2047 \\
\hline anti-SSB & $\begin{array}{l}\text { negativo } \\
\text { positivo }\end{array}$ & $\begin{array}{r}98,0 \\
100,0\end{array}$ & $\begin{array}{r}95,6 \\
100,0\end{array}$ & $\begin{array}{r}89,3 \\
100,0\end{array}$ & $\begin{array}{r}82,5 \\
100,0\end{array}$ & 0,5614 \\
\hline Células LE & $\begin{array}{l}\text { negativo } \\
\text { positivo }\end{array}$ & $\begin{array}{l}96,4 \\
97,7\end{array}$ & $\begin{array}{l}94,3 \\
92,6\end{array}$ & $\begin{array}{l}84,7 \\
86,8\end{array}$ & $\begin{array}{l}72,6 \\
70,1\end{array}$ & 0,8674 \\
\hline Total & & 98,0 & $\overline{95,0}$ & 89,7 & 76,9 & \\
\hline
\end{tabular}

A fim de serem definidos os fatores de risco para a ocorrência de IRT em pacientes com LES, elaborou-se o modelo de riscos proporcionais de Cox multivariado. Inicialmente, realizou-se a análise univariada para a escolha daquelas variáveis que entrariam nessa análise, como mostra a tabela 21. As variáveis escolhidas para a elaboração do modelo multivariado foram: hipertensão arterial $(p=0,0038)$, idade $(p=0,0237)$, alteração hematológica $(p=0,0284)$, envolvimento cárdio-pulmonar $(p=0,0324)$, sexo $(p=0,2286)$ e uso de imunossupressor $(\mathrm{p}=0,7748)$. As demais variáveis não foram testadas pela sua baixa significância estatística na análise univariada e/ou por não apresentarem interesse clínico no contexto da perda de função renal. 
Tabela 21. Análise univariada dos fatores de risco para o acometimento de insuficiência renal terminal em pacientes com LES, através do modelo de riscos proporcionais de Cox. Clínica de Reumatologia do Hospital Heliópolis. São Paulo - 1978 a 1995

\begin{tabular}{|c|c|c|c|c|c|c|}
\hline Variável & categoria & coef.(Bi) & $\mathrm{HR}_{\mathrm{b}}{ }^{*}$ & IC $_{95 \%}$ (HR) & p(categoria) & p(variável) \\
\hline $\begin{array}{l}\text { imunossupressor } \\
\text { anti-DNA } \\
\text { anti-Sm } \\
\text { anti-RNP } \\
\text { anti-SSA } \\
\text { anti-SSB } \\
\text { Células LE }\end{array}$ & $\begin{array}{l}\text { feminino } \\
\text { masculino } \\
\text { não branco } \\
\text { branco } \\
7 \text { a } 15 \\
16 \text { a } 34 \\
35 \text { a } 60 \\
\text { não } \\
\text { sim } \\
\text { não } \\
\text { pulmão } \\
\text { coração } \\
\text { pulmão e coração } \\
\text { não } \\
\text { sim } \\
\text { não } \\
\text { psicose } \\
\text { convulsão } \\
\text { psicose e convulsão } \\
\text { não } \\
\text { anemia } \\
\text { leucopenia } \\
\text { plaquetopenia } \\
\text { múltiplos } \\
\text { não } \\
\text { sim } \\
\text { negativo } \\
\text { positivo } \\
\text { negativo } \\
\text { positivo } \\
\text { negativo } \\
\text { positivo } \\
\text { negativo } \\
\text { positivo } \\
\text { negativo } \\
\text { positivo } \\
\text { negativo } \\
\text { positivo }\end{array}$ & $\begin{array}{c}-0,8328 \\
\text { ref. } \\
\text { ref. } \\
-0,0899 \\
1,2656 \\
\text { ref. } \\
-0,8836 \\
\text { ref. } \\
-0,2926 \\
\text { ref. } \\
-1,3088 \\
-0,2419 \\
1,2012 \\
\text { ref. } \\
1,2836 \\
\text { ref. } \\
0,4275 \\
0,2551 \\
-15,0122 \\
\text { ref. } \\
1,8218 \\
-0,8773 \\
1,5861 \\
0,1406 \\
\text { ref. } \\
0,1401 \\
\text { ref. } \\
0,5104 \\
\text { ref. } \\
0,4324 \\
\text { ref. } \\
-0,5284 \\
\text { ref. } \\
-1,1533 \\
\text { ref. } \\
-15,1034 \\
\text { ref. } \\
0,0845\end{array}$ & $\begin{array}{l}0,44 \\
1,00 \\
1,00 \\
0,91 \\
3,55 \\
1,00 \\
0,41 \\
1,00 \\
0,75 \\
1,00 \\
0,27 \\
0,79 \\
3,33 \\
1,00 \\
3,61 \\
1,00 \\
1,53 \\
1,29 \\
0,00 \\
1,00 \\
6,18 \\
0,42 \\
4,89 \\
1,15 \\
1,00 \\
1,15 \\
1,00 \\
1,23 \\
1,00 \\
1,54 \\
1,00 \\
0,59 \\
1,00 \\
0,32 \\
1,00 \\
0,00 \\
1,00 \\
1,09\end{array}$ & $\begin{array}{c}{[0,37 ; 2,27]} \\
{[1,27 ; 9,91]} \\
{[0,09 ; 1,83]} \\
{[0,31 ; 1,79]} \\
{[0,04 ; 2,07]} \\
{[0,10 ; 6,03]} \\
{[1,26 ; 8,77]} \\
{[1,52 ; 8,59]} \\
{[0,35 ; 6,69]} \\
{[0,37 ; 4,47]} \\
\text { não definido } \\
{[1,71 ; 22,37]} \\
{[0,09 ; 1,85]} \\
{[1,08 ; 22,13]} \\
{[0,15 ; 8,82]} \\
{[0,45 ; 2,98]} \\
\\
{[0,50 ; 3,02]} \\
{[0,46 ; 5,14]} \\
{[0,16 ; 2,18]} \\
{[0,07 ; 1,53]} \\
\text { não definido } \\
{[0,40 ; 3,00]}\end{array}$ & $\begin{array}{l}0,8463 \\
0,0158 \\
0,2436 \\
0,5118 \\
\\
0,2076 \\
0,8161 \\
0,0151 \\
0,0037 \\
\\
0,5696 \\
0,6873 \\
0,9901 \\
0,0055 \\
0,2489 \\
0,0397 \\
0,8924 \\
\\
0,7726 \\
\\
0,6455 \\
0,4818 \\
0,4288 \\
0,1529\end{array}$ & $\begin{array}{l}0,7748 \\
0,6480 \\
0,4934 \\
0,4103 \\
0,1192 \\
0,3663 \\
0,8678\end{array}$ \\
\hline
\end{tabular}

${ }^{*} \mathrm{HR}_{\mathrm{b}}$ : hazard ratio bruta

Iniciou-se o processo de modelagem multivariada pela hipertensão arterial sistêmica e, a seguir, acrescentou-se a idade ao diagnóstico. Esta variável foi mantida no modelo multivariado, pois foi estatisticamente significante e também 
melhorou a significância do modelo; ainda, verificou-se que foi variável de confusão para hipertensão arterial sistêmica. Posteriormente, foi acrescentada a alteração hematológica no modelo multivariado; essa variável foi estatisticamente significante e também foi variável de confusão para hipertensão arterial. Embora a plaquetopenia tenha apresentado significância estatística na análise univariada, ao se elaborar o modelo multivariado, ela perdeu essa significância; por isso, optou-se por incorporá-la na categoria "outras alterações hematológicas", na análise multivariada. Por último foram acrescentadas as variáveis "envolvimento cárdio-pulmonar", "sexo" e "uso de imunossupressor", uma a uma, mas nenhuma delas foi estatisticamente significante. Finalmente foram testadas as interações entre hipertensão arterial e idade (has*idade) e entre hipertensão arterial e alteração hematológica (has*alteração hematológica); no entanto nenhuma dessas interações foi estatisticamente significante e, além disso, encobriram a significância estatística das variáveis já existentes no modelo multivariado. Sendo assim, tomou-se a decisão de retirá-las do modelo multivariado final.

A tabela 22 apresenta o modelo multivariado final dos fatores de risco para a ocorrência de IRT, em pacientes portadores de lúpus eritematoso sistêmico.

Tabela 22. Modelo multivariado final dos fatores de risco para a insuficiência renal terminal em pacientes com LES, através do modelo de Cox. Clínica de Reumatologia do Hospital Heliópolis. São Paulo - 1978 a 1995

\begin{tabular}{|c|c|c|c|c|c|c|}
\hline Variável & categoria & coef.(Bi) & HR* $_{\text {brua }}$ & $\mathrm{HR}_{\text {almande }}$ & IC $95 \%$ (HRa) & p(variável) \\
\hline $\begin{array}{l}\text { idade no } \\
\text { diagnóstico } \\
\text { (anos) }\end{array}$ & $\begin{array}{l}7 \text { a } 15 \\
16 \text { a } 34 \\
35 \text { a } 60\end{array}$ & $\begin{array}{c}1,2852 \\
\text { ref. } \\
-1,0561\end{array}$ & $\begin{array}{l}3,55 \\
1,00 \\
0,41\end{array}$ & $\begin{array}{l}3,61 \\
1,00 \\
0,34\end{array}$ & $\begin{array}{c}{[1,14 ; 11,46]} \\
{[0,07 ; 1,56]}\end{array}$ & 0,0203 \\
\hline $\begin{array}{l}\text { hipertensão } \\
\text { arterial }\end{array}$ & $\begin{array}{l}\text { não } \\
\text { sim }\end{array}$ & $\begin{array}{c}\text { ref. } \\
1,6507\end{array}$ & $\begin{array}{l}1,00 \\
3,61\end{array}$ & $\begin{array}{l}1,00 \\
5,21\end{array}$ & {$[2,03 ; 13,35]$} & 0,0006 \\
\hline $\begin{array}{l}\text { alteração } \\
\text { hematológica }\end{array}$ & $\begin{array}{l}\text { não } \\
\text { anemia } \\
\text { outras alterações }\end{array}$ & $\begin{array}{c}\text { ref. } \\
2,2357 \\
-0,1166\end{array}$ & $\begin{array}{l}1,00 \\
6,01 \\
0,82\end{array}$ & $\begin{array}{l}1,00 \\
9,35 \\
0,89\end{array}$ & $\begin{array}{c}{[2,36 ; 37,06]} \\
{[0,31 ; 2,59]}\end{array}$ & 0,0040 \\
\hline
\end{tabular}

*HR: hazard ratio significância do modelo final $\rightarrow p<0,0001$ 
Nesta coorte, pode ser admitido que os fatores de risco para o acometimento de IRT em pacientes com LES foram a idade no momento do diagnóstico, a presença de hipertensão arterial e de anemia hemolítica.

Pacientes jovens com LES têm maior risco de desenvolver IRT, quando comparados com aqueles entre 16 e 34 anos. A razão entre os de riscos de IRT de pacientes com idade de início da doença entre 7 e 15 anos e daqueles entre 16 e 34 anos é igual a $3,61(\mathrm{IC}=[1,14 ; 11,46])$. Os pacientes mais velhos $(35$ a 60 anos) não apresentaram risco para a IRT estatisticamente diferente ao do grupo de referência, ou seja, entre 16 e 34 anos. Esses achados confirmam um prognóstico pior para o rim em crianças ${ }^{70}$ e a menor agressividade para esse órgão nos pacientes mais idosos ${ }^{12,90}$.

A hipertensão arterial sistêmica também foi um fator de risco significante para a IRT na análise multivariada $(\mathrm{p}=0,0006)$. A razão entre os riscos de pacientes com hipertensão arterial sistêmica no início da doença e daqueles normotensos é 5,21 (IC= $[2,03 ; 13,35])$. Ginzler e colaboradores ${ }^{24}$ encontraram valores de odds ratio para IRT variando de 2,3 a 4,6 vezes para pacientes portadores de hipertensão arterial.

Finalmente, o outro fator de risco significante para a ocorrência de IRT foi a alteração hematológica desenvolvida no primeiro ano do $\operatorname{LES}(p=0,0040)$. Pacientes com anemia hemolítica têm risco de desenvolver IRT 9,35 vezes o de pacientes sem alteração hematológica, porém, a princípio não há explicação clínica para esse achado. Já a presença das outras alterações hematológicas (isoladas ou conjuntas) não representaram risco maior quando comparadas com os pacientes sem alterações. No modelo multivariado optou-se por agrupar todas as alterações hematológicas, com exceção da anemia, em um só grupo, pois nenhuma delas foi significante per se na análise multivariada. Não foram 
encontrados relatos em literatura dessa associação entre anemia hemolítica e o desenvolvimento de IRT, em pacientes com LES.

Vale lembrar que o envolvimento cárdio-pulmonar, que foi risco na análise univariada pelo modelo de Cox, não confirmou esse comportamento no modelo multivariado para IRT.

Muito embora a IRT seja um fator de risco para o óbito descrito por vários autores e também encontrado neste trabalho, não se encontrou, na literatura, estudos que identifiquem os fatores de risco para a ocorrência da IRT, utilizando a análise multivariada.

Nota-se que os fatores de risco para o óbito (quais sejam, envolvimento cárdio-pulmonar e a não utilização de imunossupressor) não o foram para o desenvolvimento de IRT. Para se evitar essa alteração, a atenção deve ser voltada para os pacientes onde a doença se iniciou antes dos 16 anos, nos casos com anemia hemolítica e nos pacientes com hipertensão arterial sistêmica.

A partir do desenvolvimento da IRT, as complicações desta, como por exemplo, a uremia, desequilíbrio hidro-eletrolítico, aquelas decorrentes da diálise ou de um eventual transplante, mudam o quadro inicialmente causado apenas pelo LES, interferindo na evolução natural da doença. 


\subsection{Análise de sobrevida até o óbito dos pacientes com nefrite lúpica}

Nesta etapa do trabalho houve o interesse em avaliar como os 118 pacientes portadores de nefrite lúpica comportaram-se em relação ao óbito e a importância dos fatores de risco para o mesmo, nesse grupo de pacientes.

A tabela 24 apresenta a distribuição dos 118 pacientes com nefrite lúpica, segundo a presença de óbito e as características demográficas. Observa-se que não houve associação estatisticamente significante entre a ocorrência de óbito de um paciente com nefrite e sexo, ou raça ou idade (respectivamente $p=0,4276$, $\mathrm{p}=0,9572$ e $\mathrm{p}=0,2762$ ). Porém ao se analisarem os pacientes em diferentes faixas etárias, verifica-se que a maior porcentagem de óbitos, $33,3 \%$, ocorreu entre os pacientes nos quais a doença iniciou-se antes dos 16 anos (gráfico 42).

Tabela 24. Número e porcentagem de óbitos, segundo as características demográficas dos pacientes com nefrite. Clínica de Reumatologia do Hospital Heliópolis. São Paulo - 1978 a 1995

\begin{tabular}{|c|c|c|c|c|c|c|c|c|}
\hline \multirow[t]{2}{*}{ Variável } & \multirow[t]{2}{*}{ categoria } & \multicolumn{2}{|c|}{ censura } & \multicolumn{2}{|c|}{ óbito } & \multicolumn{2}{|c|}{ Total } & \multirow{2}{*}{$\begin{array}{l}\text { valor } \\
\text { de } p^{\star}\end{array}$} \\
\hline & & $\mathrm{n}^{\circ}$ & $\%$ & $n^{\circ}$ & $\%$ & $\overline{n^{\circ}}$ & $\%$ & \\
\hline sexo & $\begin{array}{l}\text { feminino } \\
\text { masculino }\end{array}$ & $\begin{array}{r}88 \\
8\end{array}$ & $\begin{array}{l}82,2 \\
72,7\end{array}$ & $\begin{array}{r}19 \\
3\end{array}$ & $\begin{array}{l}17,8 \\
27,3\end{array}$ & $\begin{array}{r}107 \\
11\end{array}$ & $\begin{array}{l}100,0 \\
100,0\end{array}$ & 0,4276 \\
\hline raça & $\begin{array}{l}\text { não branco } \\
\text { branco }\end{array}$ & $\begin{array}{l}37 \\
59\end{array}$ & $\begin{array}{l}82,2 \\
80,8\end{array}$ & $\begin{array}{r}8 \\
14\end{array}$ & $\begin{array}{l}17,8 \\
19,2\end{array}$ & $\begin{array}{l}45 \\
73\end{array}$ & $\begin{array}{l}100,0 \\
100,0\end{array}$ & 0,9572 \\
\hline $\begin{array}{l}\text { idade no } \\
\text { diagnóstico } \\
\text { (anos) }\end{array}$ & $\begin{array}{l}7 \text { a } 15 \\
16 \text { a } 34 \\
35 \text { a } 60\end{array}$ & $\begin{array}{r}8 \\
23 \\
65\end{array}$ & $\begin{array}{l}66,7 \\
88,5 \\
81,3\end{array}$ & $\begin{array}{r}4 \\
3 \\
15\end{array}$ & $\begin{array}{l}33,3 \\
11,5 \\
18,7\end{array}$ & $\begin{array}{l}12 \\
26 \\
80\end{array}$ & $\begin{array}{l}100,0 \\
100,0 \\
100,0\end{array}$ & 0,2762 \\
\hline Total & & 96 & 81,4 & 22 & 18,6 & 118 & 100,0 & \\
\hline
\end{tabular}

*p: nível descritivo do teste de associação pelo $\chi^{2}$. 


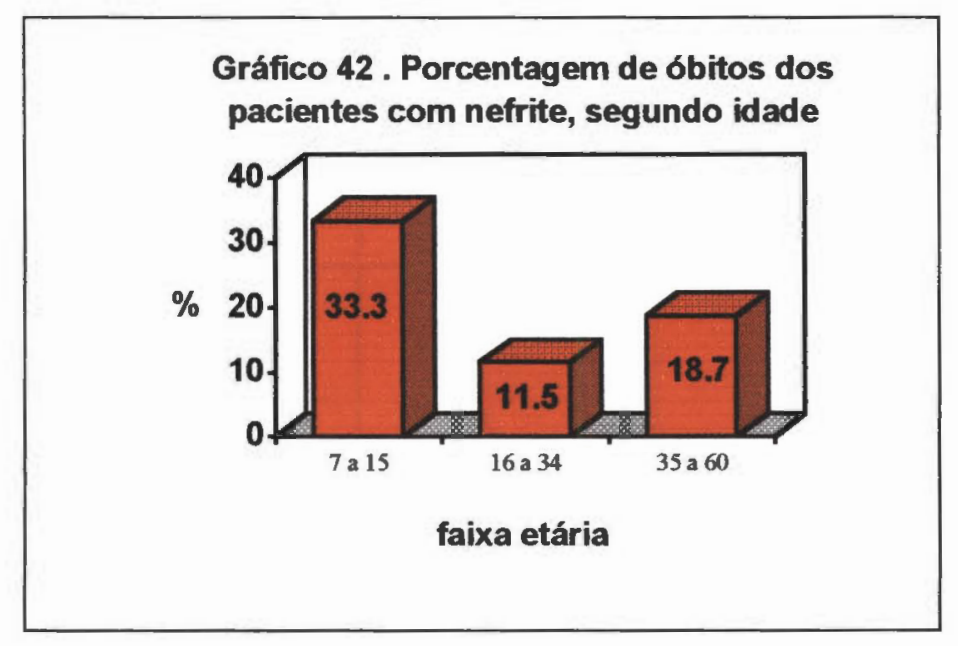

Na tabela 25 estão apresentadas as distribuições de freqüência dos pacientes com nefrite lúpica, segundo a ocorrência de óbito e as variáveis clínicas e laboratoriais. Para a maioria delas não foi detectada associação estatisticamente significante com a ocorrência de óbito, com excȩ̧ão da presença de insuficiência renal terminal $(p=0,0267)$ e da utilização de imunossupressor (que está no limite da significância estatística, $\mathrm{p}=0,0580$ ).

Dos pacientes com nefrite lúpica que desenvolveram insuficiência renal terminal, $38,1 \%$ foi a óbito, enquanto $14,4 \%$ dos pacientes sem o acometimento desse problema morreram, como mostra o gráfico 43. Houve uma maior porcentagem de óbito dentre os pacientes com nefrite lúpica que não utilizaram imunossupressor, quando comparados com os que utilizaram esse medicamento, respectivamente, $24,1 \%$ e $7,7 \%$ (gráfico 44 ). 
Tabela 25.Distribuicão dos pacientes com nefrite lúpica, segundo ocorrência de óbito e as variáveis clínicas e laboratoriais.Clínica de Reumatologia do Hospital Heliópolis.São Paulo-1978 a 1995

\begin{tabular}{|c|c|c|c|c|c|c|c|c|}
\hline \multirow[t]{2}{*}{ Variável } & \multirow[t]{2}{*}{ categoria } & \multicolumn{2}{|c|}{ censura } & \multicolumn{2}{|c|}{ óbito } & \multicolumn{2}{|c|}{ Total } & \multirow{2}{*}{$\begin{array}{l}\text { valor } \\
\text { de } \mathbf{p}^{\star}\end{array}$} \\
\hline & & $n^{\circ}$ & $\%$ & $n^{\circ}$ & $\%$ & $n^{\circ}$ & $\%$ & \\
\hline ulcerações & กão & 51 & 81,0 & 12 & 19,0 & $\overline{63}$ & 100,0 & 0,9073 \\
\hline de mucosa & $\operatorname{sim}$ & 45 & 81,8 & 10 & 18,2 & 55 & 100,0 & \\
\hline envolvimento & não & 63 & 85,1 & 11 & 14,9 & 74 & 100,0 & 0,2014 \\
\hline \multirow[t]{3}{*}{ cárdio-pulmonar } & pulmão & 16 & 84,2 & 3 & 15,8 & 19 & 100,0 & \\
\hline & coração & 7 & 77,8 & 2 & 22,8 & 9 & 100,0 & \\
\hline & pulmão e coração & 10 & 62,5 & 6 & 37,5 & 16 & 100,0 & \\
\hline hipertensão & não & 56 & 78,9 & 15 & 21,1 & 71 & 100,0 & 0,5421 \\
\hline arterial & $\operatorname{sim}$ & 40 & 85,1 & 7 & 14,9 & 47 & 100,0 & \\
\hline acometimento de & não & 74 & 82,2 & 16 & 17,8 & 90 & 100,0 & 0,6151 \\
\hline sistema nervoso & psicose & 7 & 77,8 & 2 & 22,2 & 9 & 100,0 & \\
\hline \multirow[t]{2}{*}{ central } & convulsão & 12 & 85,7 & 2 & 14,3 & 14 & 100,0 & \\
\hline & psicose e convulsão & 3 & 60,0 & 2 & 40,0 & 5 & 100,0 & \\
\hline alterações & não & 60 & 78,9 & 16 & 21,1 & 76 & 100,0 & 0,8392 \\
\hline \multirow[t]{4}{*}{ hematológicas } & anemia & 5 & 83,3 & 1 & 16,7 & 6 & 100,0 & \\
\hline & leucopenia & 24 & 88,9 & 3 & 11,1 & 27 & 100,0 & \\
\hline & plaquetopenia & 4 & 80,0 & 1 & 20,0 & 5 & 100,0 & \\
\hline & múltiplos & 3 & 75,0 & 1 & 25,0 & 4 & 100,0 & \\
\hline insuficiência & não & 83 & 85,6 & 14 & 14,4 & 97 & 100,0 & 0,0267 \\
\hline renal terminal & $\operatorname{sim}$ & 13 & 61,9 & 8 & 38,1 & 21 & 100,0 & \\
\hline \multirow[t]{2}{*}{ imunossupressor } & não & 60 & 75,9 & 19 & 24,1 & 79 & 100,0 & 0.0580 \\
\hline & $\operatorname{sim}$ & 36 & 92,3 & 3 & 7,7 & 39 & 100,0 & \\
\hline \multicolumn{2}{|l|}{ Total } & 96 & 81,4 & 22 & 18,6 & 118 & 100,0 & \\
\hline
\end{tabular}

*p: nível descritivo do teste de associação pelo $\chi^{2}$. 


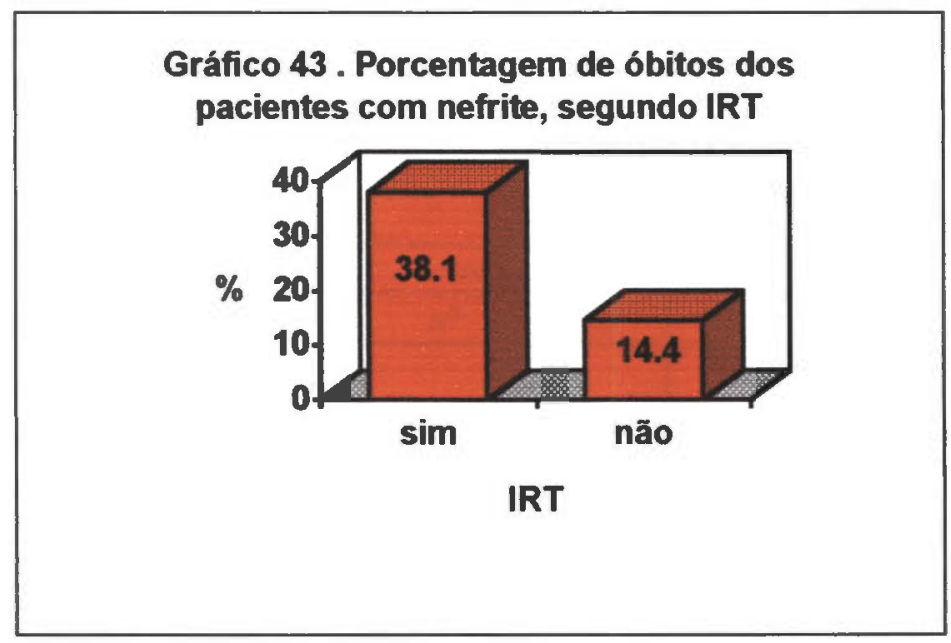

Gráfico 44. Porcentagem de óbitos dos pacientes com nefrite, segundo uso de imunossupressor

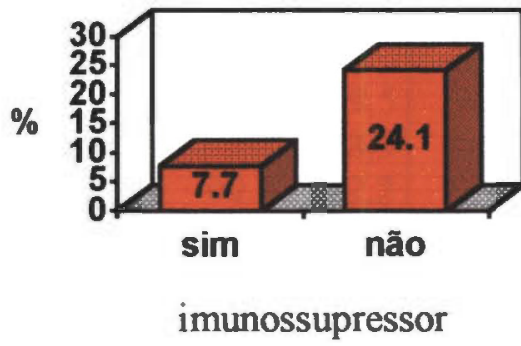

A tabela 26 apresenta as distribuições de freqüência dos pacientes com nefrite lúpica, segundo ocorrência de óbito $\mathrm{e}$ as alterações imunológicas laboratoriais; verifica-se que nenhuma delas esteve associada, estatisticamente, à ocorrência do óbito. 
Tabela 26. Distribuição dos pacientes com nefrite lúpica, segundo a ocorrência de óbito e as alteraç̃̃es imunológicas laboratoriais.Clínica de Reumatologia do Hospital Heliópolis.São Paulo -1978 a 1995

\begin{tabular}{|c|c|c|c|c|c|c|c|c|}
\hline \multirow[t]{2}{*}{ Variável } & \multirow[t]{2}{*}{ categoria } & \multicolumn{2}{|c|}{ censura } & \multicolumn{2}{|c|}{ óbito } & \multicolumn{2}{|c|}{ Total } & \multirow{2}{*}{$\begin{array}{l}\text { valor } \\
\text { de } p^{\star}\end{array}$} \\
\hline & & $\mathrm{n}^{\circ}$ & $\%$ & $n^{\circ}$ & $\%$ & $\mathrm{n}^{\circ}$ & $\%$ & \\
\hline \multirow[t]{3}{*}{ anti DNA } & negativo & 44 & 81,5 & 10 & 18,5 & 54 & 100,0 & 0,8145 \\
\hline & positivo & 40 & 81,6 & 9 & 18,4 & 49 & 100,0 & \\
\hline & não realizado & 12 & 80,0 & 3 & 20,0 & 15 & 100,0 & \\
\hline \multirow[t]{3}{*}{ anti-Sm } & negativo & 37 & 84,1 & 7 & 15,9 & 44 & 100,0 & 0,7414 \\
\hline & positivo & 19 & 79,2 & 5 & 20,8 & 24 & 100,0 & \\
\hline & não realizado & 40 & 80,0 & 10 & 20,0 & 50 & 100,0 & \\
\hline \multirow[t]{3}{*}{ anti-RNP } & negativo & 37 & 80,4 & 9 & 19,6 & 46 & 100,0 & 0,7379 \\
\hline & positivo & 19 & 86,4 & 3 & 13,6 & 22 & 100,0 & \\
\hline & não realizado & 40 & 80,0 & 10 & 20,0 & 50 & 100,0 & \\
\hline \multirow[t]{3}{*}{ anti-SSA } & negativo & 20 & 83,3 & 4 & 16,7 & 24 & 100,0 & 0,7130 \\
\hline & positivo & 16 & 76,2 & 5 & 23,8 & 21 & 100,0 & \\
\hline & não realizado & 60 & 82,2 & 13 & 17,8 & 73 & 100,0 & \\
\hline \multirow[t]{3}{*}{ anti-SSB } & negativo & 31 & 79,5 & 8 & 20,5 & 39 & 100,0 & 1,0000 \\
\hline & positivo & 5 & 83,3 & 1 & 16,7 & 6 & 100,0 & \\
\hline & não realizado & 60 & 82,2 & 13 & 17,8 & 73 & 100,0 & \\
\hline \multirow[t]{3}{*}{ Células LE } & negativo & 18 & 72,0 & 7 & 28,0 & 25 & 100,0 & 0,5134 \\
\hline & positivo & 40 & 81,6 & 9 & 18,4 & 49 & 100,0 & \\
\hline & não realizado & 38 & 86,4 & 6 & 13,6 & 44 & 100,0 & \\
\hline \multicolumn{2}{|l|}{ Total } & $\overline{96}$ & 81,4 & 22 & 18,6 & 118 & 100,0 & \\
\hline
\end{tabular}

*p: nível descritivo do teste de associação pelo $\chi^{2}$. Para a realização do teste foram excluídas as categorias de "não realizado".

Quanto aos resultados da análise de sobrevida global para os pacientes que desenvolveram nefrite lúpica, a tabela 27 mostra a probabilidade de sobrevida acumulada calculada pelo método da Kaplan-Meier, de acordo com as características demográficas dos mesmos. 
Tabela 27. Probabilidade de sobrevida acumulada para o óbito dos pacientes com nefrite lúpica, calculada pelo método de Kaplan-Meier, segundo as características demográficas. Clínica de Reumatologia do Hospital Heliópolis. São Paulo - 1978 a 1995

\begin{tabular}{|c|c|c|c|c|c|c|}
\hline \multirow[t]{2}{*}{ Variável } & \multirow{2}{*}{ categoria } & \multicolumn{4}{|c|}{$\begin{array}{ll}\text { prob. sobrevida acumulada }(\%) \\
\end{array}$} & \multirow{2}{*}{$\begin{array}{c}\log \text { rank } \\
\text { (p) }\end{array}$} \\
\hline & & 1 ano & 5 anos & 10 anos & 15 anos & \\
\hline \multirow[t]{2}{*}{ Sexo } & feminino & 95,7 & 85,3 & 78,5 & 69,8 & 0,8388 \\
\hline & masculino & 90,0 & 75,0 & 75,0 & 75,0 & \\
\hline \multirow[t]{2}{*}{ Raça } & não branco & 94,7 & 80,2 & 80,2 & 80,2 & 0,9409 \\
\hline & branco & 95,3 & 85,5 & 77,4 & 68,8 & \\
\hline Idade no & 7 a 15 & 100,0 & 81,8 & 81,8 & 54,5 & 0,8223 \\
\hline diagnóstico & 16 a 34 & 94,0 & 85,4 & 77,3 & 77,3 & \\
\hline (anos) & 35 a 60 & 95,8 & 81,5 & 81,5 & 81,5 & \\
\hline \multicolumn{2}{|l|}{ Total } & 90,3 & 79,7 & 74,3 & 66,9 & \\
\hline
\end{tabular}

Não houve diferença estatisticamente significante entre as curvas de sobrevida acumulada das diversas categorias de sexo, raça ou idade (respectivamente, $\mathrm{p}=0,8388, \mathrm{p}=0,9409$ e $\mathrm{p}=0,8223$ ). Levando-se em conta o total de pacientes com nefrite, verifica-se que após 5 anos do diagnóstico de nefrite, a proporção de vivos era de $79,7 \%$, caindo para $66,9 \%$ após 15 anos do diagnóstico. O gráfico 45 apresenta a curva de probabilidade de sobrevida acumulada para o total de pacientes com nefrite lúpica.

Gráfico 45. Prob. de sobrevida acumulada dos pacientes

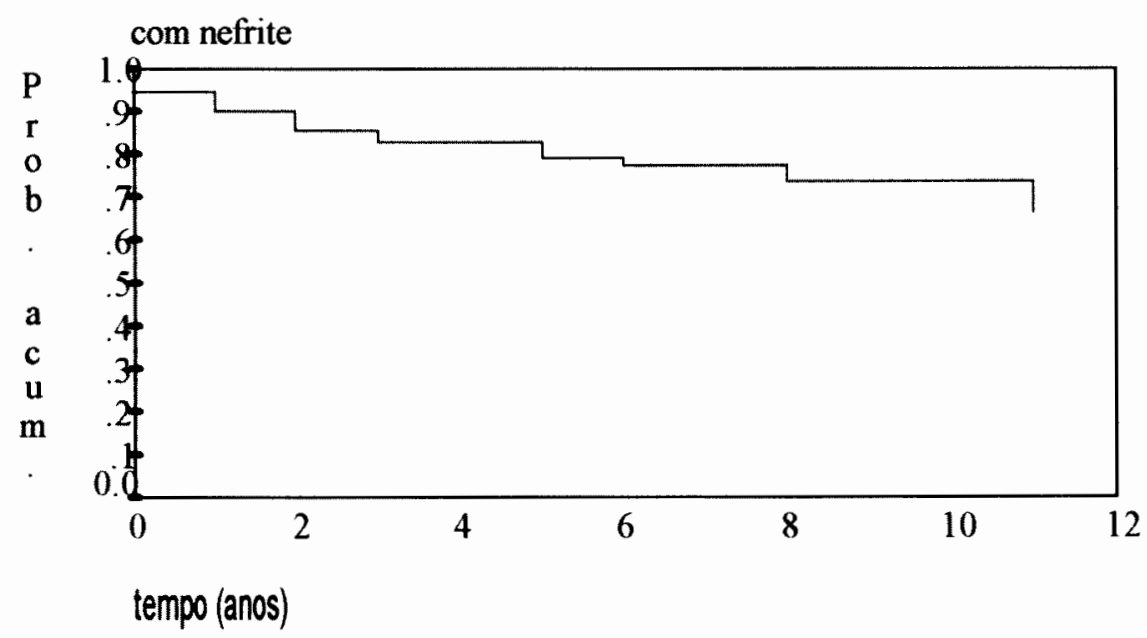


Na tabela 28 pode ser analisada a sobrevida até o óbito dos pacientes com nefrite lúpica, segundo as variáveis clínicas e laboratoriais.

Tabela 28. Probabilidade de sobrevida acumulada para o óbito dos pacientes com nefrite lúpica, calculada pelo método de Kaplan-Meier, segundo as variáveis clínicas e laboratoriais. Clínica de Reumatologia do Hospital Heliópolis. São Paulo - 1978 a 1995

\begin{tabular}{|c|c|c|c|c|c|c|}
\hline \multirow[t]{2}{*}{ Variável } & \multirow[t]{2}{*}{ categoria } & \multicolumn{3}{|c|}{ prob. sobrevida acumulada } & \multirow{2}{*}{\begin{tabular}{|l|}
$(\%)$ \\
15 anos \\
\end{tabular}} & \multirow{2}{*}{$\begin{array}{c}\log \text { rank } \\
\text { (p) }\end{array}$} \\
\hline & & 1 ano & $5 \operatorname{anos}$ & 10 anos & & \\
\hline ulcerações & não & 94,7 & 78,7 & 73,8 & 73,8 & 0,2551 \\
\hline de mucosas & $\operatorname{sim}$ & 95,6 & 89,3 & 84,0 & 72,0 & \\
\hline envolvimento & não & 96,9 & 87,9 & 82,1 & 82,1 & 0,0698 \\
\hline \multirow[t]{3}{*}{ cárdio-pulmonar } & pulmão & 100,0 & 71,1 & 71,1 & 71,1 & \\
\hline & coração & 100,0 & 100,0 & 80,0 & 80,0 & \\
\hline & pulmão e coração & 80,0 & 64,0 & 64,0 & 42,7 & \\
\hline hipertensão & não & 94,8 & 84,1 & 78,8 & 78,8 & 0,9942 \\
\hline arterial & $\operatorname{sim}$ & 95,5 & 83,7 & 77,7 & 77,7 & \\
\hline acometimento de & não & 96,1 & 85,9 & 81,6 & 71,4 & 0,3431 \\
\hline sistema nervoso & psicose & 75,0 & 75,0 & 75,0 & 75,0 & \\
\hline \multirow[t]{2}{*}{ central } & convulsão & 100,0 & 100,0 & 75,0 & 75,0 & \\
\hline & psicose e convulsão & 100,0 & 53,3 & 53,3 & 53,3 & \\
\hline alteração & não & 95,4 & 81,4 & 81,4 & 67,9 & 0,5325 \\
\hline \multirow[t]{4}{*}{ hematológica } & anemia & 100,0 & 75,0 & 75,0 & 75,0 & \\
\hline & leucopenia & 95,8 & 91,0 & 81,9 & 81,9 & \\
\hline & plaquetopenia & 66,7 & 66,7 & 66,7 & 66,7 & \\
\hline & múltiplos & 100,0 & 100,0 & 0,00 & 0,00 & \\
\hline insuficiência & não & 96,3 & 88,1 & 83,5 & 83,5 & 0,0036 \\
\hline renal terminal & $\operatorname{sim}$ & 90,5 & 69,6 & 61,9 & 30,9 & \\
\hline \multirow[t]{2}{*}{ imunossupressor } & não & 92,3 & 77,1 & 73,1 & 73,1 & 0,0508 \\
\hline & sim & 100,0 & 95,5 & 87,5 & 72,9 & \\
\hline \multicolumn{2}{|l|}{ Total } & 90,3 & 79,7 & 74,3 & 66,9 & \\
\hline
\end{tabular}

Embora um pouco acima do nível de significância assumido neste estudo $(\alpha=5 \%)$, as probabilidades de sobrevida acumulada dos portadores de nefrite lúpica conforme o acometimento cárdio-pulmonar foram diferentes entre si $(\mathrm{p}=0,0698$ ). Após 5 anos do diagnóstico da nefrite, a proporção de indivíduos 
portadores de envolvimento no pulmão e coração vivos era de $64,0 \%$, enquanto para os pacientes sem essa alteração a porcentagem de vivos era de $87,9 \%$. Essas proporcões de vivos eram, respectivamente, $71,1 \%$, quando o acomentimento era só no pulmão, e 100,0\%, quando o acometimento era só no coração. Essas diferenças são praticamente as mesmas ao longo do seguimento, como se observa pelo gráfico 46. Novamente aqui, o envolvimento no coração e pulmão conjuntamente influencia na redução da sobrevida dos pacientes com nefrite, em análise univariada.

Gráfico 46. Prob. de sobrevida acumulada dos pacientes

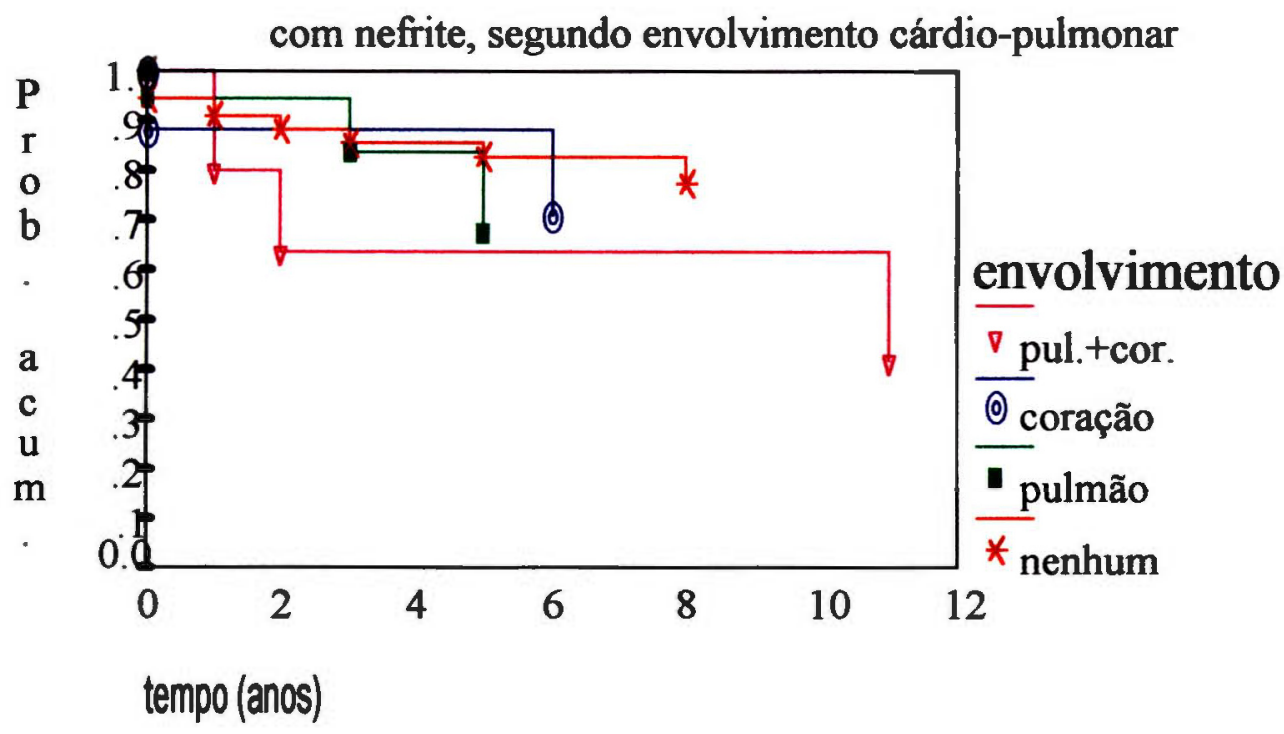

A presença de IRT também foi um fator que alterou a sobrevida global de um paciente com nefrite ( $\mathrm{p}=0,0036)$. Após 10 anos do diagnóstico da nefrite, a porcentagem de pacientes vivos dentre aqueles que adquiriram IRT era de $61,9 \%$ e a dos que não adquiriram IRT era $83,5 \%$ (gráfico 47 ). 


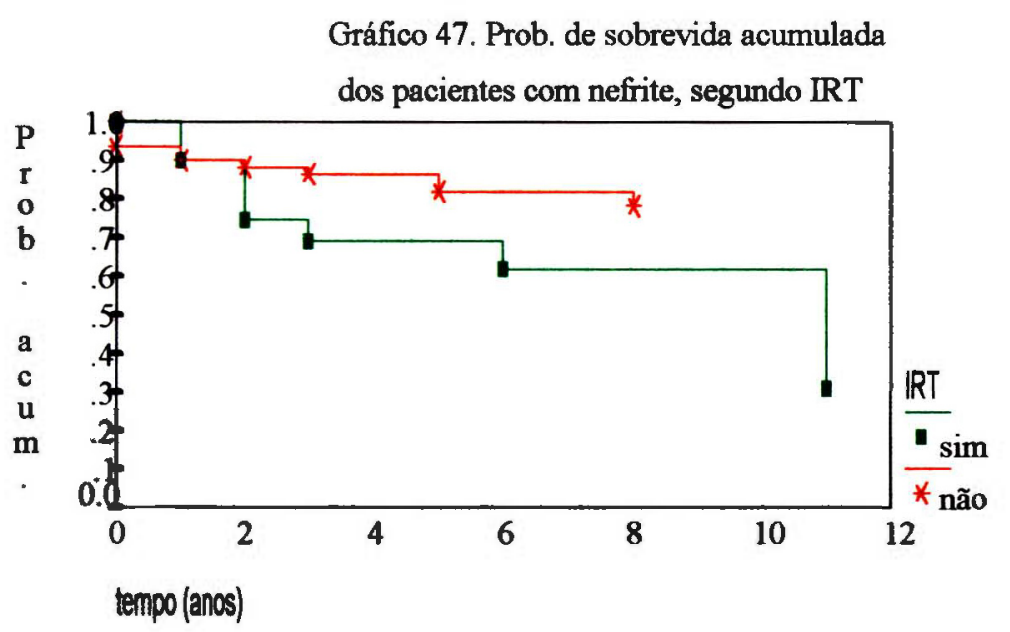

A utilização de imunossupressor também influenciou na sobrevida de um paciente com nefrite, embora um pouco acima do nível de significância estatística definido $(\mathrm{p}=0,0508)$. Conclue-se que a probabilidade de sobrevida de um paciente com nefrite que venha a tomar imunossupressor será sempre superior à daquele que não fará uso do medicamento (gráfico 48).

Gráfico 48. Prob. de sobrevida acumulada dos pacientes

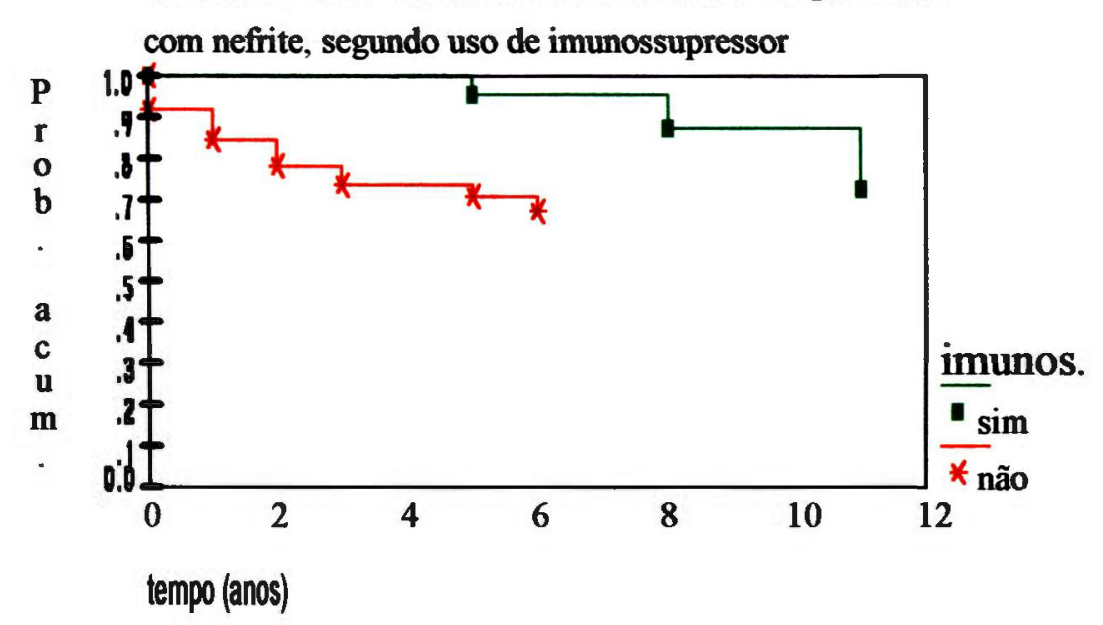


A tabela 29 apresenta as probabilidades de sobrevida acumulada dos pacientes com nefrite, segundo as alterações imunológicas laboratoriais. Para todas essas condições não foram detectadas diferenças estatisticamente significantes.

Tabela 29. Probabilidade de sobrevida acumulada dos pacientes com nefrite calculadas pelo método de Kaplan-Meier, segundo as alterações imunológicas laboratoriais. Clínica de Reumatologia do Hospital Heliópolis. São Paulo - 1978 a 1995

\begin{tabular}{|c|c|c|c|c|c|c|}
\hline \multirow{2}{*}{ Variável } & \multirow{2}{*}{ categoria } & \multicolumn{3}{|c|}{ prob. sobrevida acumulada } & \multirow{2}{*}{\begin{tabular}{|l|}
$(\%)$ \\
15 anos \\
\end{tabular}} & \multirow{2}{*}{$\begin{array}{l}\log \text { rank } \\
\text { (p) }\end{array}$} \\
\hline & & 1 ano & $5 \operatorname{anos}$ & 10 anos & & \\
\hline anti DNA & $\begin{array}{l}\text { negativo } \\
\text { positivo }\end{array}$ & $\begin{array}{l}91,7 \\
97,7\end{array}$ & $\begin{array}{l}83,1 \\
86,1\end{array}$ & $\begin{array}{l}77,1 \\
80,0\end{array}$ & $\begin{array}{l}61,7 \\
80,0\end{array}$ & 0,7014 \\
\hline anti-Sm & $\begin{array}{l}\text { negativo } \\
\text { positivo }\end{array}$ & $\begin{array}{l}97,5 \\
95,5\end{array}$ & $\begin{array}{l}88,9 \\
82,6\end{array}$ & $\begin{array}{l}88,9 \\
55,1\end{array}$ & $\begin{array}{l}66,7 \\
55,1\end{array}$ & 0,3214 \\
\hline anti-RNP & $\begin{array}{l}\text { negativo } \\
\text { positivo }\end{array}$ & $\begin{array}{r}100,0 \\
90,5\end{array}$ & $\begin{array}{l}88,4 \\
84,0\end{array}$ & $\begin{array}{l}79,6 \\
84,0\end{array}$ & $\begin{array}{l}53,0 \\
84,0\end{array}$ & 0,9730 \\
\hline anti-SSA & $\begin{array}{l}\text { negativo } \\
\text { positivo }\end{array}$ & $\begin{array}{r}100,0 \\
95,0\end{array}$ & $\begin{array}{l}88,0 \\
84,4\end{array}$ & $\begin{array}{l}88,0 \\
67,6\end{array}$ & $\begin{array}{l}44,0 \\
67,6\end{array}$ & 0,5727 \\
\hline anti-SSB & $\begin{array}{l}\text { negativo } \\
\text { positivo }\end{array}$ & $\begin{array}{r}97,3 \\
100,0\end{array}$ & $\begin{array}{r}85,3 \\
100,0\end{array}$ & $\begin{array}{r}76,8 \\
100,0\end{array}$ & $\begin{array}{r}51,2 \\
100,0\end{array}$ & 0,4830 \\
\hline Células LE & $\begin{array}{l}\text { negativo } \\
\text { positivo }\end{array}$ & $\begin{array}{l}95,2 \\
95,5\end{array}$ & $\begin{array}{l}80,2 \\
83,3\end{array}$ & $\begin{array}{l}66,8 \\
83,3\end{array}$ & $\begin{array}{l}33,4 \\
83,3\end{array}$ & 0,3421 \\
\hline Total & & 90,3 & 79,7 & 74,3 & 66,9 & \\
\hline
\end{tabular}

Relativamente aos resultados da análise para os fatores prognósticos do óbito dos pacientes com nefrite lúpica, na tabela 30 podem ser apreciados os achados da análise univariada pelo modelo de Cox. 
Tabela 30. Análise univariada dos fatores de risco dos pacientes com nefrite, através do modelo de riscos proporcionais de Cox. Clínica de Reumatologia do Hospital Heliópolis. São Paulo 1978 a 1995

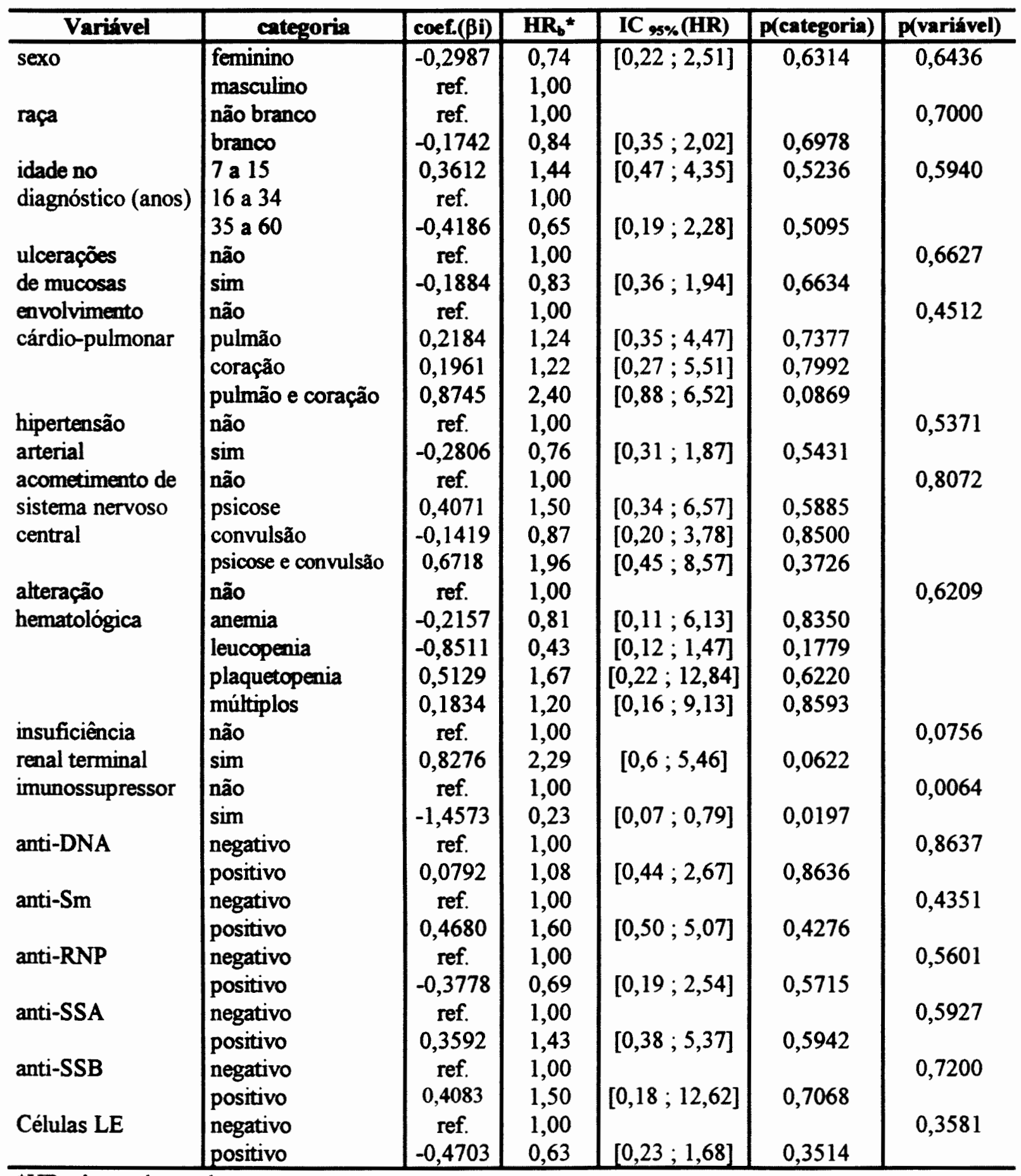

${ }^{*} \mathrm{HR}_{\mathrm{b}}$ : hazard ratio bruta

As variáveis escolhidas para a modelagem multivariada foram: uso de imunossupressor $(p=0,0064)$, insuficiência renal terminal $(p=0,0756)$, 
envolvimento cárdio-pulmonar ( $\mathrm{p}=0,4512)$, hipertensão arterial $(\mathrm{p}=0,5371)$, idade de início do diagnóstico $(\mathrm{p}=0,5940)$, alterações hematológicas $(\mathrm{p}=0,6209)$, sexo $(p=0,6436)$ e acometimento do sistema nervoso central $(p=0,8072)$, sendo essa a ordem de entrada no modelo. As alterações imunológicas laboratoriais não foram testadas na análise multivariada, pois acarretariam a exclusão de muitos casos (os pacientes que não realizaram o exame) e não foram estatisticamente significantes na análise univariada.

Iniciou-se o modelo multivariado com o uso de imunossupressor e, a seguir, acrescentou-se a IRT. A decisão foi manter as duas variáveis no modelo, pois ambas foram estatisticamente significantes. Não se observou efeito de confusão entre as duas e, por isso, não foi testada a interação. Depois foram acrescentadas, uma a uma, as seguintes variáveis: envolvimento cárdio-pulmonar, hipertensão arterial sistêmica, idade ao diagnóstico, alterações hematológicas, sexo e acometimento de sistema nervoso central. Nenhuma dessas variáveis foi mantida no modelo multivariado, pois não foram estatisticamente significantes, não melhoraram a precisão do modelo e não foram variáveis de confusão.

A tabela 31 apresenta o modelo multivariado final dos fatores de risco para o óbito dos pacientes com nefrite.

Tabela 31. Modelo multivariado final dos fatores de risco para o óbito dos pacientes com nefrite lúpica, através do modelo de riscos proporcionais de Cox. Clínica de Reumatologia do Hospital Heliópolis. São Paulo - 1978 a 1995

\begin{tabular}{|c|c|c|c|c|c|c|}
\hline Variável & categoria & coef.( $\beta \mathrm{i})$ & $H R^{\star}{ }_{\text {brata }}$ & $\mathrm{HR}^{\star}$ inmada & IC $_{95 \%}$ (HRa) & p(variável) \\
\hline $\begin{array}{l}\text { insuficiência } \\
\text { renal terminal }\end{array}$ & $\begin{array}{l}\text { não } \\
\text { sim }\end{array}$ & $\begin{array}{l}\text { ref. } \\
1,0136\end{array}$ & $\begin{array}{l}1,00 \\
2,29\end{array}$ & $\begin{array}{l}1,00 \\
2,75\end{array}$ & {$[1,12 ; 6,80]$} & 0,0258 \\
\hline imunossupressor & $\begin{array}{l}\text { não } \\
\text { sim }\end{array}$ & $\begin{array}{c}\text { ref. } \\
-1,4144\end{array}$ & $\begin{array}{l}1,00 \\
0,23\end{array}$ & $\begin{array}{l}1,00 \\
0,24\end{array}$ & {$[0,07 ; 0,84]$} & 0,0279 \\
\hline
\end{tabular}

*HR: hazard ratio

significância do modelo final : $\mathrm{p} \rightarrow 0,0060$ 
Os fatores prognósticos significantes para o óbito de um paciente com nefrite lúpica foram a utilização de imunossupressor e a presença de IRT. A razão de riscos para o óbito entre os pacientes com nefrite que usaram imunossupressor e os que não fizeram uso desse medicamento foi de 0,24 (IC $=[0,07 ; 0,84])$; a razão de riscos de óbito de pacientes com nefrite e IRT e os sem essa última complicação é 2,75 (IC $=[1,12 ; 6,80])$

Efetivamente, a utilização de imunossupressor na nefrite protegeu esses pacientes para o óbito. É sabido que essa terapêutica protege o rim, postergando a evolução para a IRT ${ }^{28,82}$. A proteção ao óbito novamente poderia ser explicada pelo efeito poupador de corticosteróides, bem como pela eficácia terapêutica da droga. Conclue-se, novamente, que a IRT é um fator de risco para o óbito, também nos pacientes com nefrite clínica.

Relacionados estes achados aos encontrados na análise de sobrevida com o total de pacientes, nota-se que a insuficiência renal terminal é fator de risco para o óbito, na mesma ordem de grandeza, tanto no total de pacientes $(H R=2,73)$, como nos pacientes com nefrite $(H R=2,75)$. Já o uso de imunossupressor apresenta um valor de proteção maior nos pacientes com nefrite $(H R=0,24)$ do que para o total de pacientes $(\mathrm{HR}=0,45)$. O envolvimento cárdio-pulmonar só foi importante para o óbito no total de pacientes, não tendo sido detectada tal significância na análise multivariada dos pacientes com nefrite. O pequeno número de óbitos ocorrido nos pacientes com nefrite e com envolvimento cárdiopulmonar, talvez, explique esse fato. 


\subsection{Análise de sobrevida até o desenvolvimento de insuficiência renal terminal (IRT) dos pacientes com nefrite lúpica}

Neste ítem foram estudados os 118 pacientes com nefrite lúpica em relação à ocorrência de IRT e aos fatores relacionados à sobrevida renal, pois essa análise se refere ao período compreendido entre a data de diagnóstico da nefrite até a ocorrência de IRT.

A tabela 32 apresenta as distribuições de frequêencia dos 118 pacientes com nefrite lúpica, segundo a presença de IRT e as características demográficas. Observa-se que não houve associação estatisticamente significante entre a presença de IRT em pacientes com nefrite, e o sexo ou a raça (respectivamente, $\mathrm{p}=0,6534$ e $\mathrm{p}=0,8011$ ). Porém, ao se analisar a variável "idade", ela esteve associada à presença de IRT. Dos pacientes com nefrite, cujo diagnóstico de LES foi feito até 15 anos, $41,7 \%$ apresentaram IRT, enquanto que nas outras faixas etárias essa porcentagem foi de 7,7\% e 17,5\%, respectivamente, para aqueles pacientes entre 16 e 34 anos e de 35 a 60 anos no momento do diagnóstico (gráfico 49). Esses achados concordam com vários autores, relativamente, à associação de início do LES na criança com um mau prognóstico renal $^{10,11,70}$.

Tabela 32. Distribuições dos pacientes com nefrite lúpica, segundo a ocorrência de IRT e as características demográficas. Clínica de Reumatologia do Hospital Heliópolis. São Paulo - 1978 a 1995

\begin{tabular}{|c|c|c|c|c|c|c|c|c|}
\hline \multirow[t]{2}{*}{ Variável } & \multirow[t]{2}{*}{ categoria } & \multicolumn{2}{|c|}{ censura } & \multicolumn{2}{|c|}{ IRT } & \multicolumn{2}{|c|}{ Total } & \multirow{2}{*}{$\begin{array}{l}\text { valor } \\
\text { de } p^{*}\end{array}$} \\
\hline & & $\mathbf{n}^{\circ}$ & $\%$ & $\mathbf{n}^{\circ}$ & $\%$ & $n^{\circ}$ & $\%$ & \\
\hline Sexo & $\begin{array}{l}\text { feminino } \\
\text { masculino }\end{array}$ & $\begin{array}{r}89 \\
8\end{array}$ & $\begin{array}{l}83,2 \\
72,7\end{array}$ & $\begin{array}{r}18 \\
3\end{array}$ & $\begin{array}{l}16,8 \\
27,3\end{array}$ & $\begin{array}{r}107 \\
11\end{array}$ & $\begin{array}{l}100,0 \\
100,0\end{array}$ & 0,6534 \\
\hline Raça & $\begin{array}{l}\text { não branco } \\
\text { branco }\end{array}$ & $\begin{array}{l}38 \\
59\end{array}$ & $\begin{array}{l}84,4 \\
80,8\end{array}$ & $\begin{array}{r}7 \\
14\end{array}$ & $\begin{array}{l}15,6 \\
19,2\end{array}$ & $\begin{array}{l}45 \\
73\end{array}$ & $\begin{array}{l}100,0 \\
100,0\end{array}$ & 0,8011 \\
\hline $\begin{array}{l}\text { Idade no } \\
\text { diagnóstico } \\
(\text { anos) }\end{array}$ & $\begin{array}{l}7 \text { a } 15 \\
16 \text { a } 34 \\
35 \text { a } 60\end{array}$ & $\begin{array}{r}7 \\
24 \\
66\end{array}$ & $\begin{array}{l}58,3 \\
92,3 \\
82,5\end{array}$ & $\begin{array}{r}5 \\
2 \\
14\end{array}$ & $\begin{array}{r}41,7 \\
7,7 \\
17,5\end{array}$ & $\begin{array}{l}12 \\
26 \\
80\end{array}$ & $\begin{array}{l}100,0 \\
100,0 \\
100,0\end{array}$ & 0,0389 \\
\hline Total & & 97 & 82,2 & 21 & 17,8 & 118 & 100,0 & \\
\hline
\end{tabular}

${ }^{*}$ p: nível descritivo do teste de associação pelo $\chi^{2}$. 
Grefico 49. Porcentagem de pocientes com nefrite húpica e IRT, segundo faixa etaria

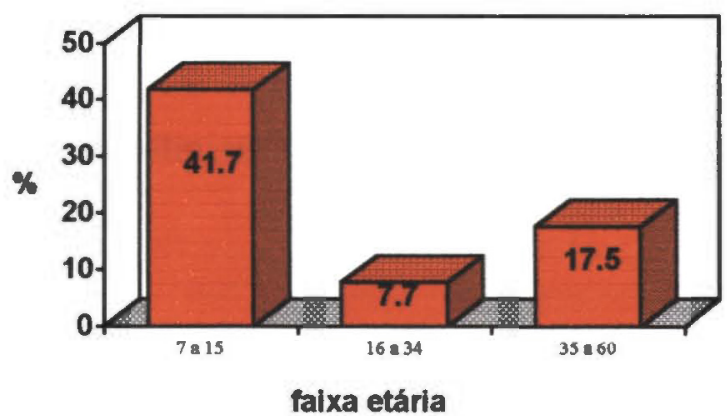

Na tabela 33 podem ser verificadas as distribuições de pacientes com nefrite lúpica, segundo a presença de IRT e as variáveis clínicas e laboratoriais; para nenhuma delas foi detectada associação estatisticamente significante com a presença de IRT.

Tabela 33. Distribuições de pacientes com nefrite lúpica, segundo a presença de IRT e as variáveis clínicas e laboratoriais. Clínica de Reumatologia do Hospital Heliópolis. São Paulo 1978 a 1995

\begin{tabular}{|c|c|c|c|c|c|c|c|c|}
\hline \multirow[t]{2}{*}{ Variável } & \multirow[t]{2}{*}{ categoria } & \multicolumn{2}{|c|}{ censura } & \multicolumn{2}{|c|}{ IRT } & \multicolumn{2}{|c|}{ Total } & \multirow{2}{*}{$\begin{array}{l}\text { valor } \\
\text { de } p^{*}\end{array}$} \\
\hline & & $\mathrm{n}^{\circ}$ & $\%$ & $n^{\circ}$ & $\%$ & $\mathrm{n}^{\circ}$ & $\%$ & \\
\hline $\begin{array}{l}\text { ulcerações } \\
\text { de mucosas }\end{array}$ & $\begin{array}{l}\text { não } \\
\text { sim }\end{array}$ & $\begin{array}{l}53 \\
44\end{array}$ & $\begin{array}{l}84,1 \\
80,0\end{array}$ & $\begin{array}{l}10 \\
11\end{array}$ & \begin{tabular}{l|}
15,9 \\
20,0
\end{tabular} & $\begin{array}{l}63 \\
55\end{array}$ & $\begin{array}{l}100,0 \\
100,0\end{array}$ & 0,7313 \\
\hline $\begin{array}{l}\text { envolvimento } \\
\text { cárdio-pulmonar }\end{array}$ & $\begin{array}{l}\text { não } \\
\text { pulmão } \\
\text { coração } \\
\text { pulmão e coração }\end{array}$ & $\begin{array}{r}61 \\
18 \\
8 \\
10\end{array}$ & $\begin{array}{l}82,4 \\
94,7 \\
88,9 \\
62,5\end{array}$ & $\begin{array}{r}13 \\
1 \\
1 \\
6\end{array}$ & $\begin{array}{r}17,6 \\
5,3 \\
11,1 \\
37,5\end{array}$ & $\begin{array}{r}74 \\
19 \\
9 \\
16\end{array}$ & $\begin{array}{l}100,0 \\
100,0 \\
100,0 \\
100,0\end{array}$ & 0,0872 \\
\hline $\begin{array}{l}\text { hipertensão } \\
\text { arterial }\end{array}$ & $\begin{array}{l}\text { não } \\
\text { sim }\end{array}$ & $\begin{array}{l}62 \\
35\end{array}$ & $\begin{array}{l}87,3 \\
74,5\end{array}$ & $\begin{array}{r}9 \\
12\end{array}$ & $\begin{array}{l}12,7 \\
25,5\end{array}$ & $\begin{array}{l}71 \\
47\end{array}$ & $\begin{array}{l}100,0 \\
100,0\end{array}$ & 0,1232 \\
\hline $\begin{array}{l}\text { acometimento de } \\
\text { sistema nervoso } \\
\text { central }\end{array}$ & $\begin{array}{l}\text { não } \\
\text { psicose } \\
\text { convulsão } \\
\text { psicose e convulsão }\end{array}$ & $\begin{array}{r}74 \\
7 \\
11 \\
5\end{array}$ & $\begin{array}{r}82,2 \\
77,8 \\
78,6 \\
100,0\end{array}$ & $\begin{array}{r}16 \\
2 \\
3 \\
-\end{array}$ & $\begin{array}{r}17,8 \\
22,2 \\
21,4 \\
-\end{array}$ & $\begin{array}{r}90 \\
9 \\
14 \\
5\end{array}$ & $\begin{array}{l}100,0 \\
100,0 \\
100,0 \\
100,0\end{array}$ & 0,7222 \\
\hline $\begin{array}{l}\text { alterações } \\
\text { hematológicas }\end{array}$ & $\begin{array}{l}\text { não } \\
\text { anemia } \\
\text { leucopenia } \\
\text { plaquetopenia } \\
\text { múltiplos }\end{array}$ & $\begin{array}{r}63 \\
3 \\
25 \\
3 \\
3\end{array}$ & $\begin{array}{l}82,9 \\
50,0 \\
92,6 \\
60,0 \\
75,0\end{array}$ & $\begin{array}{r}13 \\
3 \\
2 \\
2 \\
1\end{array}$ & $\begin{array}{r}17,1 \\
50,0 \\
7,4 \\
40,0 \\
25,0\end{array}$ & $\begin{array}{r}76 \\
6 \\
27 \\
5 \\
4\end{array}$ & $\begin{array}{l}100,0 \\
100,0 \\
100,0 \\
100,0 \\
100,0\end{array}$ & 0,0880 \\
\hline imunossupressor & $\begin{array}{l}\text { não } \\
\text { sim }\end{array}$ & $\begin{array}{l}64 \\
33 \\
\end{array}$ & $\begin{array}{l}81,0 \\
84,6 \\
\end{array}$ & $\begin{array}{r}15 \\
6 \\
\end{array}$ & $\begin{array}{l}19,0 \\
15,4 \\
\end{array}$ & $\begin{array}{r}79 \\
39 \\
\end{array}$ & $\begin{array}{l}100,0 \\
100,0 \\
\end{array}$ & 0,8216 \\
\hline Total & & 97 & 82,2 & 21 & 17,8 & 118 & 100,0 & \\
\hline
\end{tabular}

*p: nivel descritivo do teste de associação pelo $\chi^{2}$. 
A tabela 34 apresenta as distribuições dos pacientes com nefrite lúpica, segundo a presença de IRT e as alterações imunológicas laboratoriais; também aqui nenhuma associação estatisticamente significante foi encontrada entre elas e a presença de IRT.

Tabela 34. Distribuição de pacientes com nefrite lúpica, segundo a presença de IRT e as alterações imunológicas laboratoriais.Clínica de Reumatologia do Hospital Heliópolis.São Paulo -1978 a 1995

\begin{tabular}{|c|c|c|c|c|c|c|c|c|}
\hline \multirow[t]{2}{*}{ Variável } & \multirow[t]{2}{*}{ categoria } & \multicolumn{2}{|c|}{ censura } & \multicolumn{2}{|c|}{ IRT } & \multicolumn{2}{|c|}{ Total } & \multirow{2}{*}{$\begin{array}{l}\text { valor } \\
\text { de } p^{*}\end{array}$} \\
\hline & & $n^{\circ}$ & $\%$ & $\mathrm{n}^{\circ}$ & $\%$ & $n^{\circ}$ & $\%$ & \\
\hline \multirow[t]{3}{*}{ anti DNA } & negativo & 42 & 77,8 & 12 & 22,2 & 54 & 100,0 & 0,6128 \\
\hline & positivo & 41 & 83,7 & 8 & 16,3 & 49 & 100,0 & \\
\hline & não realizado & 14 & 93,3 & 1 & 6,7 & 15 & 100,0 & \\
\hline \multirow[t]{3}{*}{ anti-Sm } & negativo & 36 & 81,8 & 8 & 18,2 & 44 & 100,0 & 1,0000 \\
\hline & positivo & 20 & 83,3 & 4 & 16,7 & 24 & 100,0 & \\
\hline & não realizado & 41 & 82,0 & 9 & 18,0 & 50 & 100,0 & \\
\hline \multirow[t]{3}{*}{ anti-RNP } & negativo & 37 & 80,4 & 9 & 19,6 & 46 & 100,0 & 0,7379 \\
\hline & positivo & 19 & 86,4 & 3 & 13,6 & 22 & 100,0 & \\
\hline & não realizado & 41 & 82,0 & 9 & 18,0 & 50 & 100,0 & \\
\hline \multirow[t]{3}{*}{ anti-SSA } & negativo & 17 & 70,8 & 7 & 29,2 & 24 & 100,0 & 0,1420 \\
\hline & positivo & 19 & 90,5 & 2 & 9,5 & 21 & 100,0 & \\
\hline & não realizado & 61 & 83,6 & 12 & 16,4 & 73 & 100,0 & \\
\hline \multirow[t]{3}{*}{ anti-SSB } & negativo & 30 & 76,9 & 9 & 23,1 & 39 & 100,0 & 0,3231 \\
\hline & positivo & 6 & 100,0 & - & & 6 & 100,0 & \\
\hline & não realizado & 61 & 83,6 & 12 & 16,4 & 73 & 100,0 & \\
\hline \multirow[t]{3}{*}{ Células LE } & negativo & 19 & 76,0 & 6 & 24,0 & 25 & 100,0 & 0,8870 \\
\hline & positivo & 38 & 77,6 & 11 & 22,4 & 49 & 100,0 & \\
\hline & não realizado & 40 & 90,9 & 4 & 9,1 & 44 & 100,0 & \\
\hline \multicolumn{2}{|l|}{ Total } & $\overline{97}$ & 82,2 & 21 & 17,8 & 118 & 100,0 & \\
\hline
\end{tabular}

*p: nível descritivo do teste de associação pelo $\chi^{2}$. Para a realização do teste foi excluída a categoria "não realizado".

Os resultados da análise de sobrevida até a ocorrência de IRT para os pacientes que desenvolveram nefrite lúpica estão na tabela 35, mostrando, ainda, a probabilidade de sobrevida acumulada calculada pelo método da Kaplan-Meier, para as caracteristicas clínicas desses pacientes. A sobrevida renal total 
acumulada foi de $91,3 \%$ após um ano da nefrite, $81,9 \%$ após 5 anos, 69,4\% após 10 anos e 61,7\% após 12 anos (gráfico 50).

Tabela 35. Probabilidade de sobrevida acumulada para IRT nos pacientes com nefrite lúpica, calculada pelo método de Kaplan-Meier, segundo as características demográficas. Clínica de Reumatologia do Hospital Heliópolis. São Paulo - 1978 a 1995

\begin{tabular}{|c|c|c|c|c|c|c|}
\hline \multirow[t]{2}{*}{ Variável } & \multirow[t]{2}{*}{ categoria } & \multicolumn{4}{|c|}{$\begin{array}{l}\text { prob. sobrevida acumulada } \quad \text { (\%) } \\
\end{array}$} & \multirow{2}{*}{$\begin{array}{l}\text { log rank } \\
\text { (p) }\end{array}$} \\
\hline & & 1 ano & 5 anos & 10 anos & 12 anos & \\
\hline Sexo & $\begin{array}{l}\text { feminino } \\
\text { masculino }\end{array}$ & $\begin{array}{l}93,4 \\
80,0\end{array}$ & $\begin{array}{l}82,7 \\
80,0\end{array}$ & $\begin{array}{l}70,4 \\
64,0\end{array}$ & $\begin{array}{l}61,6 \\
64,0\end{array}$ & 0,6112 \\
\hline Raça & $\begin{array}{l}\text { não branco } \\
\text { branco }\end{array}$ & $\begin{array}{l}92,1 \\
92,1\end{array}$ & $\begin{array}{l}79,0 \\
84,3\end{array}$ & $\begin{array}{l}67,7 \\
73,2\end{array}$ & $\begin{array}{l}67,7 \\
64,1\end{array}$ & 0,7615 \\
\hline $\begin{array}{l}\text { Idade no } \\
\text { diagnóstico } \\
\text { (anos) }\end{array}$ & $\begin{array}{l}7 \text { a } 15 \\
16 \text { a } 34 \\
35 \text { a } 60 \\
\end{array}$ & $\begin{array}{r}100,0 \\
89,6 \\
95,8 \\
\end{array}$ & $\begin{array}{l}78,8 \\
79,5 \\
95,8 \\
\end{array}$ & $\begin{array}{l}59,1 \\
69,7 \\
71,9 \\
\end{array}$ & $\begin{array}{l}39,4 \\
69,7 \\
71,9 \\
\end{array}$ & 0,3737 \\
\hline Total & & 91,3 & 81,9 & 69,4 & 61,7 & \\
\hline
\end{tabular}

Gráfico 50. Prob. de sobrevida acumulada para IRT, nos pacientes com nefrite

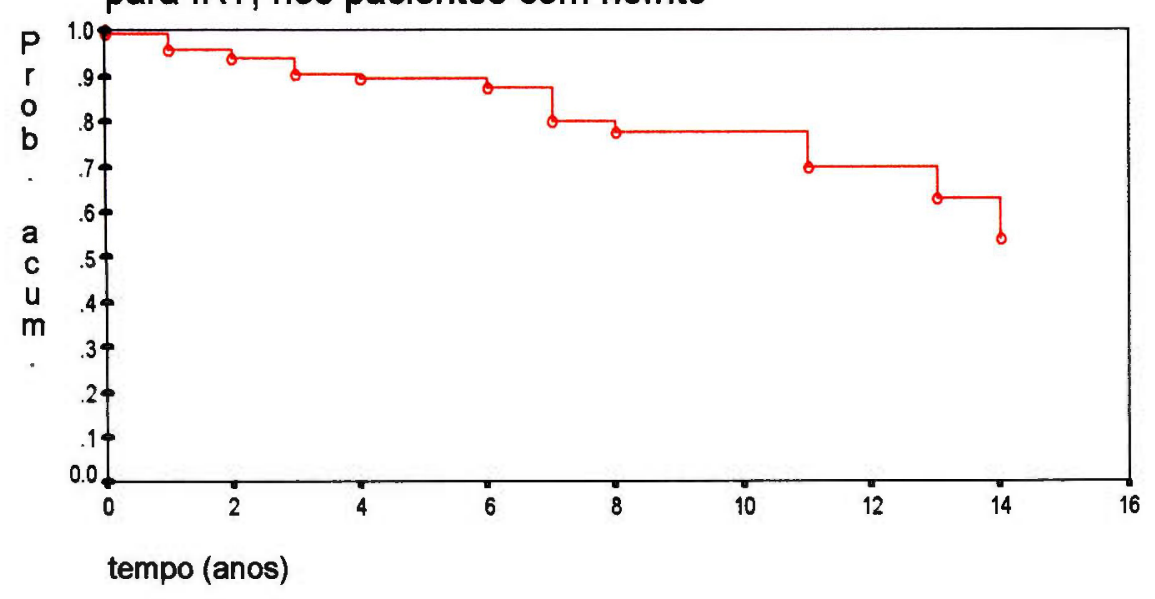

Tanto para a variável "sexo" quanto para raça não foram detectadas diferenças estatisticamente significantes entre as curvas de probabilidade de sobrevida renal acumulada (respectivamente, $\mathrm{p}=0,6112$ e $\mathrm{p}=0,7615$ ). $\mathrm{O}$ mesmo aconteceu com a idade, embora, nesta amostra, os pacientes mais jovens tenham 
tido sempre sobrevida renal inferior quando comparada com a dos pacientes entre 16 e 34 anos e de 35 a 60 anos (gráfico 51). Após 5 anos do diagnóstico da nefrite, a proporção de indivíduos entre 35 e 60 anos sem ter tido IRT era de $95,8 \%$ e de $79,5 \%$ e $78,8 \%$ respectivamente para aqueles entre 16 e 34 anos e entre 7 e 15 anos. Após 10 e 12 anos de seguimento, a partir do diagnóstico da nefrite, as diferenças se acentuam; assim, dos pacientes mais velhos, $71,9 \%$ não apresentaram IRT (em ambos os tempos); dos pacientes entre 16 e 34 anos, 69,7\% não desenvolveram IRT. Entre os pacientes mais jovens, as proporções dos que não apresentaram IRT foram, respectivamente, iguais a $59,1 \%$ e $39,4 \%$, para sobrevida renal de 10 e 12 anos.

\section{Gráfico 51. Prob. de sobrevida acumulada}

para IRT dos pac. com nefrite, segundo idade

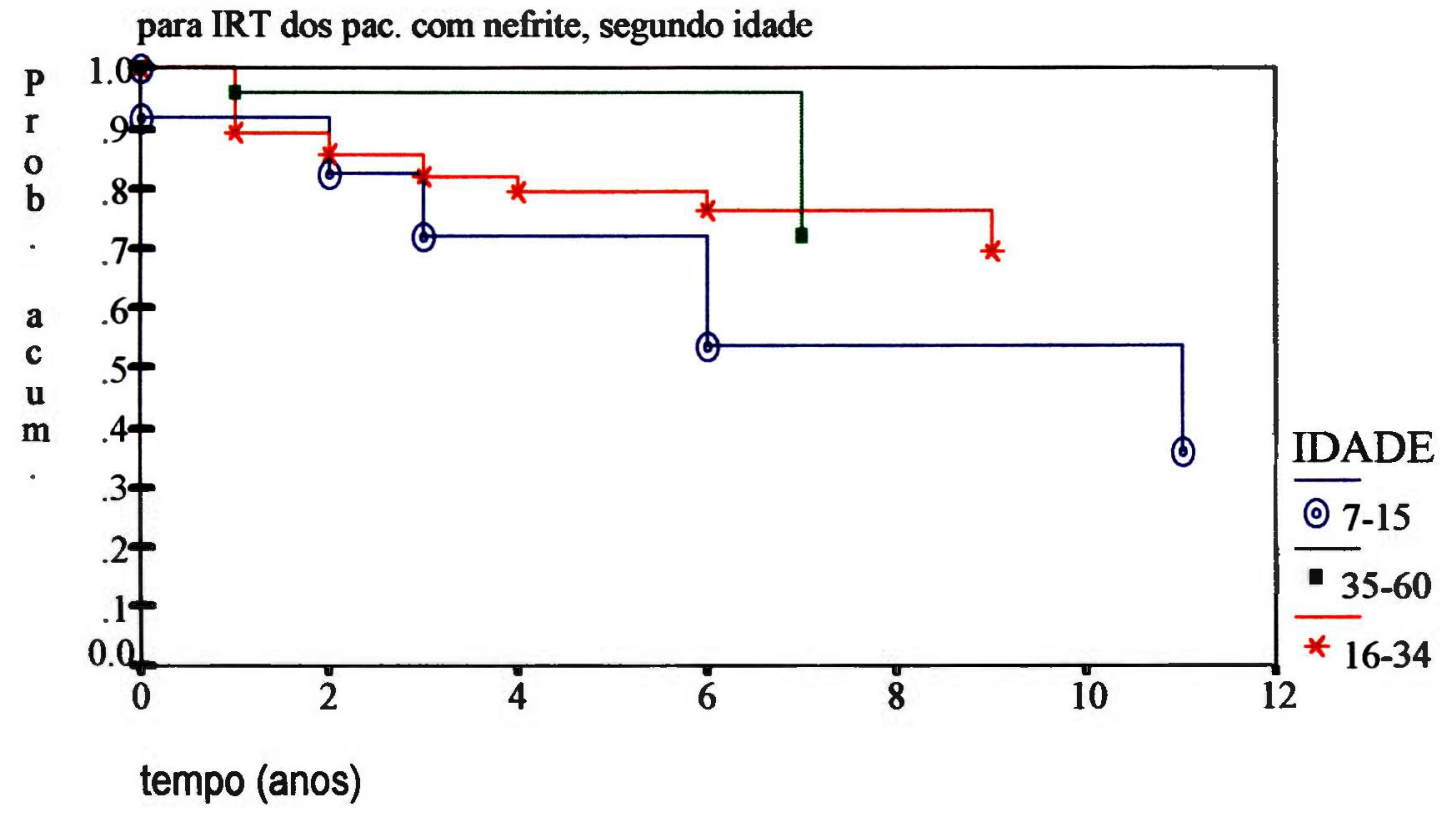

A tabela 36 mostra a análise da sobrevida até a ocorrência da IRT nos pacientes com nefrite lúpica, segundo as variáveis clínicas e laboratoriais.

Tanto a presença de ulcerações de mucosas, quanto o envolvimento cárdio-pulmonar ou o acometimento do sistema nervoso central não propiciaram estimativas de probabilidade acumulada diferentes de desenvolver IRT. Embora 
não fosse detectada significância estatística, a presença de hipertensão arterial sistêmica (HAS) mostrou curva de probabilidade de sobrevida acumulada acima da dos indivíduos que não apresentaram esse agravo (gráfico 52). Após 10 anos do diagnóstico da nefrite, 45,6\% dos indivíduos com HAS não tinham IRT, contra $85,1 \%$ dos que não tinham HAS. Essas porcentagens permaneceram constantes até os 12 anos de acompanhamento. A hipertensão arterial parece se comportar como risco após 5 anos do desenvolvimento da nefrite, em análise univariada, confirmando os achados de alguns autores que consideram comportamento diferente do LES nos primeiros anos da doença e após 5 anos do diagnóstico, com complicações crônicas mais tardiamente na evolução da mesma $^{1,92}$.

Tabela 36. Probabilidade de sobrevida acumulada até a IRT nos pacientes com nefrite lúpica, calculada pelo método de Kaplan-Meier, segundo as variáveis clínicas e laboratoriais. Clínica de Reumatologia do Hospital Heliópolis. São Paulo - 1978 a 1995

\begin{tabular}{|c|c|c|c|c|c|c|}
\hline \multirow[t]{2}{*}{ Variável } & \multirow[t]{2}{*}{ categoria } & \multicolumn{4}{|c|}{ prob. sobrevida acumulada (\%) } & \multirow{2}{*}{$\begin{array}{c}\log \text { rank } \\
\text { (p) }\end{array}$} \\
\hline & & 1 ano & 5 anos & 10 anos & 12 anos & \\
\hline ulcerações & não & 94,7 & 81,5 & 70,6 & 70,6 & 0,9741 \\
\hline de mucosas & $\operatorname{sim}$ & 88,6 & 83,1 & 71,1 & 59,2 & \\
\hline envolvimento & não & 92,1 & 83,8 & 68,1 & 68,1 & 0,1178 \\
\hline \multirow[t]{3}{*}{ cárdio-pulmonar } & pulmão & 100,0 & 88,9 & 88,9 & 88,9 & \\
\hline & coração & 100,0 & 100,0 & 80,0 & 80,0 & \\
\hline & pulmão e coração & 80,0 & 58,3 & 58,3 & 29,2 & \\
\hline hipertensão & não & 91,4 & 85,1 & 85,1 & 85,1 & 0,0809 \\
\hline arterial & $\operatorname{sim}$ & 93,0 & 78,2 & 45,6 & 45,6 & \\
\hline acometimento de & não & 92,1 & 81,7 & 72,6 & 62,2 & 0,6180 \\
\hline sistema nervoso & psicose & 75,0 & 75,0 & 75,0 & 75,0 & \\
\hline \multirow{2}{*}{ central } & convulsão & 100,0 & 85,7 & 28,6 & 28,6 & \\
\hline & psicose e convulsão & 100,0 & 100,0 & 100,0 & 100,0 & \\
\hline alteração & não & 92,2 & 83,3 & 70,0 & 56,0 & 0,0021 \\
\hline \multirow[t]{4}{*}{ hematológica } & anemia & 83,3 & 44,4 & 44,4 & 44,4 & \\
\hline & leucopenia & 100,0 & 94,4 & 87,2 & 87,2 & \\
\hline & plaquetopenia & 33,3 & 33,3 & 33,3 & 33,3 & \\
\hline & múltiplos & 100,0 & 100,0 & 0,0 & 0,0 & \\
\hline \multirow[t]{2}{*}{ imunossupressor } & não & 90,6 & 82,0 & 60,9 & 60,9 & 0,3158 \\
\hline & sim & 94,6 & 84,1 & 84,1 & 67,3 & \\
\hline \multicolumn{2}{|l|}{ Total } & 91,3 & 81,9 & 69,4 & 61,7 & \\
\hline
\end{tabular}


Gráfico 52. Prob. de sobrevida acum. para IRT nos pac.

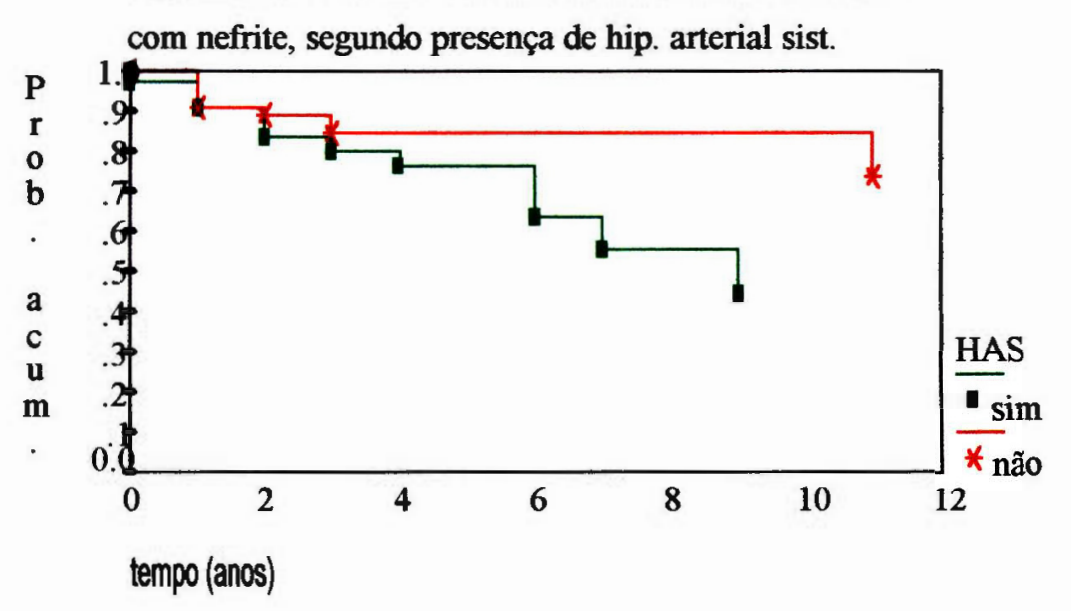

As curvas de probabilidade de sobrevida acumulada para IRT nos pacientes com nefrite, segundo as alterações hematológicas, diferiram estatisticamente $(p=0,0021)$. As maiores estimativas de probabilidades de sobrevida renal foram para os pacientes com leucopenia (gráfico 53). Após 10 anos do diagnóstico da nefrite, entre pacientes sem alteração hematológica, $70 \%$ não apresentava IRT; para pacientes com anemia, esta proporção foi de $44,4 \%$, enquanto que para os pacientes com plaquetopenia, apenas 33,3\% não desenvolveu IRT. Apenas um dos quatro pacientes com múltiplas alterações hematológicas teve tempo de observação completo e esse paciente teve perda da função renal. 
Gráfico 53. Prob. de sobrevida acumulada para IRT nos

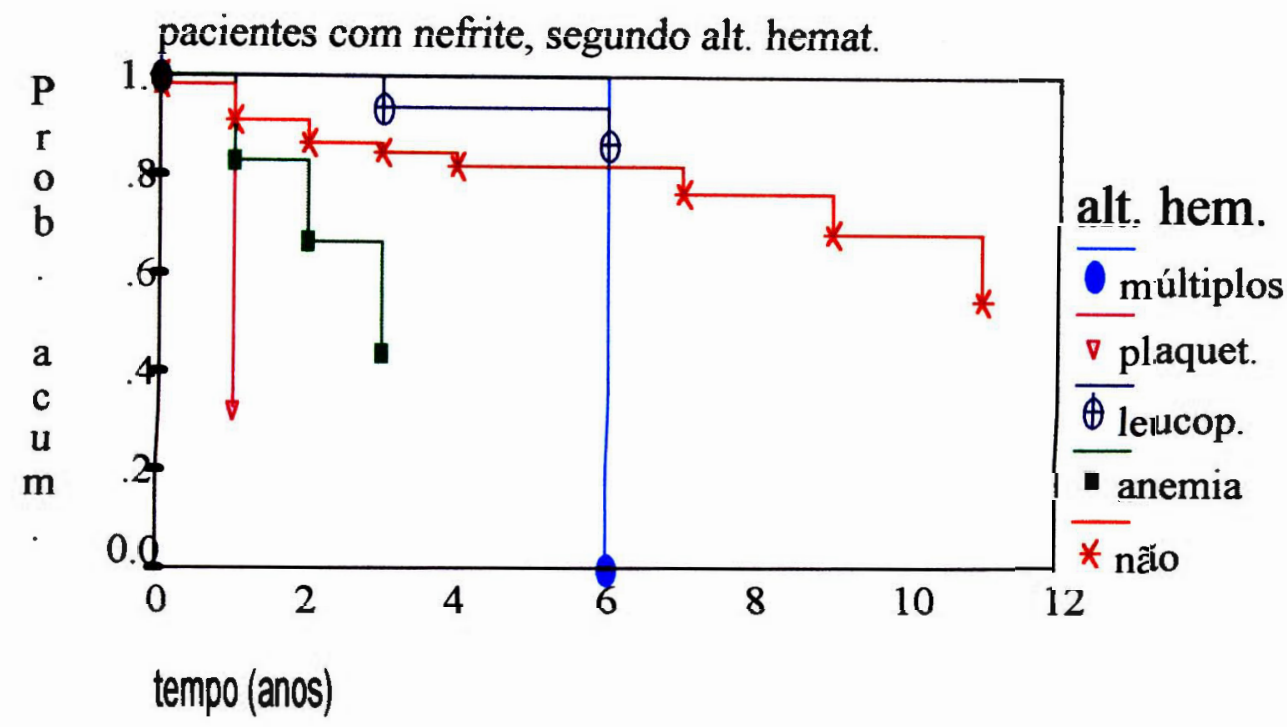

Quanto à utilização de imunossupressor (IS), não foi detectada diferença estatisticamente signicante entre as curvas de probabilidade de sobrevida acumulada na análise pelo método de Kaplan-Meier $(p=0,3158)$. No entanto, os resultados mostraram que aqueles pacientes que não fizeram uso deste medicamento tiveram, no decorrer do seguimento, sobrevida renal inferior à daqueles que utilizaram (gráfico 54). Após 10 anos do diagnóstico da nefrite $60,9 \%$ dos pacientes que não fizeram uso de IS não tiveram IRT, contra $84,1 \%$ daqueles que usaram.

Gráfico 54. Prob. de sobrevida acumulada para IRT nos

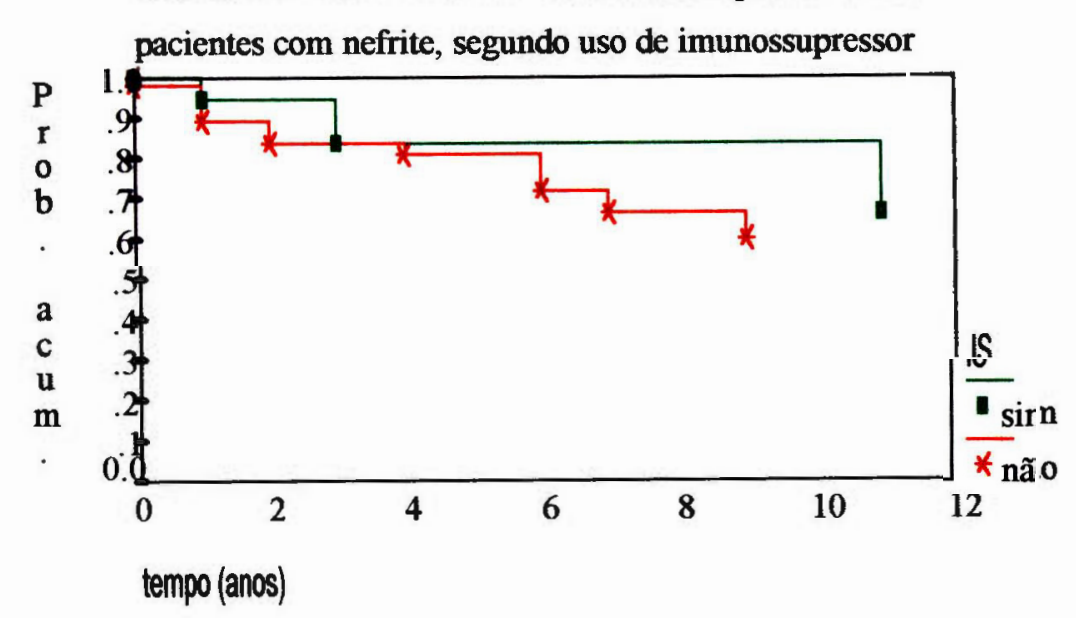


A tabela 37 apresenta as probabilidades de sobrevida acumulada renal dos pacientes com nefrite, segundo as alterações clínicas e laboratoriais. Para todas essas variáveis as probabilidades não diferiram, estatisticamente.

Tabela 37. Probabilidade de sobrevida acumulada para IRT nos pacientes com nefrite lúpica calculadas pelo método de Kaplan-Meier, segundo as alterações imunológicas laboratoriais. Clínica de Reumatologia do Hospital Heliópolis. São Paulo - 1978 a 1995

\begin{tabular}{|c|c|c|c|c|c|c|}
\hline \multirow[t]{2}{*}{ Variável } & \multirow[t]{2}{*}{ categoria } & \multicolumn{4}{|c|}{ prob. sobrevida acumulada (\%) } & \multirow{2}{*}{$\begin{array}{l}\text { log rank } \\
\text { (p) }\end{array}$} \\
\hline & & 1 ano & 5 anos & 10 anos & 12 anos & \\
\hline \multirow[t]{2}{*}{ anti-DNA } & negativo & 91,5 & 80,3 & 67,5 & 54,0 & 0,8224 \\
\hline & positivo & 93,0 & 83,9 & 69,9 & 69,9 & \\
\hline \multirow[t]{2}{*}{ anti-Sm } & negativo & 97,5 & 85,1 & 73,1 & 54,9 & 0,9270 \\
\hline & positivo & 85,7 & 85,7 & 85,7 & 85,7 & \\
\hline \multirow[t]{2}{*}{ anti-RNP } & negativo & 92,5 & 82,8 & 76,9 & 51,3 & 0,6493 \\
\hline & positivo & 95,2 & 88,9 & 71,1 & 71,1 & \\
\hline \multirow[t]{2}{*}{ anti-SSA } & negativo & 90,5 & 77,8 & 64,8 & 32,4 & 0,1522 \\
\hline & positivo & 100,0 & 87,7 & 87,7 & 87,7 & \\
\hline \multirow[t]{2}{*}{ anti-SSB } & negativo & 94,4 & 81,0 & 74,2 & 49,5 & 0,3893 \\
\hline & positivo & 100,0 & 100,0 & 100,0 & 100,0 & \\
\hline \multirow[t]{2}{*}{ Células LE } & negativo & 90,5 & 74,1 & 74,1 & 37,0 & 0,7735 \\
\hline & positivo & 88,6 & 79,5 & 59,5 & 59,5 & \\
\hline \multicolumn{2}{|l|}{ Total } & 91,3 & 81,9 & 69,4 & 61,7 & \\
\hline
\end{tabular}

Na tabela 38 estão apresentados os resultados da análise dos fatores de risco para a sobrevida renal, após o diagnóstico de nefrite, sendo que a análise univariada foi feita pelo modelo de Cox. 
Tabela 38. Análise univariada dos fatores de risco para IRT nos pacientes com nefrite lúpica, através do modelo de riscos proporcionais de Cox. Clínica de Reumatologia do Hospital Heliópolis. São Paulo - 1978 a 1995

\begin{tabular}{|c|c|c|c|c|c|c|}
\hline Variável & categoria & coef.( $\beta$ i) & $\mathrm{HR}_{\mathrm{b}}{ }^{*}$ & IC 95\%(HR) & p(categoria) & p(variável) \\
\hline Sexo & $\begin{array}{l}\text { feminino } \\
\text { masculino }\end{array}$ & $\begin{array}{c}-0,2649 \\
\text { ref. }\end{array}$ & $\begin{array}{l}0,77 \\
1,00\end{array}$ & {$[0,23 ; 2,62]$} & 0,6722 & 0,6817 \\
\hline Raça & $\begin{array}{l}\text { não branco } \\
\text { branco }\end{array}$ & $\begin{array}{c}\text { ref. } \\
-0,0510\end{array}$ & $\begin{array}{l}1,00 \\
0,95\end{array}$ & {$[0,38 ; 2,38]$} & 0,9133 & 0,9135 \\
\hline $\begin{array}{l}\text { Idade no } \\
\text { diagnóstico (anos) }\end{array}$ & $\begin{array}{l}7 \text { a } 15 \\
16 \text { a } 34\end{array}$ & $\begin{array}{c}0,6523 \\
\text { ref. }\end{array}$ & $\begin{array}{l}1,92 \\
1,00\end{array}$ & {$[0,69 ; 5,38]$} & 0,2148 & 0,2054 \\
\hline ulcerações & $\begin{array}{l}35 \text { a } 60 \\
\text { não }\end{array}$ & $\begin{array}{c}-0,7618 \\
\text { ref. }\end{array}$ & $\begin{array}{l}0,47 \\
1,00\end{array}$ & {$[0,11 ; 2,06]$} & 0,3147 & 0,8377 \\
\hline & $\begin{array}{l}\text { sim } \\
\text { não }\end{array}$ & $\begin{array}{c}0,0906 \\
\text { ref. }\end{array}$ & $\begin{array}{l}1,10 \\
1,00\end{array}$ & {$[0,46 ; 2,61]$} & 0,8378 & 0,1754 \\
\hline cárdio-pulmonar & $\begin{array}{l}\text { pulmão } \\
\text { coração } \\
\text { pulmão e coracão }\end{array}$ & $\begin{array}{c}-0,9902 \\
-0,7555 \\
0,7768\end{array}$ & $\begin{array}{l}0,37 \\
0,47 \\
2,17\end{array}$ & $\begin{array}{l}{[0,05 ; 2,85]} \\
{[0,06 ; 3,60]} \\
{[0,82 ; 5,57]}\end{array}$ & $\begin{array}{l}0,3407 \\
0,4673 \\
0,1172\end{array}$ & \\
\hline hipertensão & não & ref. & 1,00 & & & 0,0574 \\
\hline $\begin{array}{l}\text { arterial } \\
\text { acometimento de }\end{array}$ & $\begin{array}{l}\text { sim } \\
\text { não }\end{array}$ & & $\begin{array}{l}2,33 \\
1,00\end{array}$ & {$[0,97 ; 5,60]$} & 0,0592 & 0,4700 \\
\hline sistema nervoso & psicose & 0,3801 & 1,46 & {$[0,34 ; 6,39]$} & 0,6134 & \\
\hline central & $\begin{array}{l}\text { convulsão } \\
\text { psicose e convulsão }\end{array}$ & $\begin{array}{c}0,2992 \\
-15,0381\end{array}$ & $\begin{array}{l}1,35 \\
0,00\end{array}$ & $\begin{array}{l}{[0,39 ; 4,65]} \\
\text { não definido }\end{array}$ & $\begin{array}{l}0,6355 \\
0,9890\end{array}$ & \\
\hline alteração & não & ref. & 1,00 & & & 0,0182 \\
\hline hematol & anemia & 1,2922 & 3,64 & {$[1,00 ; 13,30]$} & 0,0506 & \\
\hline & leucopenia & $-1,1104$ & 0,33 & {$[0,07 ; 1,48]$} & 0,1477 & \\
\hline & plaquetopenia & 1,9004 & 6,69 & {$[1,43 ; 31,25]$} & 0,0157 & \\
\hline imunossupressor & $\begin{array}{l}\text { múltiplos } \\
\text { não }\end{array}$ & $\begin{array}{l}0,4958 \\
\text { ref. }\end{array}$ & $\begin{array}{l}1,64 \\
1,00\end{array}$ & {$[0,21 ; 12,86]$} & 0,6368 & 0,2572 \\
\hline & $\operatorname{sim}$ & $-0,5319$ & 0,59 & {$[0,23 ; 1,52]$} & 0,2729 & \\
\hline anti DNA & negativo & ref. & 1,00 & & & 0,6663 \\
\hline anti-Sm & $\begin{array}{l}\text { positivo } \\
\text { negativo }\end{array}$ & $\begin{array}{l}-0,1967 \\
\text { ref. }\end{array}$ & $\begin{array}{l}0,82 \\
1,00\end{array}$ & $2,02]$ & 681 & 0,7455 \\
\hline & positivo & 0,2030 & 1,23 & {$[0,37 ; 4,11]$} & 0,7426 & \\
\hline anti-RNP & $\begin{array}{l}\text { negativo } \\
\text { positivo }\end{array}$ & $\begin{array}{c}\text { ref. } \\
-0,4161\end{array}$ & $\begin{array}{l}1,00 \\
0,66\end{array}$ & {$[0,18 ; 2,44]$} & 0,5330 & 0,5197 \\
\hline anti-SSA & negativo & ref. & 1,00 & & & 0,0902 \\
\hline anti-SSB & $\begin{array}{l}\text { positivo } \\
\text { negativo }\end{array}$ & $\begin{array}{c}-1,2458 \\
\text { ref. }\end{array}$ & $\begin{array}{l}0,29 \\
1,00\end{array}$ & {$[0,06 ; 1,39]$} & 0,1218 & 0,1981 \\
\hline & positivo & $-15,1741$ & 0,00 & não definido & 0,9905 & \\
\hline Células LE & negativo & ref. & 1,00 & & & 0,7809 \\
\hline & positivo & $-0,1426$ & 0,87 & {$[0,32 ; 2,35]$} & 0,7793 & \\
\hline
\end{tabular}

${ }^{*} \mathrm{HR}_{\mathrm{b}}$ : hazard ratio bruta

As variáveis escolhidas para a modelagem multivariada, sequencialmente, foram: alterações hematológicas ( $\mathrm{p}=0,0182)$, hipertensão arterial $(\mathrm{p}=0,0574)$, envolvimento cárdio-pulmonar $(\mathrm{p}=0,1754)$, idade no diagnóstico $(\mathrm{p}=0,2054)$, uso 
de imunossupr ssor $(\mathrm{p}=0,2572)$, acometimento do sitema nervoso central $(p=0,4700)$, sexo $(p=0,6436)$, ulceracões de mucosas $(p=0,8377)$ e raça $(\mathrm{p}=0,9135)$. As alterações imunológicas laboratoriais não foram testadas na análise multivariada, pois acarretariam a exclusão de muitos casos (os pacientes que não realizaram o exame) e não foram estatisticamente significantes na análise univariada.

Iniciou-se o processo de modelagem multivariada com a variável alteração hematológica e, a seguir, foram acrescentadas as outras variáveis, uma a uma, na ordem acima citada. Nenhuma outra variável foi estatisticamente significante, na presença da alteração hematológica, fato esse que talvez se explique pelo pequeno número de pacientes com IRT ( 21 casos), dentre os 118 pacientes com nefrite. Também não se observou efeito de confusão entre elas. Sendo assim o modelo multivariado final na verdade permaneceu univariado, com apenas a variável presença de alteração hematológica. A tabela 39 apresenta o modelo univariado final dos fatores de risco para a IRT dos pacientes com nefrite.

Tabela 39. Modelo univariado final dos fatores de risco para a sobrevida renal nos pacientes com nefrite lúpica, através do modelo de riscos proporcionais de Cox. Clínica de Reumatologia do Hospital Heliópolis. São Paulo - 1978 a 1995

\begin{tabular}{|c|c|c|c|c|c|}
\hline Variável & categoria & coef.( $(\beta i)$ & $H_{R_{\text {bruta }}}{ }^{*}$ & $\mathrm{IC}_{95 \%}\left(\mathrm{HR}_{\mathrm{b}}\right)$ & p(variável) \\
\hline $\begin{array}{l}\text { alteração } \\
\text { hematológica }\end{array}$ & $\begin{array}{l}\text { não } \\
\text { anemia } \\
\text { leucopenia } \\
\text { plaquetopenia } \\
\text { múltiplas }\end{array}$ & $\begin{array}{c}\text { ref. } \\
1,2922 \\
-1,1104 \\
1,9004 \\
0,4958\end{array}$ & $\begin{array}{l}1,00 \\
3,64 \\
0,33 \\
6,69 \\
1,64\end{array}$ & $\begin{array}{c}{[1,00 ; 13,30]} \\
{[0,07 ; 1,48]} \\
{[1,43 ; 31,25]} \\
{[0,21 ; 12,86]}\end{array}$ & 0,0182 \\
\hline
\end{tabular}

${ }^{*} \mathrm{HR}$ : hazard ratio

significância do modelo final : $\mathrm{p} \rightarrow 0,0336$

$\mathrm{O}$ único fator de risco significante para a sobrevida renal dos pacientes com nefrite lúpica foi a alteração hematológica. 
As alterações hematológicas de risco para a perda de função renal a partir da nefrite foram a plaquetopenia, seguida da anemia hemolítica. A razão entre os riscos de ter IRT dos pacientes com plaquetopenia ao diagnóstico e pacientes sem alteração hematológica é igual a 6,69 (IC=[1,43;31,25]). Já para pacientes com anemia hemolítica essa razão de riscos é igual a 3,64 (IC $=[1,00 ; 13,30)]$ quando são comparados aos pacientes sem alteração hematológica. $\mathrm{Na}$ literatura consultada não foram encontrados dados numéricos referentes a essas associações.

A idade de início do diagnóstico anterior a 16 anos, que apresentou associação com e curva de sobrevida inferior a dos mais velhos, na análise univariada, passou a não apresentar significância estatística, na análise multivariada.

Como se observou, a anemia hemolítica pode ser considerada como fator de risco para a IRT tanto para qualquer paciente com LES, como para aqueles especificamente com nefrite; porém a razão de riscos foi bem maior no total de pacientes $(H R=9,35)$ do que nos pacientes com nefrite lúpica $(H R=3,64)$. A plaquetopenia é fator de risco para a IRT apenas nos pacientes com nefrite, não se encontrando explicações clínicas consistentes para esse achado.

Pela análise multivariada, para os pacientes com LES, a hipertensão arterial é fator de risco para IRT; entretanto, para aqueles pacientes com nefrite lúpica, deixa de ser. O mesmo acontece com a faixa etária mais jovem (de 7 a 15 anos) que se apresentou como fator de risco para IRT apenas na análise multivariada do total de pacientes; talvez pelo pequeno número de óbitos 
ocorridos nos pacientes com nefrite lúpica menores de 16 anos, tal fato não pode ser observado.

\subsection{Análise de sobrevida até o óbito após a insuficiência renal terminal}

Nesta última parte são apresentados os resultados referentes aos 21 pacientes com insuficiência renal terminal. Devido ao pequeno número de pacientes nesse grupo, decidiu-se analisar apenas os fatores associados ao óbito, sem considerar os fatores prognósticos para o óbito, após o paciente ter perda da função renal. Ocorreram, nesse grupo, 8 óbitos $(38,1 \%)$.

$\mathrm{Na}$ tabela 40 pode ser apreciada a distribuição dos pacientes com perda da função renal, segundo a ocorrência de óbito e as características demográficas. Nenhuma dessas variáveis esteve associada, estatisticamente, à ocorrência de óbito em um paciente com IRT.

Tabela 40. Distribuição dos pacientes com perda da função renal, segundo a ocorrência de óbito e as características demográficas. Clínica de Reumatologia do Hospital Heliópolis. São Paulo - 1978 a 1995

\begin{tabular}{|c|c|c|c|c|c|c|c|c|}
\hline \multirow[t]{2}{*}{ Variável } & \multirow[t]{2}{*}{ categoria } & \multicolumn{2}{|c|}{ censura } & \multicolumn{2}{|c|}{ óbito } & \multicolumn{2}{|c|}{ Total } & \multirow{2}{*}{$\begin{array}{l}\text { valor } \\
\text { de } p^{*}\end{array}$} \\
\hline & & $\mathrm{n}^{\circ}$ & $\%$ & $n^{\circ}$ & $\%$ & $n^{\circ}$ & $\%$ & \\
\hline Sexo & $\begin{array}{l}\text { feminino } \\
\text { masculino }\end{array}$ & $\begin{array}{r}11 \\
2\end{array}$ & $\begin{array}{l}61,1 \\
66,7\end{array}$ & $\begin{array}{l}7 \\
1\end{array}$ & $\begin{array}{l}38,9 \\
33,3\end{array}$ & $\begin{array}{r}18 \\
3\end{array}$ & $\begin{array}{l}100,0 \\
100,0\end{array}$ & 1,000 \\
\hline Raça & $\begin{array}{l}\text { não branco } \\
\text { branco }\end{array}$ & $\begin{array}{r}4 \\
59\end{array}$ & $\begin{array}{l}57,1 \\
80,8\end{array}$ & $\begin{array}{r}3 \\
14\end{array}$ & $\begin{array}{l}42,9 \\
19,2\end{array}$ & $\begin{array}{r}7 \\
73\end{array}$ & $\begin{array}{l}100,0 \\
100,0\end{array}$ & 1,000 \\
\hline $\begin{array}{l}\text { Idade no } \\
\text { diagnóstico } \\
\text { (anos) }\end{array}$ & $\begin{array}{l}7 \text { a } 15 \\
16 \text { a } 34 \\
35 \text { a } 60\end{array}$ & $\begin{array}{l}3 \\
1 \\
9\end{array}$ & $\begin{array}{l}60,0 \\
50,0 \\
64,3\end{array}$ & $\begin{array}{l}2 \\
1 \\
5\end{array}$ & $\begin{array}{l}40,0 \\
50,5 \\
35,7\end{array}$ & $\begin{array}{r}5 \\
2 \\
14\end{array}$ & $\begin{array}{l}100,0 \\
100,0 \\
100,0\end{array}$ & 0,922 \\
\hline Total & & 13 & 61,9 & $\overline{8}$ & 38,1 & 21 & $\overline{100,0}$ & \\
\hline
\end{tabular}

*p: nível descritivo do teste de associação pelo Fisher 
A tabela 41 mostra as distribuições dos pacientes com IRT, segundo ocorrência de óbito e as variáveis clínicas e laboratoriais; também aqui não foi detectada associação estatisticamente significante entre as variáveis e o óbito.

Tabela 41. Distribuições dos pacientes com IRT, segundo a ocorrência de óbito e as variáveis clínicas e laboratoriais. Clínica de Reumatologia do Hospital Heliópolis. São Paulo - 1978 a 1995

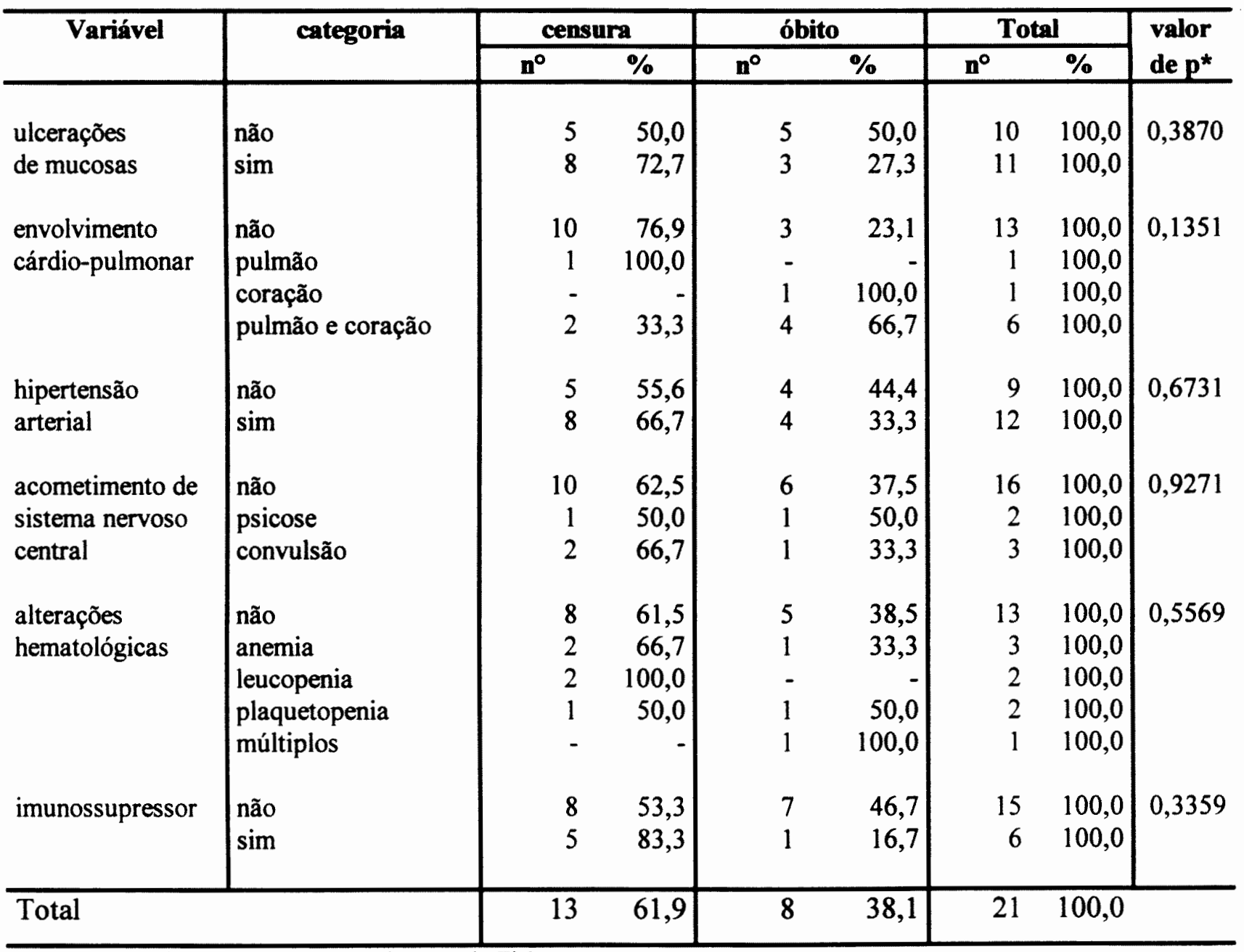

*p: nível descritivo do teste de associação pelo Fisher

A tabela 42 apresenta as distribuições dos pacientes com IRT, segundo a ocorrência de óbito e as alterações imunológicas laboratoriais. Verifica-se que para nenhuma delas houve associação estatisticamente significante com ocorrência do óbito em pacientes com IRT. 
Tabela 42. Distribuições dos pacientes com IRT, segundo a ocorrência de óbito e alterações imunológicas laboratoriais.Clínica de Reumatologia do Hospital Heliópolis.São Paulo - 1978 a 1995

\begin{tabular}{|c|c|c|c|c|c|c|c|c|}
\hline \multirow[t]{2}{*}{ Variável } & \multirow[t]{2}{*}{ categoria } & \multicolumn{2}{|c|}{ censura } & \multicolumn{2}{|c|}{ óbito } & \multicolumn{2}{|c|}{ Total } & \multirow{2}{*}{$\begin{array}{l}\text { valor } \\
\text { de } p^{\star}\end{array}$} \\
\hline & & $\mathbf{n}^{\circ}$ & $\%$ & $\mathbf{n}^{\circ}$ & $\%$ & $n^{\circ}$ & $\%$ & \\
\hline \multirow[t]{3}{*}{ anti DNA } & negativo & 8 & 66,7 & 4 & 33,3 & 12 & 100,0 & 0,6479 \\
\hline & positivo & 4 & 50,0 & 4 & 50,0 & 8 & 100,0 & \\
\hline & não realizado & 1 & 100,0 & - & & 1 & 100,0 & \\
\hline \multirow[t]{3}{*}{ anti-Sm } & negativo & 5 & 62,5 & 3 & 37,5 & 8 & 100,0 & 1,0000 \\
\hline & positivo & 3 & 75,0 & 1 & 25,0 & 4 & 100,0 & \\
\hline & não realizado & 5 & 55,6 & 4 & 44,4 & 9 & 100,0 & \\
\hline \multirow[t]{3}{*}{ anti-RNP } & negativo & 6 & 66,7 & 3 & 33,3 & 9 & 100,0 & 1,0000 \\
\hline & positivo & 2 & 66,7 & 1 & 33,3 & 3 & 100,0 & \\
\hline & não realizado & 5 & 55,6 & 4 & 44,4 & 9 & 100,0 & \\
\hline \multirow[t]{3}{*}{ anti-SSA } & negativo & 4 & 57,1 & 3 & 42,9 & 7 & 100,0 & 1,0000 \\
\hline & positivo & 1 & 50,0 & 1 & 50,0 & 2 & 100,0 & \\
\hline & não realizado & 8 & 66,7 & 4 & 33,3 & 12 & 100,0 & \\
\hline \multirow[t]{3}{*}{ anti-SSB } & negativo & 5 & 55,6 & 4 & 44,4 & 9 & 100,0 & กล̃o \\
\hline & $\begin{array}{l}\text { positivo } \\
\text { não realizado }\end{array}$ & : & & - & - & - & - & \\
\hline & & & 00,7 & 4 & 33,3 & 12 & 100,0 & \\
\hline \multirow[t]{3}{*}{ Células LE } & negativo & 4 & 66,7 & 2 & 33,3 & 6 & 100,0 & 1,0000 \\
\hline & positivo & 7 & 63,6 & 4 & 36,4 & 11 & 100,0 & \\
\hline & não realizado & 2 & 50,0 & 2 & 50,0 & 4 & 100,0 & \\
\hline \multicolumn{2}{|l|}{ Total } & 13 & 61,9 & 8 & 38,1 & 21 & 100,0 & \\
\hline
\end{tabular}

*p: nivel descritivo do teste de associação pelo Fisher. Para a realização do teste foram excluidas as categorias de "não realizado".

Como pode ser observado, uma vez desenvolvida a IRT, não se encontra associação das variáveis independentes demográficas, clínicas e laboratoriais presentes nesses pacientes e a ocorrência de óbito. 


\section{CONSIDERAÇÕES FINAIS}

Esta pesquisa pode ser considerada como a pioneira, em nível nacional, a utilizar análise multivariada de sobrevivência para detectar fatores prognósticos de morte, entre pacientes com lúpus eritematoso sistêmico. Do ponto de vista clínico, é mister não só identificar esses fatores, como, também, quantificá-los, para que procedimentos preventivos possam ser realizados com um maior conhecimento da relação risco-benefício. Um bom exemplo seria a possibilidade de optar por uma terapêutica mais agressiva em pacientes com maior risco em potencial.

A casuística deste estudo foi obtida no Serviço de Reumatologia do Hospital Heliópolis, que existe desde 1976 e, a partir de 1982, instituiu protocolo padronizado para registro de dados em cada uma das doenças reumatológicas.

Há de se mencionar que vários problemas são comuns em estudos longos. Neste sentido, e considerando que a fonte de dados é o prontuário médico, o principal problema a ser apontado é o mau preenchimento desses prontuários que pode ocasionar lacunas no conhecimento dos dados ou falha na qualidade dos mesmos. Para minimizar essa dificuldade, as variáveis aqui utilizadas foram aquelas que, desde o início da década de 70, são rotineiramente coletadas para definir e firmar o diagnóstico do LES; portanto, fazem parte da grande maioria dos prontuários preenchidos por qualquer médico da especialidade. Como uma atitude bem rigorosa, prontuários cujas informações não se apresentavam confiáveis, foram excluídos do trabalho. O preenchimento de um protocolo mais completo, a partir de 1982, foi fundamental para a obtenção dos dados, levando a um mínimo de informações ignoradas. 
A supervisão do trabalho por um único investigador, desde o início do seguimento, deu uniformidade à coleta e homogeneidade de conceitos e critérios, fato que deve ser aqui salientado.

Outro ponto a ser comentado é o caráter acadêmico do Serviço, onde a pesquisa foi feita; com isso houve facilidade na coleta dos dados, uma vez que os residentes da especialidade têm interesse maior no acompanhamento dos pacientes, contribuindo para que houvesse uma melhor qualidade do preenchimento dos prontuários e dos protocolos da pesquisa.

Outra questão importante refere-se às declarações de óbito, pois como é amplamente divulgado, a causa básica do óbito nem sempre é corretamente preenchida pelos médicos. Este fato teve pouca relevância neste trabalho, uma vez que a grande maioria dos óbitos ocorreu no próprio Serviço. Dos quatro óbitos que ocorreram fora do Serviço, apenas em dois , a informação familiar foi considerada adequada; nos outros casos, os óbitos foram classificados como de causa não definida.

A presente casuística refere-se aos pacientes do Serviço acompanhados em 17 anos, com tempo de seguimento semelhante aos de trabalhos mais recentes. Os totais de casos estudados e de óbitos são comparáveis com os de centros europeus e da maioria dos centros brasileiros; apenas pesquisas americanas e canadenses possuem casuísticas maiores, principalmente, por serem estudos do tipo multicêntricos. Considerando-se de extrema importância a realização de estudos multicêntricos no Brasil, recomenda-se a utilização de protocolos padronizados que possibilitariam uma casuística de maior magnitude, melhorando tanto o poder estatístico da análise, como auferindo mais confiabilidade nos resultados e dando uma visão mais próxima do comportamento da doença no país. 
Outra dificuldade, em trabalhos de longos períodos de acompanhamento, é a possibilidade de haver um número muito grande de perdas no seguimento. No Brasil, especialmente em serviço público, isso ocorre de modo mais marcante, onde o paciente, por uma série de questões sócio-econômicas, comportamentais e estruturais (por exemplo, greves constantes), deixa de manter o acompanhamento adequado, no local onde iniciou o tratamento. Muitas vezes, somente procura auxílio médico nos casos de agravamento da doença; esta demanda não obrigatoriamente se dará no Serviço onde foi feito o dignóstico. Na pesquisa aqui relatada, o total de perdas, nos 17 anos, foi cerca de $25 \%$. Os poucos autores, que informam o número de perdas ${ }^{1,19,21}$, apontam valores entre 10 e $30 \%$, o que faz com que a porcentagem de perdas deste estudo esteja próxima a dos relatados. Apesar das perdas, há de ser mencionado que as técnicas estatísticas, aqui adotadas para análise, permitiram o melhor aproveitamento das informações e a obtenção de estimativas confiáveis.

Finalmente, é importante estimular os serviços que tratam pacientes com lúpus eritematoso sistêmico para que coletem e analisem os dados referentes a seus pacientes, a exemplo do que foi feito com a experiência do Serviço de Reumatologia do Hospital Heliópolis. Com isto, haverá a possibilidade de se ter uma série de resultados que possam gerar um referencial brasileiro servindo como padrão de comparação para outros países e localidades com características semelhantes. 


\section{CONCLUSÕES}

1. As proporções de pacientes com lúpus eritematoso sistêmico que sobreviveram, respectivamente, após 5, 10 e 15 anos de seguimento foram $89,9 \%, 79,6 \%$ e $71,8 \%$. Para os pacientes com nefrite lúpica essas porcentagens de sobreviventes até o óbito foram, respectivamente, $79,7 \%, 74,3 \%$ e $66,9 \%$.

2. As proporções de pacientes que não tiveram acometimento de insuficiência renal terminal, respectivamente, após 5, 10 e 15 anos de seguimento, foram 95,0\%, 89,7\% e 76,9\%,. Para os pacientes com nefrite lúpica essas porcentagens de sobreviventes até o óbito foram, respectivamente, $81,9 \%, 69,4 \%$ e $61,7 \%$.

3. Os fatores de risco para o óbito dos pacientes com lúpus eritematoso sistêmico, estatisticamente significantes, foram: a presença de insuficiência renal terminal, de envolvimento pulmonar isolado ou associado com envolvimento cardíaco e a não utilização de imunossupressor.

4. Os fatores de risco para o óbito dos pacientes com nefrite lúpica, que apresentaram significância estatística, foram: a presença de insuficiência renal terminal e a não utilização de imunossupressor.

5. Os fatores de risco, estatisticamente significantes, para o desenvolvimento de insuficiência renal terminal dos pacientes com lúpus eritematoso sistêmico foram: a idade entre 7 e 15 anos no início da doença, a presença de hipertensão arterial sistêmica e a presença de anemia hemolítica. 
6. O fator de risco para a perda da função renal dos pacientes com nefrite lúpica, com significância estatística, foi a presença de alteração hematológica do tipo anemia hemolítica ou plaquetopenia.

7. Uma vez desenvolvida a insuficiência renal terminal, não se detectou associação estatisticamente significante entre os fatores demográficos, clínicos ou laboratoriais com a ocorrência do óbito. 


\section{REFERÊNCIAS BIBLIOGRÁFICAS}

1.ABU-SHAKRA,M et al. Mortality studies in systemic lupus erythematosus: results from a single center I. Causes of death. J.Rheumatol., 22: 1259-64, 1995.

2.ABU-SHAKRA,M et al. Mortality studies in systemic lupus erythematosus: results from a single center II. Predictor variables of mortality. J.Rheumatol., 22: 1265-70, 1995.

3.ALARCON-SEGOVIA,D. et al. Deforming arthropathy of the hands in SLE. J.Rheumatol., 15: 65-72, 1988.

4.ARNETT,F.C. et al. Systemic lupus erythematosus:current state of the genetic hypothesis. Semin.Arthritis Rheum.,14:24-9, 1984.

5.AUSTIN,H.A.III et al. Diffuse proliferative lupus nephritis:identification of specific pathologic features affecting renal outcome. Kidney Int., 25: 68995, 1984.

6.BALOW,J.E. Therapeutic trials in lupus nephritis. Nephron, 27: 171-6, 1981.

7.BEUFILLS,M. et al. Clinical significance of anti-Sm antibodies in systemic lupus erythematosus. Amer.J.Med., 74: 201-12, 1983.

8.BUMGARDNER,G.L. et al. Long-term outcome of renal transplantation in patients with SLE. Transplant.Proc., 21: 2031-45, 1989.

9.CALLAHAN,L.F. \& PINCUS,T. Associations between clinical status questionnaire scores and formal educational levels in persons with SLE. Arthritis Rheum, 33: 407 - 11, 1986.

10.CASSIDY,J.T. Juvenile systemic lupus erythematosus, dermatomyositis, scleroderma and vasculitis. In: KELLEY,W.N. et al. (eds). Textbook of rheumatology. Philadelphia, W.B. Sanders Company, 1993. p:1224-47. 
11.CASSIDY,J.T et al. Lupus nephritis and encephalopathy: prognosis in 58 children. Arthritis Rheum, 20: 315 - 21, 1977.

12.COSTALLAT,L.T.L. \& COIMBRA,A.M.V. Systemic lupus erythematosus: clinical and laboratory aspects related to age at disease.

Clin.Exp.Rheumatol., 12:603-7, 1994.

13.COSTALLAT,L.T.L. \& COIMBRA,A.M.V. Lúpus eritematoso sistêmico: análise clínica e laboratorial de 272 pacientes em um hospital universitário. Rev. Bras.Reumatol., 35:23-9, 1995.

14.COX,D.R. Regression models and life-tables. J.R.Stat.Soc., Series B, 34: 187202, 1972.

15.CROLEY,J. \& BRESLOW,N. Statistical analysis of survival data. Assoc.Rev. Public Health, 5:385-411, 1994.

16.DALLOU,S.P. et al. Clinical features of SLE: differences related to race and age of onset. Arthritis Rheum, 25: 55 - 60, 1982.

17.DEAPEN,D.M. et al. A revised estimate of twin concordance in SLE: a survey of 138 pairs. Arthritis Rheum., 29:S26, 1986.

18.DUBOIS,E.L. \& WALLACE,D.J. Clinical and laboratory manifestations of SLE. In: WALLACE,D.J. \& DUBOIS,E.L., eds. Lupus erythematosus. Philadelphia, Lea \& Febiger, 1987. p. 317-449.

19.ESTES,D. \& CHRISTIAN,C. The natural history of systemic lupus erythematosus by prospective analysis. Medicine (Baltimore), 50:85-95, 1971.

20.FESSEL,W.J. Systemic lupus erythematosus in the community: incidence, prevalence, outcome, and first symptoms; the high prevalence in black women. Arch.Intern.Med., 134: 1027-35, 1974. 
21.FRIES,J.F. et al. Estimating prognosis in systemic lupus erythematosus. Am.J.Med., 57:561:5, 1974.

22.GANCZARCZYK,L.; UROWITZ,M.B. \& GLADMAN,D.D. Latent lupus. J.Rheumatol., 16: 475-8, 1989.

23.GINZLER, E.M. et al. A multi-center study outcome in systemic lupus erythematosus. Arthritis Rheum., 25: 601 - 11, 1982.

24.GINZLER, E.M.; et al. Hipertension increases the risk of renal deterioration in systemic lupus erythematosus. J.Rheumatol., 20: 1694-700, 1993.

25.GLADMAN,D.D. Prognosis of systemic lupus erythematosus and factors that affect it. Curr.Opin. Rheumatol, 4: 681-7, 1992.

26.GRIPENBERG,M. \& HELVE,T. Outcome of systemic lupus erythematosus. A study of 66 patients over 7 years with special reference to the predictive value of anti-DNA antibody determination. Scand.J.Rheumatol., 20:104-9, 1991.

27.GULKO,P.S. et al. Survival impact of autoantibodies in systemic lupus erythematosus. J.Rheumatol., 21: 224-8, 1994.

28.HAHN,B.H. Management of systemic lupus erythematosus. In: KELLEY,W.N. et al., eds. Textbook of rheumatology. Philadelphia, W.B. Saunders Company, 1993. p.1043-56.

29.HARVEY,A.M. et al. Systemic lupus erythematous: review of literature and clinical analysis of 138 cases. Medicine, 33: 291- 437, 1954.

30.HELLMANN,D.B. et al. Fatal infections in systemic lupus erythematosus: the role of opportunistic organisms. Medicine, 66: 341-8, 1987.

31.HELVE,T. Prevalence and mortality rates of SLE and causes of death in Finland. Scand.J.Rheumatol., 14: 43 - 6, 1985. 
32.HOCHBERG,M.C. The incidence of systemic lupus erythematosus in Baltimore, Maryland, 1970-1977. Arthritis Rheum, 28:80-6, 1985.

33.HOCHBERG,M.C. Epidemiology of systemic lupus erythematosus. In: LAHITA,R.G., ed. Systemic lupus erythematosus. New York, Churchill Livingstone, 1992. p:103-17.

34.JOHNSON,A.E. et al. The prevalence and incidence of systemic lupus erythematosus in Birmingham, England. Arthritis Rheum., 38:551-8, 1995.

35.JONSSON,H. et al. Outcome in systemic lupus erythematosus: a prospective study of patients from a defined population. Medicine (Baltimore), 68:141$50,1989$.

36.KAPLAN,E.L. \& MEIER,P. Nonparametric estimation from incomplete observations. J.Am.Stat.Assoc., 53: 457-81, 1958.

37.KAUFMAN,L.D. et al. Male Lupus: retrospective analyses of the clinical and laboratory features of 52 patients, with a review of the literature. Semin. Arthritis. Rheum., 18: 189 - 97, 1989.

38.KELLUM,R.E. \& HASERICKE,J.R. Systemic lupus erythematosus, a statistical evaluation of mortality based on a consecutive series of 299 patients. Arch.Intern.Med., 113:200-7, 1964.

39.KERR,G.S. \& HOFFMAN,G.S. Systemic lupus erythematosus and cardiovascular system. In: LAHITA,R.G., ed. Systemic lupus erythematosus. New York, Churchill Livingstone, 1992. p.719-29.

40.KLEINBAUM,D.G., KUPPER,L.L. \& MULLER,K.E. Applied regression analysis and other multivariable methods. $2^{\text {nd }}$ ed. Belmont, Duxbury Press, 1988. 
41.LATORRE,L.C. Caracterização tecidual e sorológica de complexos Sm e RNP na nefropatia lúpica: correlações e significado clínico. São Paulo, 1987. [Dissertação de Mestrado - Faculdade de Medicina da Universidade de São Paulo].

42.LATORRE,L.C. et al. Nefrite lúpica recidivada em rim transplantado. Rev.Paul. Med., 107: 186-8, 1989.

43.LATORRE, M.R.D.O. Comparação entre alguns métodos estatísticos em análise de sobrevivência: aplicação em uma coorte de pacientes com câncer de pênis. São Paulo, 1996. [Tese de Doutorado - Faculdade de Saúde Pública da Universidade de São Paulo].

44.LAURENCE,J.; WONG,J.E.L. \& NACHMAN,R. The cellular hematology of systemic lupus erythematosus. In: LAHITA,R.G., ed. Systemic lupus erythematosus. New York, Churchill Livingstone, 1992. p.771-806.

45.LAWRENCE,E.C. Systemic lupus erythematosus and the lung. In: LAHITA,R.G., ed. Systemic lupus erythematosus. New York, Churchill Livingstone, 1992. p. 731-45.

46.LAWRENCE,E.C. et al. Estimates of prevalence of selected arthritic and musculoskeletal diseases in the United States. J.Rheumatol, 16:427-41, 1989.

47.LIANG,M.F. et al. Strategies for reducing excess morbidity and mortality in blacks with systemic lupus erythematosus. Arthritis Rheum., 34: 1187 - 96, 1991.

48.LOVE,P.E. \& SANTORO,S.A. Anti-phospholipid antibodies: anticardiolipin and the Lupus anticoagulant in systemic lupus erythematosus (SLE) and in nonSLE disorders: prevalence and the clinical significance. Ann.Intern.Med., 112: 682-95, 1990.

49.LUTALO,S.K. Chronic inflamatory rheumatic diseases in black zimbabweans. Ann.Rheum.Dis., 44: 121- 5, 1985. 
50.MASI,A.T. \& KASLOW,R.A. Sex effects in systemic lupus erythematosus: a clue to pathogenesis. Arthritis Rheum., 21:480-95, 1978.

51.McCARTY,D.J. et al. Incidence of systemic lupus erythematosus: race and gender differences. Arthritis Rheum., 38:1260-70, 1995.

52.MCLAUGHLIN,J. et al. Kidney biopsy in systemic lupus erythematosus. Part II: survival analysis according to biopsy results. Arthritis Rheum., 34:1268-73, 1991.

53.MEDDINGS,J. et al. The prevalence of systemic lupus erythematosus in Dunedin. N.Z.Med.J., 91:205 - 13, 1980.

54.MERREL,M. \& SHULMAN,L.E. Determination of prognosis in chronic disease, illustred by lupus erythematosus. J.Chronic Dis., 1: 12-32, 1955.

55.MICHET,C.J. et al. Epidemiology of SLE and other connective tissue disorders in Rochester, Minnesota, 1950-1979. Mayo Clin.Proc., 60: 105-13 , 1985.

56.MILLER,M.H.; UROWITZ,M.B. \& GLADMAN,D.D. The significance of thrombocytopenia in systemic lupus erythematosus. Arthritis Rheum.,26:1181-6, 1983.

57.NIVED,O. et al. Systemic lupus erythematosus in an adult population in Southern Sweden: incidence, prevalence and validity of ARA revised classification criteria. Br.J.Rheumatol., 24: 147 - 54 , 1985.

58.NOTMAN,O.D.; KURATA,N. \& TAN,E.M. Profiles of antinuclear antibodies in systemic rheumatoid diseases. Ann.Intern.Med., 83: 464-79, 1975.

59.PETRI,M. Clinical features of systemic lupus erythematosus.

Curr.Opin.Rheumatol., 7:395-401, 1995.

60.PISTINER,M. et al. Lupus erythematosus in the 1980s: a survey of 570 patients. Semin.Arthritis Rheum. 21: 55-64, 1991. 
61.POLLAK,V.E. \& KANT,K.S. Systemic lupus erythematosus and the kidney. In: LAHITA,R.G., ed. Systemic lupus erythematosus. New York, Churchill Livingstone, 1992. p. 683-705.

62.REVEILLE,J.D. et al. Prognosis in SLE: negative impact of increasing age in onset, black race, and thrombocytopenia, as well as causes of death. Arthritis Rheum., 33: 37 - 48, 1990.

63.ROSNER,S. et al. Multicenter study of outcome in lupus erythematosus: causes of death. Arthritis Rheum., 25: 612-7, 1982.

64.ROTHFIELD,N.F. Clinical features of SLE. In: KELLEY,W.N., et al, eds. Textbook of rheumatology. Philadelphia, W.B. Saunders Company, 1981. p. 1020 - 45.

65.ROTHFIELD,N.F. Renal diseases. In: SCHUR,P.H., ed. The clinical management of systemic lupus erythematosus. Orlando, Grune \& Stratton, 1983. p. 137-151.

66.ROTHFIELD,N.F. Cardiopulmonary manifestations. In: SCHUR,P.H., ed. The clinical management of systemic lupus erythematosus. Orlando, Grune \& Stratton, 1983. p.113-22.

67.ROTHFIELD,N.F. Systemic lupus erythematosus: clinical aspects and treatment. In:MC CARTY,D.J. \& KOOPMAN,W.J., eds. Arthritis and allied conditions. Philadelphia, Lea \& Febiger, 1993, p.1155-77.

68.SATO,E.I. Lupus eritematoso sistêmico: aspectos clínicos, laboratoriais e terapêuticos de 201 pacientes. São Paulo, 1994. [Tese de Livre-Docência Escola Paulista de Medicina].

69.SATO,E.I. et al. Fatores prognósticos no lúpus eritematoso sistêmico. Rev. Bras. Reumatol., 35:235-41, 1995.

70.SCHALLER,J. Lupus in childhood. Clin.Rheumatol.Dis., 8: 219 - 50, 1982. 
71.SCHUR,P.H., et al. Associations between systemic lupus erythematosus and the major histocompatibility complex:clinical and immunological considerations. Clin.Immunol. Immunopathol.,24:263-70, 1982.

72.SCHUR,P.H. Inherited complement component abnormalities. Annu.Rev.Med., 37: 333-7, 1986.

73.SCHUR,P.H. Clinical features of SLE. In: KELLEY,W.N. et al., eds. Textbook of rheumatology. Philadelphia, W.B. Saunders Company, 1993. p.1017-42.

74.SELEZNICK,M.J. \& FRIES,J.F. Variables associated with decreased survival in systemic lupus erythematosus. Semin.Arthritis Rheum., 21: 73-80, 1991.

75.SERDULA,M.K. \& RHOAD,G.G. Frequency of SLE in different ethnic groups in Hawaii. Arthritis Rheum, 22: 328-33, 1979.

76.SHOENFELD,Y. \& SCHWARTZ,R.S. Hematologic manifestations. In: SCHUR,P.H., ed. The clinical management of systemic lupus erythematosus. Orlando, Grune \& Stratton, 1983. p.123-36.

77.SIBLEY,J.T. et al. The incidence and prognosis of central nervous system disease in SLE. J.Rheumatol, 19: 47-52, 1992.

78.SIEGEL,M. \& LEE,S.L. The epidemiology of systemic lupus erythematosus. Semin.Arthritis Rheum., 3:1-25, 1973.

79.SONTHEIMER,R.D. \& GILLLAN,J.N. Systemic lupus erythematosus and the skin. In: LAHITA,R.G., ed. Systemic lupus erythematosus. New York, Churchill Livingstone, 1992. p. 657-81.

80.STAFFORD-BRADY,F. et al. Lupus retinophaty: patterns associations and prognosis. Arthritis Rheum., 31:1105-10, 1988.

81.STEINBERG,A.D. Concepts of pathogenesis of systemic lupus erythematosus. Clin.Immunol.Immunopathol., 63:19-25, 1992. 
82.STEINBERG,A.D. \& STEINBERG,S.C. Long-term preservation of renal function in patients with lupus nephritis receiving treatment that includes cyclophosphamide versus those treated with prednisone alone. Arthritis Rheum., 34: 945-51, 1991.

83.STEPHEN,J.W. et al. Divergent racial trends in mortality from systemic lupus erythematosus. J.Rheumatol., 22:1663-8, 1995.

84.SWAAK,A.J.G. et al. Systemic lupus erythematosus.I. Outcome and survival:dutch experience with 110 patients studied prospectively. Ann. Rheum.Dis., 48:447-54, 1989.

85.TAN,E.M. et al. The 1982 revised criteria for the classification of systemic lupus erythematosus. Arthritis Rheum., 25:1271-7, 1982.

86.TAN,E.M. Autoantibodies in systemic lupus erythematosus. In:MC CARTY,D.J. \& KOOPMAN,W.J., eds. Arthritis and allied conditions. Philadelphia, Lea \& Febiger, 1993, p.1179-84.

87.TUCKER,L.B. et al. Adult and childhood-onset systemic lupus erythematosus: a comparison of onset, clinical features, serology, and outcome. Br.J. Rheumathol.,34:866-72, 1995.

88. WAALER,E. Connective tissue disorders and related conditions in Scandinavia. In: WAGNER,B., ed. The connective tissue. Baltimore, Williams \& Wilkins, 1967.

89.WALLACE,D.J. et al. Systemic lupus erythematosus: survival patterns. JAMA, 245:934-8, 1981.

90.WARD,M.M. \& POLISSON,R.P. A meta-analysis of the clinical manifestation of older-onset SLE. Arthritis Rheum., 32: 1226-32, 1989. 
91.WARD,M.M. \& STUDENSKI,S. Clinical manifestations of SLE: identification of racial and socioeconomic influences. Arch. Intern. Med., 150: 849 - 53, 1990.

92.WARD,M.M; PYUN,E. \& STUDENSKI,S. Causes of death in systemic lupus erythematosus: long-term follow-up of an inception cohort. Arthritis Rheum., 38: 1492-9, 1995.

93.WENER,M.H. \& MANNIK,M. Mechanisms of immune deposit formation in renal glomeruli. Springer Semin.Immunopathol., 9:219-27, 1986.

94.WOODS Jr,V.L. Pathogenesis of systemic lupus erythematosus In KELLEY,W.N. et al., eds. Textbook of rheumatology. Philadelphia,W.B.Sanders Company, 1993. p.999-1016.

95.ZERBINI,C.A.F. Estudo da capacidade de fixação do complemento dos anticorpos antinucleares anti-Sm e anti-RNP em portadores de lúpus eritematoso sistêmico. São Paulo, 1984. [Tese de Doutorado - Faculdade de Medicina da Universidade de São Paulo]. 


\section{ANEXO 1}

Número e porcentagem de pacientes com LES, segundo ano de diagnóstico. Clínica de Reumatologia do Hospital Heliópolis. São Paulo - 1978 a 1995

\begin{tabular}{cccc}
\hline ANO & NÚMERO & $\%$ & \% acumulada \\
\hline 1978 & 10 & 4,0 & 4,0 \\
1979 & 11 & 4,3 & 8,3 \\
1980 & 15 & 5,9 & 14,2 \\
1981 & 6 & 2,4 & 16,6 \\
1982 & 18 & 7,1 & 23,7 \\
1983 & 10 & 4,0 & 27,7 \\
1984 & 18 & 7,1 & 34,8 \\
1985 & 23 & 9,1 & 43,9 \\
1986 & 25 & 9,9 & 53,8 \\
1987 & 25 & 9,9 & 63,7 \\
1988 & 15 & 5,9 & 69,6 \\
1989 & 13 & 5,1 & 74,7 \\
1990 & 16 & 6,3 & 81,0 \\
1991 & 15 & 5,9 & 86,9 \\
1992 & 16 & 6,3 & 93,2 \\
1993 & 9 & 3,6 & 96,8 \\
1994 & 8 & 3,2 & 100,0 \\
\hline Total & 253 & 100,0 & \\
\hline
\end{tabular}




\section{ANEXO 2}

\section{Protocolo completo}

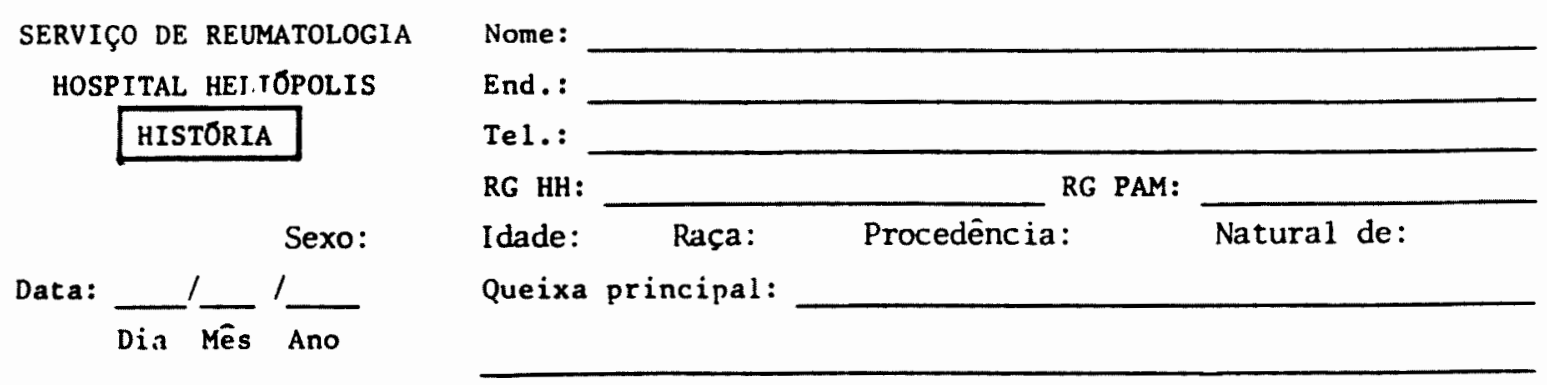

Histōria da moléstia atual:

Interrogatório sobre diversos aparelhos:

\section{Passado \\ Presente}

$\begin{array}{llll}0 & 1 & 2 & 3 \\ 0 & 1 & 2 & 3\end{array}$

$\begin{array}{llll}0 & 1 & 2 & 3\end{array}$

$\begin{array}{llll}0 & 1 & 2 & 3\end{array}$

01

01

Fadiga

Febre

Perda de peso

Pele

$\begin{array}{llll}0 & 1 & 2 & 3\end{array}$

$\begin{array}{llll}0 & 1 & 2 & 3\end{array}$

$\begin{array}{llll}0 & 1 & 2 & 3\end{array}$

$\begin{array}{llll}0 & 1 & 2 & 3\end{array}$

$\begin{array}{llll}0 & 1 & 2 & 3\end{array}$

$\begin{array}{llll}0 & 1 & 2 & 3\end{array}$

0123

0123

$\begin{array}{llll}0 & 1 & 2 & 3\end{array}$

$\begin{array}{llll}0 & 1 & 2 & 3\end{array}$

$\begin{array}{llll}0 & 1 & 2 & 3\end{array}$

$\begin{array}{llll}0 & 1 & 2 & 3\end{array}$

$\begin{array}{llll}0 & 1 & 2 & 3\end{array}$

$\begin{array}{llll}0 & 1 & 2 & 3\end{array}$

$\begin{array}{llll}0 & 1 & 2 & 3\end{array}$

$\begin{array}{llll}0 & 1 & 2 & 3\end{array}$

$\begin{array}{llll}0 & 1 & 2 & 3\end{array}$

$\begin{array}{llll}0 & 1 & 2 & 3\end{array}$

$\begin{array}{llll}0 & 1 & 2 & 3\end{array}$

$\begin{array}{llll}0 & 1 & 2 & 3\end{array}$

$\begin{array}{llll}0 & 1 & 2 & 3\end{array}$

$\begin{array}{llll}0 & 1 & 2 & 3\end{array}$

$\begin{array}{llll}0 & 1 & 2 & 3\end{array}$

$\begin{array}{llll}0 & 1 & 2 & 3\end{array}$

$\begin{array}{llll}0 & 1 & 2 & 3\end{array}$

$\begin{array}{llll}0 & 1 & 2 & 3\end{array}$

0123

$\begin{array}{llll}0 & 1 & 2 & 3\end{array}$

$\begin{array}{llll}0 & 1 & 2 & 3\end{array}$

$\begin{array}{llll}0 & 1 & 2 & 3\end{array}$

$\begin{array}{llll}0 & 1 & 2 & 3\end{array}$

$\begin{array}{llll}0 & 1 & 2 & 3\end{array}$

$\begin{array}{llll}0 & 1 & 2 & 3\end{array}$

$\begin{array}{llll}0 & 1 & 2 & 3\end{array}$

$\begin{array}{llll}0 & 1 & 2 & 3\end{array}$

01123

$\begin{array}{llll}0 & 1 & 2 & 3\end{array}$

$\begin{array}{llll}0 & 1 & 2 & 3\end{array}$

$\begin{array}{llll}0 & 1 & 2 & 3\end{array}$

01

0123

$\begin{array}{llll}0 & 1 & 2 & 3\end{array}$

$\begin{array}{llll}0 & 1 & 2 & 3\end{array}$

$\begin{array}{lll}0 & 1\end{array}$

Alopecia

Fotossensibilidade

F. Raynaud

Rash

\section{Cabeca e Pescoço}

Conjuntivite

Olhos secos

Boca seca

Olceras mucosas

Sinusopatia

Tinnitus

\section{Cärdio-pulmonar}

Dispnéia

Edema MMII

Pleurisia

Outra queixa torácica

\section{Gastrointestinal}

Sintomas pēpticos

Disfagia

Hematềmese/melena

Dor abdominal

Diarréia

Genito-urinärio

Ulceração genital

Corrimento uretral

Cálculo/cólica renal

Anormalidade menstrual
Passado Presente Articular

$\begin{array}{llllll} & \text { hs } & & & \text { hs } & \text { Rigidez matinal } \\ 012 & 3 & 012 & 3 & \text { Artralgias }\end{array}$

$\begin{array}{lllllllll}0 & 1 & 2 & 3 & 0 & 1 & 2 & 3 & \text { Artrites }\end{array}$

$\begin{array}{lllllllll}0 & 1 & 2 & 3 & 0 & 1 & 2 & 3\end{array}$ Calcaneodinea

$\begin{array}{lllllllll}0 & 1 & 2 & 3 & 0 & 1 & 2 & 3\end{array}$ Dor noturna

$\begin{array}{llllllllll}0 & 1 & 2 & 3 & 0 & 1 & 2 & 3\end{array}$ Dor cervical

$\begin{array}{lllllllll}0 & 1 & 2 & 3 & 0 & 1 & 2 & 3 & \text { Dor lombar }\end{array}$

Dor muscular

$\begin{array}{llllllll}0 & 1 & 2 & 3 & 0 & 1 & 2 & 3\end{array}$ Fraqueza muscular

$\begin{array}{lllllllll}0 & 1 & 2 & 3 & 0 & 1 & 2 & 3\end{array}$ Parestesias

$\begin{array}{lllllllll}0 & 1 & 2 & 3 & 0 & 1 & 2 & 3 & \text { Convulsões }\end{array}$

0101 Alteração de perso-

nalidade

$\begin{array}{lllll}01 & 0 & 1 & & \text { Ansiedade/tensão }\end{array}$

01001 Depressão

01101 Distúrbio do sono

Outros achados: 
SERVIÇO DE REUMATOLOGIA HOSPITAL HELIOPOLIS EXAME FISICO

Data:<smiles>CC(C)C(C)C(C)C</smiles>

Pele

Alopecia
Ulceração digital
Manchas de Grotton
Eritema nodoso
Eritema periungueal
Heliotropo
Queratodermia blenorrágica
Alteraçoes ungueais
Psoriase
Pürpura palpāvel
Rash discóide
Rash malar
Rash da ARJ
Outro rash
Escleroderma digital
Escleroderma de extremidades
Escleroderma facial
Escleroderma generalizado
Morféia
Teleangiectasia
Olho

Olho

Catarata

Conjuntivite

Doença escleral/episcleral

Irite

Uveíte

Cabeça e pescoço

Xerostomia
Ulceras orais
Aumento glândulas salivares
Tireóide anormal
Linfadenopatia
Tórax
Efusão pleural
Atrito pleural
Estertores
Dispnéia
Coração

Edema MMII

Aumento $\mathrm{P}_{2}$

Atrito pericárdico

Sopro sistólico 01 :

Sopro diastólico 01 :

Abdome

Hepatomegalia

Esplenomegalia

Sinais peritoneais

Nome:

End.:

Tel.:

RG HH: RG PAM:

Idade: Sexo: Raça: Procedencia: Natural de:

Genitália

Ulceração/Balanite $\quad \begin{array}{llll}0 & 1 & 2 & 3\end{array}$

Corrimento uretral $0 \begin{array}{llll} & 1 & 2 & 3\end{array}$

Artérias

Pulsos ausentes 0 l:

Sensibilidade artéria temporal 01223

Müsculos

Dor $\quad \begin{array}{llll}0 & 1 & 2 & 3\end{array}$

Fraqueza proxima1 01123

Fraqueza distal $0 \begin{array}{llll}1 & 2 & 3\end{array}$

Atrofia $\quad 0123$

$\begin{array}{llll}0 & 1 & 2 & 3\end{array}$

$\begin{array}{llll}0 & 1 & 2 & 3\end{array}$

$\begin{array}{llll}0 & 1 & 2 & 3\end{array}$

$\begin{array}{llll}0 & 1 & 2 & 3\end{array}$

$\begin{array}{llll}0 & 1 & 2 & 3\end{array}$

$\begin{array}{llll}0 & 1 & 2 & 3\end{array}$

$\begin{array}{llll}0 & 1 & 2 & 3\end{array}$

$\begin{array}{llll}0 & 1 & 2 & 3\end{array}$

$\begin{array}{llll}0 & 1 & 2 & 3\end{array}$

$\begin{array}{llll}0 & 1 & 2 & 3\end{array}$

Direito

Extremidade superior

Esquerdo

0123 E. clavicular

$\begin{array}{llll}0 & 1 & 2 & 3\end{array}$

0123 Acromioclavicular

$\begin{array}{llll}0 & 1 & 2 & 3\end{array}$

$\begin{array}{lllll}0 & 1 & 2 & 3 & \text { Ombro }\end{array}$

$\begin{array}{lllll}0 & 1 & 2 & 3 & \text { Cotovelo }\end{array}$

$\begin{array}{llll}0 & 1 & 2 & 3\end{array}$

$0 \begin{array}{lllll}0 & 2 & 3 & \text { Punho }\end{array}$

$\begin{array}{llll}0 & 1 & 2 & 3\end{array}$

$\begin{array}{llll}0 & 1 & 2 & 3\end{array}$

$\begin{array}{llll}0 & 1 & 2 & 3\end{array}$

$\begin{array}{llll}0 & 1 & 2 & 3\end{array}$

$\begin{array}{llll}0 & 1 & 2 & 3\end{array}$

$\begin{array}{llll}0 & 1 & 2 & 3\end{array}$

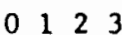

$\begin{array}{llll}0 & 1 & 2 & 3\end{array}$

$\begin{array}{llll}0 & 1 & 2 & 3\end{array}$

$\begin{array}{llll}0 & 1 & 2 & 3\end{array}$

$\begin{array}{llll}0 & 1 & 2 & 3\end{array}$

0123 Carpometacárpica

$\begin{array}{llll}0 & 1 & 2 & 3\end{array}$

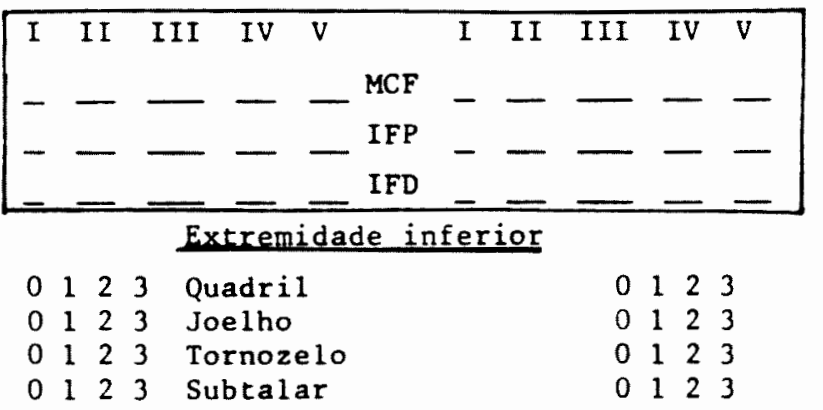

$\begin{array}{llll}0 & 1 & 2 & 3\end{array}$

$\begin{array}{llll}0 & 1 & 2 & 3\end{array}$

$\begin{array}{llll}0 & 1 & 2 & 3\end{array}$

$\begin{array}{llll}0 & 1 & 2 & 3\end{array}$

$\begin{array}{llll}0 & 1 & 2 & 3\end{array}$

01

$\begin{array}{llll}0 & 1 & 2 & 3\end{array}$

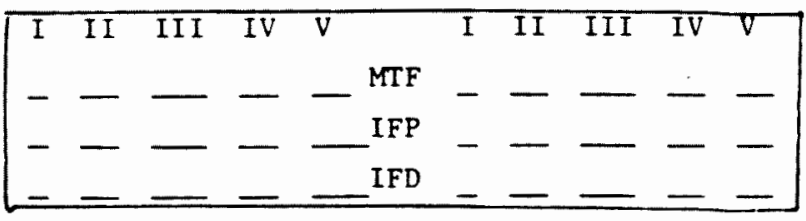

Esque le to axial

$\begin{array}{llllllllll}0 & 1 & 2 & 3 & \text { ATM } & 0 & 1 & 2 & 3\end{array}$

$\begin{array}{lllll}0 & 1 & 2 & 3 & \text { Costocondral. }\end{array}$

$\begin{array}{llll}0 & 1 & 2 & 3\end{array}$

$\begin{array}{lllll}0 & 1 & 2 & 3 & \text { Col. cervical }\end{array}$

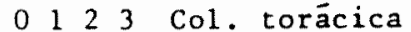

$0 \begin{array}{llll}0 & 1 & 2 & 3 \\ \text { Col. Lombar }\end{array}$

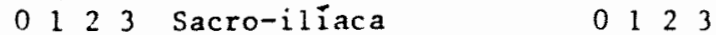

$\begin{array}{llll}0 & 1 & 2 & 3\end{array}$

$\begin{array}{llll}0 & 1 & 2 & 3\end{array}$

$\begin{array}{llll}0 & 1 & 2 & 3\end{array}$

Classe funcional ARA

1234 
SERVIÇO DE REUMATOLOGIA

HOSPITAL HELIOPOLIS

EXAMES LABORATORIAISI 1

Visita no

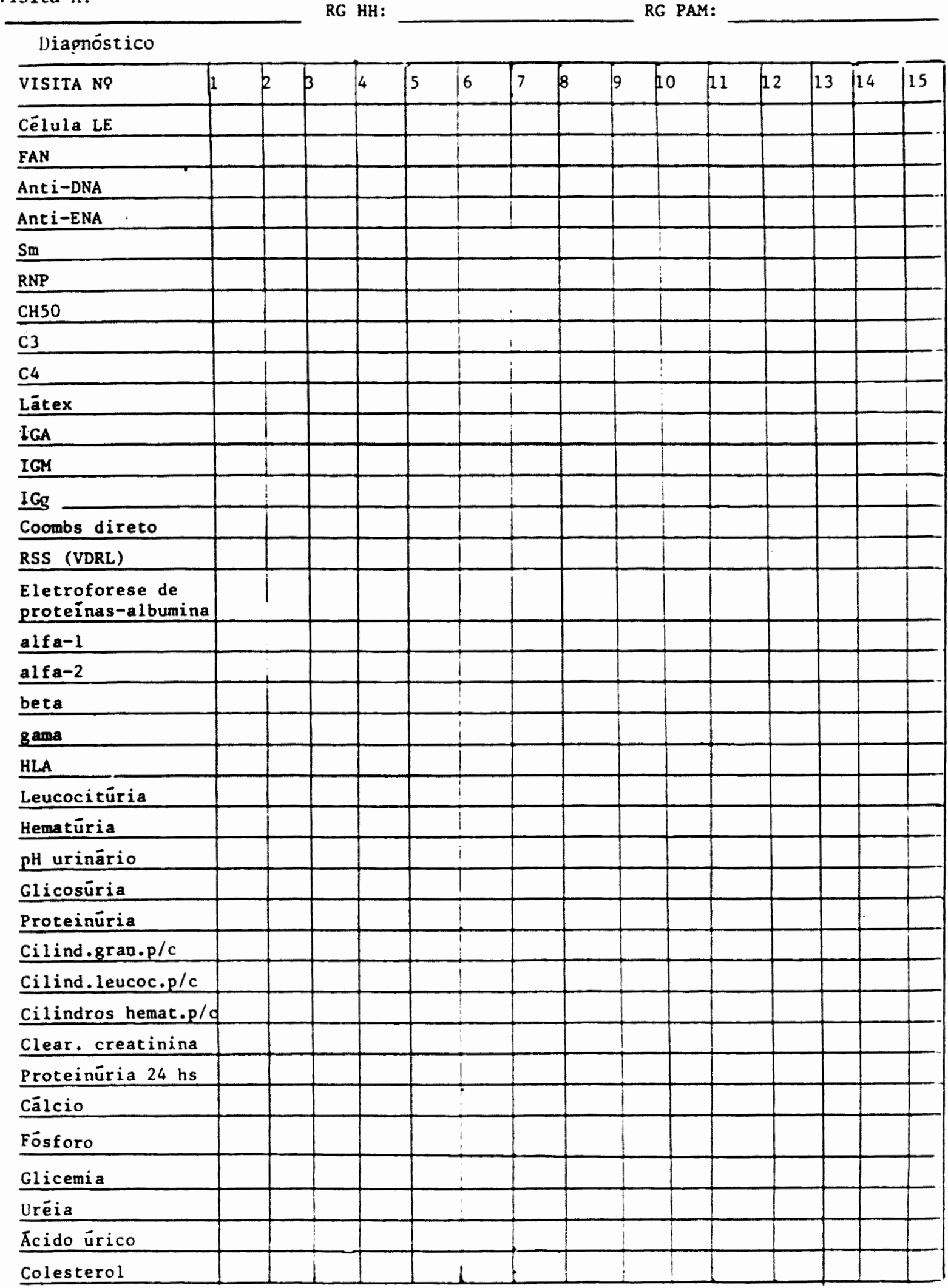

Nome :

End.:

Te1.:

RG $\mathrm{HH}$ RG PAM 
SERVIÇO DE REUMATOLOGIA

HOSPITAL HELIÓPOLIS

EXAMES LABORATORIAIS 2
Nome:

End.:

Tel.:

RG HH: RG PAM:

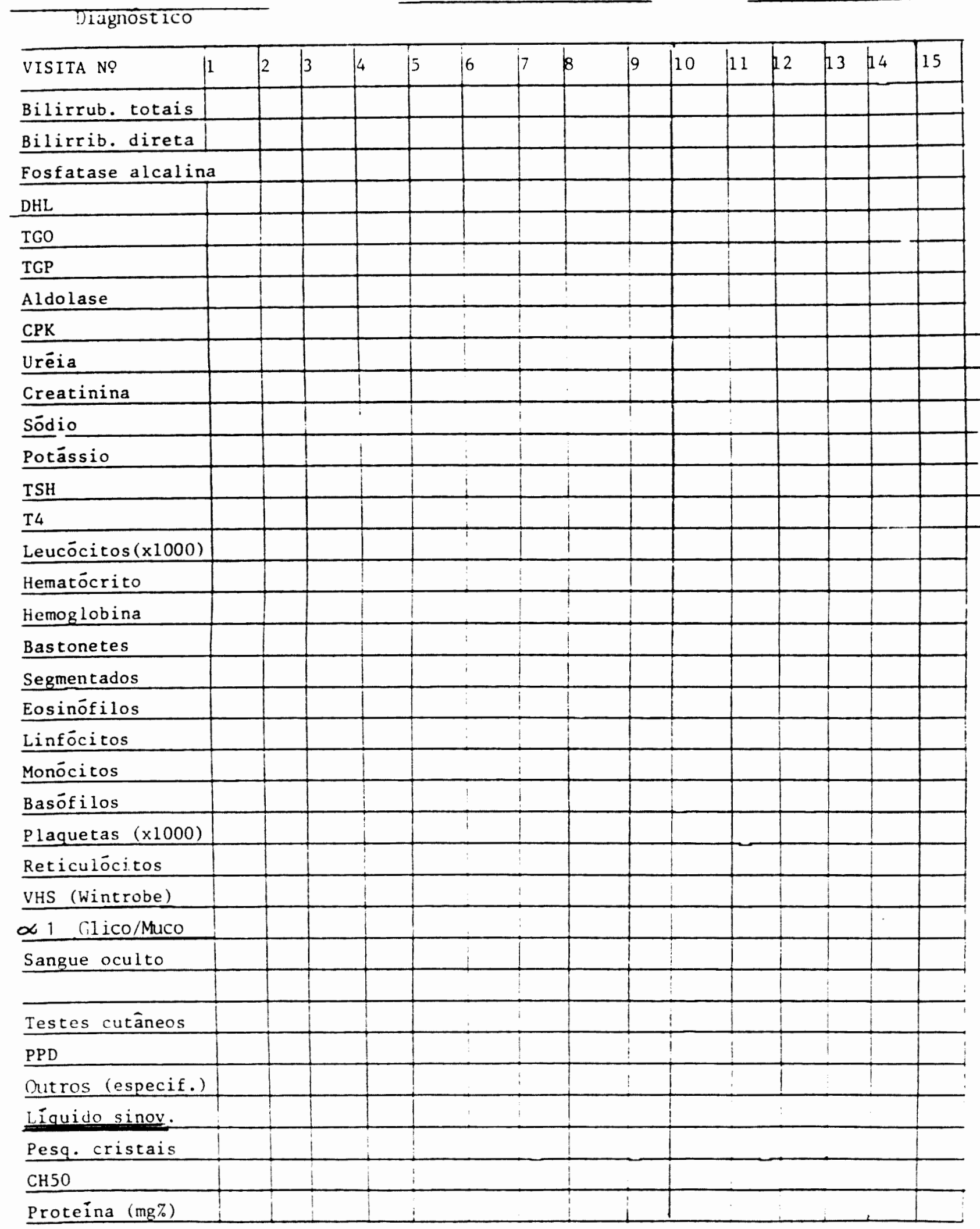


SERVIÇO DE REUMATOLOGIA HOSPITAL HELIOPOLIS

EXAMES LABORATORIAIS 3
Nome:

End.:

Te1 . :

RG HH: RG PAM:

\begin{tabular}{|c|c|c|c|c|c|c|c|c|c|c|c|c|c|c|}
\hline Diagnóstico & & & & & & & & & & & & & & \\
\hline VISITA NQ & 1 & 2 & 3 & 4 & 5 & 6 & 7 & 8 & 9 & 10 & 11 & 12 & 13 & 14,15 \\
\hline Leucöcitos $(x 1000)$ & & & & & & & & 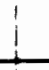 & , & 1 & 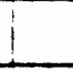 & & $\vdots$ & \\
\hline Polimorfonucl. & & & & & & & & + & : & & $!$ & & & ! \\
\hline Linfócitos $(\%)$ & & & & & & & & & 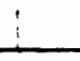 & $\vdots$ & ' & & & 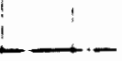 \\
\hline Glicose (mg\%) & & 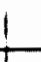 & & & & & & & 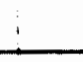 & $!$ & 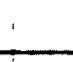 & & ' & \\
\hline Crioglobul. & & & & & & & & & & 1 & : & & & \\
\hline Hbs $\mathrm{Ag}$ & & & & & & & & & & 1 & 1 & & & \\
\hline ASLO & & & & & & & & & & 1 & & & & $:$ \\
\hline Uricosūria 24 hs & & & & & & & & & & & & & & ! \\
\hline
\end{tabular}

\begin{tabular}{l|l|l}
\hline BIOPSIA & DATA & DESCRIÇÃo DA ANORMAL IDADE \\
\hline Pele & & \\
\hline Sinovial & & \\
\hline Músculo & & \\
\hline Rim & & \\
\hline Outras (especificar) & & \\
\hline
\end{tabular}

\begin{tabular}{l|r|r|r}
\hline CULTURAS (material) & DATA & MICROORGANISMO & SENSIBILIDADE \\
\hline & & & \\
\hline RADIOLOGIA (local) & DATA & LAUDO & \\
\hline
\end{tabular}




\section{RETORNO}

SERVIÇO DE REUMATOLOGIA
HOSPITAL HELIOPULIS
LE /DMTC
VISITA NQ:

Data : 1

Peso: PA:

Pulso:
012

01223

0123

0123

0123

0123

0123

$0 \begin{array}{llll}0 & 1 & 2 & 3\end{array}$

$\begin{array}{llll}0 & 1 & 2 & 3\end{array}$

01223

0123

0123

01223

$\begin{array}{llll}0 & 1 & 2 & 3\end{array}$

Edema articular

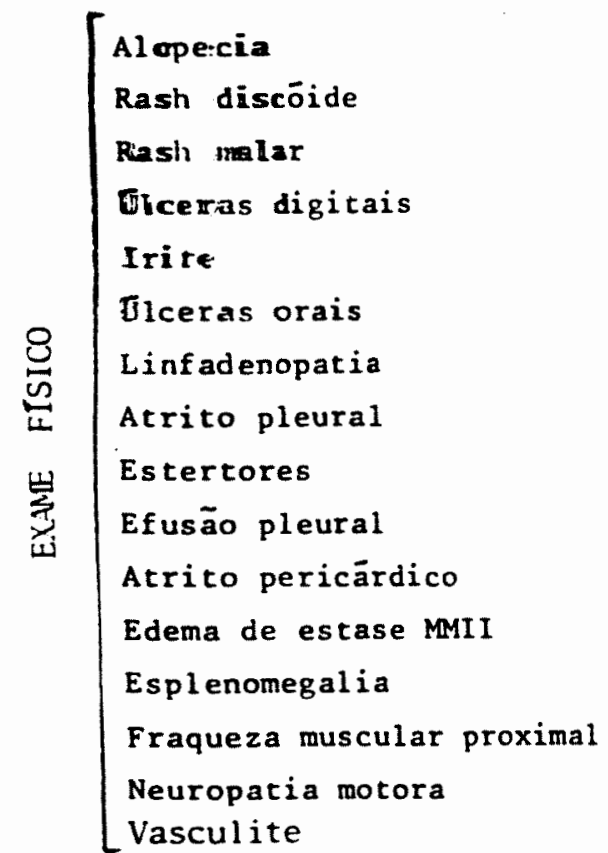

Notas :

0123

01223

0123

$\begin{array}{llll}0 & 1 & 2 & 3\end{array}$

0123

0123

$\begin{array}{llll}0 & 1 & 2 & 3\end{array}$

0123

$\begin{array}{llll}0 & 1 & 2 & 3\end{array}$

$\begin{array}{llll}0 & 1 & 2 & 3\end{array}$

$\begin{array}{llll}0 & 1 & 2 & 3\end{array}$

$\begin{array}{llll}0 & 1 & 2 & 3\end{array}$

$\begin{array}{llll}0 & 1 & 2 & 3\end{array}$
0123

\section{Direito}

\section{Extremidade superior}

$0 \begin{array}{lllll}0 & 2 & 3 & \text { E. clavicular }\end{array}$

Esquerdo

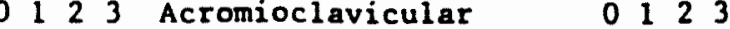

$\begin{array}{lllllllll}0 & 1 & 2 & 3 & \text { Ombro } & 0 & 1 & 2 & 3\end{array}$

$\begin{array}{llllllll}0 & 1 & 2 & 3 & \text { Cotovelo } & 0 & 123\end{array}$

$\begin{array}{lllllllllllllllll}0 & 1 & 2 & 3 & \text { Punho } & 0 & 1 & 2 & 3\end{array}$

0123 Carpometacärpica $\quad 0123$

\begin{tabular}{|c|c|c|c|c|c|c|c|c|c|c|}
\hline I & II & III & IV & $v$ & & I & II & III & IV & $\mathrm{v}$ \\
\hline- & - & - & - & - & MCF & - & - & - & - & - \\
\hline- & - & - & - & - & IFP & - & - & - & - & - \\
\hline- & - & - & - & - & IFD & - & & & & - \\
\hline
\end{tabular}

Extremidade inferior
$\begin{array}{lllll}0 & 1 & 2 & 3 & \text { Quadril }\end{array}$
$\begin{array}{lllll}0 & 1 & 2 & 3 & \text { Joelho }\end{array}$
$\begin{array}{llllllll}0 & 1 & 2 & 3 & \text { Tornozelo }\end{array}$
$\begin{array}{lllll}0 & 1 & 2 & 3 & \text { Subtalar }\end{array}$
$\begin{array}{llll}0 & 1 & 2 & 3\end{array}$
$\begin{array}{llllllll}0 & 1 & 2 & 3\end{array}$
$\begin{array}{llll}0 & 1 & 2 & 3\end{array}$
$\begin{array}{llll}0 & 1 & 2 & 3\end{array}$

\begin{tabular}{|c|c|c|c|c|c|c|c|c|c|c|}
\hline I & II & III & IV & v & & I & II & III & IV & $v$ \\
\hline- & - & - & - & - & MTF & - & - & - & - & - \\
\hline- & - & - & - & - & IFP & - & - & - & - & - \\
\hline - & - & - & - & - & IFD & - & - & - & - & - \\
\hline
\end{tabular}

$0 \begin{array}{lllll}0 & 1 & 3 & & \text { ATM }\end{array}$

$\begin{array}{llll}0 & 1 & 2 & 3\end{array}$

$\begin{array}{lllllll}0 & 1 & 2 & 3 & \text { Costocondrdi. }\end{array}$

$\begin{array}{llll}0 & 1 & 2 & 3\end{array}$

Col. cervical

$\begin{array}{llllllll}0 & 1 & 2 & 3 & \text { Col. torácica }\end{array}$

$\begin{array}{lllllllll}0 & 1 & 2 & 3 & \text { Col . Lombar }\end{array}$

$\begin{array}{lllll}0 & 1 & 2 & 3 & \text { Sacro-ilíaca }\end{array}$

0123

Classe funcional ARA

1234

Estimativa do paciente

$\begin{array}{lllll}1 & 2 & 3 & 4 & 5\end{array}$

Estimativa do médico

123245 


\section{ANEXO 3}

\section{PROTOCOLO - LÚPUS}

PACIENTE:

RG:

SEXO: OF 口M

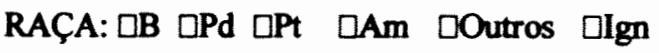

DATA DE NASCIMENTO: $1 / 1$ _ DATA DE DIAGNÓSTICO:

RIM : पN $\square$ DS DATA: $1,-1$

IRT : UN QS DATA: 1,1

ALTERAÇÃO DE MUCOSA: IN IS

ACOMETIMENTO CÁRDIO-PULMONAR: $\square N$ US TIPO:

H.A.S.: $\square N$ GS

S.N.C.: $\square N$ QS TIPO:

IMUNOSSUPRESSOR (IS): $\square \mathrm{N} \quad \square S$

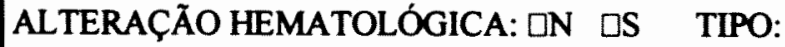

ÓBITO: $\square$ N $\square S$ DATA: I I I CAUSA:

DATA DA ULTIMA OBSERVAÇÃO: 1,1, STATUS:

C.I.D.:

CRITÉRIOS: $\square 1 \square 2 \square 3 \square 4 \square 5 \square 6 \square 7 \square 8 \square 9 \square 10 \square 11$

FAN: $\square$ N $\square S \quad$ PADRÃO FAN:

Sm $\square N \square S$

RNP $\square$ N $\square S$

SSA $\square$ N $\square S$

SSB $\square N \square S$

CELSLE $\square N \square S$

BIÓPSIA (1): $\square \mathrm{N}$ aS DATA: 1,1

BIÓPSIA (2): $\square \mathrm{N}$ 口S DATA:_I_

OBSERVAÇÕES: 